Cristiana Pacheco Martini Bolfer

\title{
Avaliação Neuropsicológica das funções executivas e da atenção em crianças com transtorno do déficit de atenção/hiperatividade (TDAH)
}

Dissertação apresentada à Faculdade de Medicina da Universidade de São Paulo para obtenção do título de Mestre em Ciências

Área de Concentração: Neurologia

Orientador: Dr. Erasmo Barbante Casella

São Paulo

2009 
"Se una crianca nãa pade aprender da maneira que é ensinada, é melhor ensiná-la da maneira que ela pade aprender" (Welchmann) 
DEDICATÓRIA 
Aos meus pais companheiros e incentivadores de todas as horas que me ensinaram a perseguir e persistir em meus ideais.

Ao meu esposo Alexandre Bolfer pela confiança e credibilidade. Por nunca medir esforços para que eu alcançasse meu objetivo e principalmente como grande incentivador.

A toda minha família e amigos pela estrutura que me permitiu tornar esse trabalho possível. 
AgRADECIMENTOS 
Ao meu orientador Dr. Erasmo Barbante Casella, pelas valiosas e eternas orientações com que guiou no desenvolvimento dessa pesquisa e, principalmente, pela compreensão em todos os momentos.

A Profa. Dra. Umbertina Conti Reed, pelo acolhimento quando nesta cidade e Instituição (FMUSP) cheguei.

A psicóloga e amiga Sandra Pasquali Pacheco por estar sempre por perto guiando-me academicamente e cuidando-me com carinho de mãe.

A neurologista Dra. Thelma Messias, pela assistência e colaboração na pesquisa.

Aos que fazem parte do Ambulatório do Distúrbio do Aprendizado do Instituto da Criança da FMUSP, pela ajuda sempre que necessária.

Aos meninos que participaram da pesquisa e aos seus pais que me confiaram seus filhos possibilitando a realização desse estudo.

A todos da Escola Estadual Keizo Ishihara, pela confiança no nosso trabalho.

A Amanda Manzini Mota e ao Prof. Dr. Marcus Vinícius Chrysóstomo Baldo, do Instituto de Ciências Biomédicas da USP, pelo apoio e uso cedido de um dos testes computadorizados por nós utilizado.

Aos funcionários da secretaria e Comissão de Pós-Graduação do Departamento de Neurologia do Instituto Central do HCFMUSP, pela paciência na explicação dos detalhes envolvidos no curso de Mestrado.

As pessoas da minha cidade Maringá-Paraná, que me apoiaram, auxiliaram e incentivaram durante o Mestrado: Freiras do Colégio Regina Mundi, Evandro e funcionários da copiadora 19 News e Julio César T. Colella. 
Esta dissertação está de acordo com as seguintes normas, em vigor no momento desta publicação:

Referências: adaptado de International Committee of Medical Journals Editors (Vancouver)

Universidade de São Paulo. Faculdade de Medicina. Serviço de Biblioteca e Documentação. Guia de apresentação de dissertações, teses e monografias. Elaborado por Anneliese Carneiro da Cunha, Maria Julia de A. L. Freddi, Maria F. Crestana, Marinalva de Souza Aragão, Suely Campos Cardoso, Valéria Vilhena. $2^{\mathrm{a}}$ ed.

São Paulo: Serviço de Biblioteca e Documentação; 2005.

Abreviaturas dos títulos dos periódicos de acordo com List of Journals Indexed in Index Medicus. 
SUMÁRIO 


\title{
S U M Á R IO
}

\author{
Lista de siglas \\ Lista de gráficos \\ Lista de figuras \\ Lista de tabelas \\ Resumo \\ Summary
}

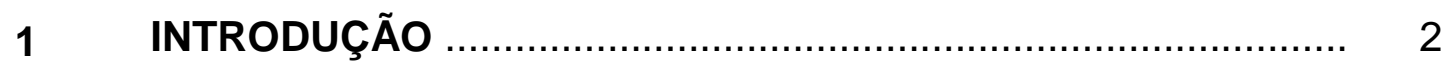

1.1 Transtorno do Déficit de Atenção/Hiperatividade (TDAH)............. 2

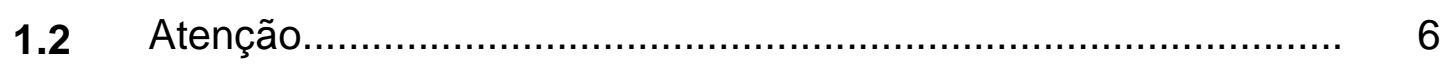

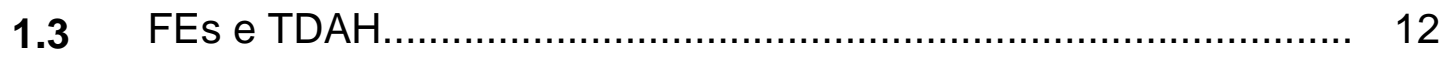

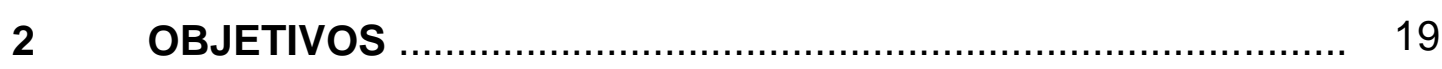

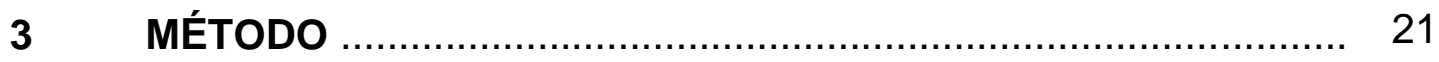

3.1 Casuística....................................................................... 21

3.1.1 Critérios de Inclusão............................................................... 22

3.1.2 Critérios de Exclusão................................................................ 22

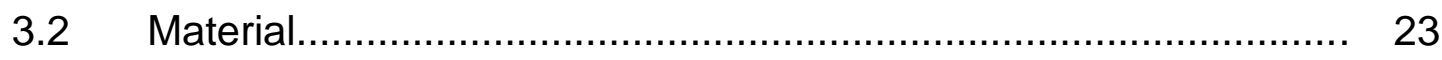

3.3 Análise Estatística................................................................ 24

3.4 Procedimento................................................................... 25

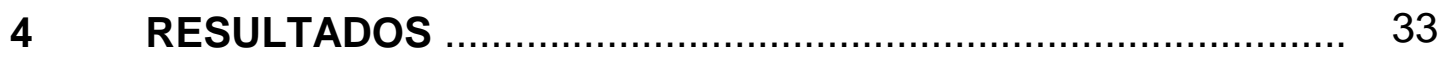


4.1 Questionário SNAP-IV............................................................ 33

4.2 WISC III (Perfil ACID+CF) - Escala de Inteligência Wechsler 39 para Crianças-Terceira Edição.

4.3 Teste Psicofísico para Atenção Voluntária (TPAVV)..................... 40

$4.4 \quad$ Teste de Cancelamento (Tc)...................................................... 43

$4.5 \quad$ Teste das Trilhas (TMT) ................................................... 44

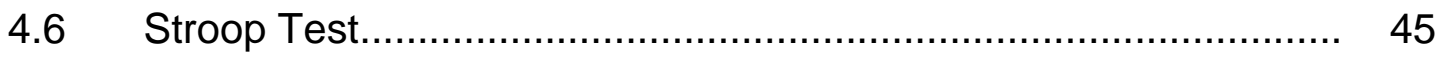

4.7 Go-No Go ..................................................................... 46

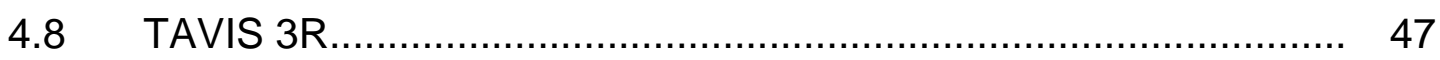

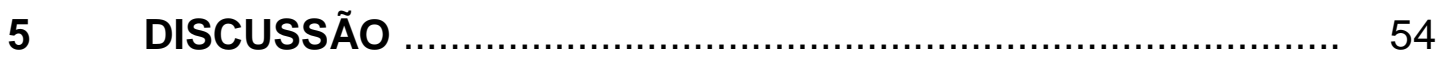

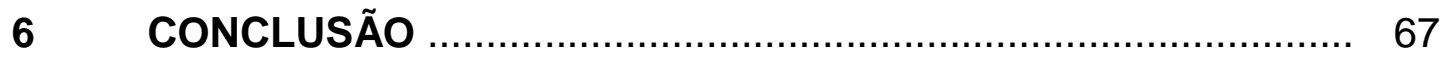

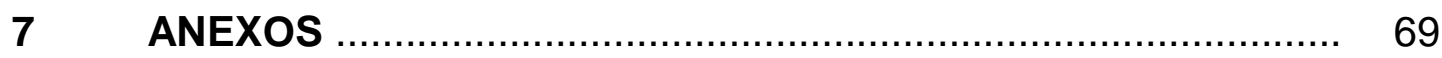

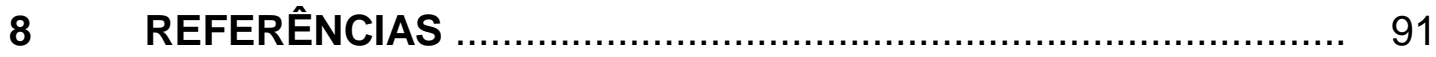


LISTAS 


\section{SIGLAS}

ACID+CF - Aritmética, Código, Informação, Dígitos e Completar Figuras

CPF - Córtex Pré-Frontal

DSM-IV Diagnostic and Statistical Manual of Mental Disorders $4^{\text {th }}$ edition

D Dígitos do WISC III

FEs - $\quad$ Funções Executivas

WISC III- Escala de Inteligência Wechsler para Criança, $3^{a}$ ed.

OD- $\quad$ Dígitos Ordem Direta do WISC III

Ol- Dígitos Ordem Indireta do WISC III

ROC- $\quad$ Receiver Operating Characteristic

SNAP-IV_ Questionário revisado da escala de Swanson, Nolan e Pelham

SRAA - Sistema Reticular Ativador Ascendente

T1 - $\quad$ Tarefa 1 do TAVIS 3R

T2- $\quad$ Tarefa 2 do TAVIS 3R

T3- $\quad$ Tarefa 3 do TAVIS 3R

Tc- $\quad$ Teste de cancelamento

TDE Teste de Desempenho Escolar

TMT- $\quad$ Trail Making Test. Testes das Trilhas

TOD- $\quad$ Transtorno Opositor Desafiante

TPAVV - Teste Psicofísico para Atenção Visual Voluntária 


\section{GráfICOS}

Gráfico 1 - Perfis de Médias do SNAP-IV Professores........................ 34

Gráfico 2 - Perfis de Médias do SNAP-IV Pais.................................... 34

Gráfico 3 - Dispersão entre SNAP-IV professores e pais 36 DESATENÇÃO........................................................

Gráfico 5 - Dispersão entre SNAP-IV professores e pais TOD............. 37

Gráfico 6 - Dispersão entre SNAP-IV professores e pais COMBINADO ........................................................ 38

Gráfico 7 - Perfis de Médias do Perfil ACID+CF............................... 39

Gráfico 8 - Perfis de Médias do TPAVV........................................... 41

Gráfico 9 - Perfis de Médias da Condição Válida e Condição Inválida. 42

Gráfico 10 - Perfis de Médias do Tc............................................... 43

Gráfico 11 - Perfis de Médias do Tempo do Teste da Trilhas partes A e 44

Gráfico 12 - Perfis de Médias do Tempo do Stroop Test....................... 45

Gráfico 13 - Perfis de Médias do Tempo de reação do TAVIS 3R....... 47

Gráfico 14 - Perfis de Médias dos erros por ação do TAVIS 3R............. 48

Gráfico 15 - Curva ROC Tarefas 2 e 1 (erros por ação) do TAVIS 3R... 50

Gráfico 16 - Curva ROC Tarefas 3 e 2 (tempo de reação) do TAVIS 3R 50

Gráfico 17 - Curva ROC perfil ACID+CF............................................ 51

Gráfico 18 - Curva ROC teste das trilhas Parte B.............................. 51 



\section{FIGURAS}

Figura 1 - Principais áreas cerebrais relacionadas às FEs e ao TDAH .17 


\section{TABELAS}

Tabela 1 - Testes utilizados e funções avaliadas................................ 31

Tabela 2 - Teste de Mann-Whitney para o SNAP-IV entre os 35 portadores de TDAH e os controles...................................

Tabela 3 - Correlação de Pearson entre os SNAP-IV Pais e 38 Professores.

Tabela 5 - Teste de Mann-Whitney para as Médias do Tempo de reação TPAVV.

Tabela 6 - Teste de Mann-Whitney para as Médias do Tempo de execução do Tc.

Tabela 7 - Teste de Mann-Whitney para as Médias dos Tempos das partes A e B do Teste das Trilhas.....

Tabela 8 - Teste de Mann-Whitney para as Médias do Tempo de execução do Stroop Teste.

Tabela 9 - Teste Exato de Fisher para verificar a homogeneidade de proporções de erros entre os grupos TDAH e controle do Stroop Teste.

Tabela 10 - Teste Exato de Fisher para verificar a proporção de erros entre os grupos TDAH e controle do Go-No Go

Tabela 11 - Teste de Mann-Whitney para as Médias do Tempo de Reação das tarefas 1, 2, e 3 do TAVIS 3R

Tabela 12 - Teste de Mann-Whitney para as Médias de Erros por ação das tarefas 1, 2, e 3 do TAVIS 3R.

Tabela 13 - Teste Exato de Fisher para verificar a proporção de erros por omissão entre os grupos TDAH e controle nas tarefas 1, 2, e 3 do TAVIS 3R.

Tabela 14 - Resultados dos testes que apresentaram Sensibilidade e Especificidade. 
RESUMo 
Bolfer CPM. Avaliação neuropsicológica das funções executivas e da atenção em crianças com transtorno do déficit de atenção/hiperatividade (TDAH) [dissertação]. São Paulo: Faculdade de Medicina, Universidade de São Paulo; 2009. 100p.

INTRODUÇÃO: O Transtorno de Déficit de Atenção/Hiperatividade (TDAH) é um problema de saúde mental bastante freqüente em crianças, adolescentes e adultos em todo o mundo. É caracterizado pela presença de três grupos de sintomas: desatenção, hiperatividade e impulsividade. As pesquisas internacionais e nacionais indicam que os indivíduos portadores do TDAH podem também apresentar, além dos déficits atencionais, alterações nas funções executivas. As crianças e adolescentes com TDAH apresentam prejuízos claros no seu funcionamento do aprendizado escolar e no desenvolvimento social e emocional. O diagnóstico do TDAH é clínico, baseado nos critérios do DSM-IV, porém os estudos dos prejuízos atencionais e das funções executivas nos pacientes com TDAH têm permitido uma melhor caracterização dos diferentes subtipos clínicos, além de serem fundamentais na elucidação diagnóstica de algumas comorbidades e na proposta de intervenção e/ou reabilitação. O objetivo desta pesquisa é a utilização de testes neuropsicológicos para auxílio na avaliação da atenção e das funções executivas em pacientes com TDAH. MÉTODOS: Neste estudo transversal realizado entre Setembro de 2006 a Junho de 2008, foram selecionados 23 pacientes do sexo masculino, entre 9 a 12 anos de idade, com diagnóstico de TDAH sem comorbidades, estabelecido segundo os critérios do DSM-IV, com QI $\geq 89$, que não tivessem sido medicados para o TDAH, que soubessem ler e escrever de acordo com o período de escolaridade cursado e que estivessem em acompanhamento no Ambulatório de TDAH do Serviço de Neurologia Infantil do Instituto Central e do Instituto da Criança do Hospital das Clínicas da Faculdade de Medicina da USP, foi comparado o desempenho nos testes neuropsicológicos com o grupo controle $(n=15)$ que seguiu os mesmos critérios em relação à idade, ao sexo e QI. A escala SNAP-IV também foi comparada entre os pacientes e 
grupo controle. RESULTADOS: 1) Ocorreram diferenças significativas $(p<0,05)$ entre o grupo de pacientes e o grupo controle no desempenho da atenção e das funções executivas; 2) Os pacientes apresentaram maiores escores para a desatenção, dificuldades na memória operacional, falhas de planejamento, maior tempo de execução, maior tempo de reação, controle inibitório comprometido, maior número de erros por ação e omissão do que os do grupo controle; 3) Os testes neuropsicológicos que demonstraram maior sensibilidade para avaliação da atenção e das funções executivas, em ordem de importância, foram: a) Tarefa 2 (erros por ação) do TAVIS 3R, b) Tarefa 3 (tempo de reação) do TAVIS 3R, c) Tarefa 2 (tempo de reação) do TAVIS 3R, d) Tarefa 1 (erros por ação) do TAVIS 3R, e) subteste Completar Figuras do teste WISC III - Terceira Edição e f)Teste das Trilhas, parte B. CONCLUSÕES: De acordo com os resultados, através da maioria dos testes neuropsicológicos utilizados, foi possível evidenciar alterações das funções executivas e da atenção em crianças com TDAH e que os testes, em ordem decrescente de importância, Tarefa 2 (erros por ação) do TAVIS 3R, Tarefa 3 (tempo de reação) do TAVIS 3R, Tarefa 2 (tempo de reação) do TAVIS 3R, Tarefa 1 (erros por ação) do TAVIS 3R, o subteste Completar Figuras do teste WISC III - Terceira Edição e o Teste das Trilhas, parte B, demonstraram maior correlação com o diagnóstico do TDAH.

Descritores: Transtorno da falta de atenção com hiperatividade; Testes Neuropsicológicos; Atenção; Funções Executivas 
SUMMARY 
Bolfer CPM. Neuropsychological assessment of the executive functions and attention in children with attention deficit hyperactivity disorder (ADHD) [dissertation]. São Paulo: "Faculdade de Medicina, Universidade de São Paulo; 2009. 100p.

NTRODUCTION: ADHD is a mental health problem which is highly frequent in children, adolescents and adults all over the world. It is characterized by the presence of three symptom groups: inattention, hyperactivity and impulsivity. Both national and international researches indicate that people with attention deficit hyperactivity disorder (ADHD) may also present, in addition to the attention deficits, alterations in the executive functions. Children and adolescents with ADHD present evident impairments in their school learning and in social and emotional development. The ADHD diagnosis is clinical, based on DSM-IV criteria; however, studies of the impairments of attention and executive functions in patients with ADHD have allowed a better characterization of the different clinical subtypes, besides being fundamental to diagnostically elucidating some comorbities and proposing intervention and / or rehabilitation. The aim of this research is to use the neuropsychological tests to aid the assessment of ADHD patients' attention and executive functions. METHODS: In this transverse study, performed from September 2006 to June 2008, 23 male patients, aged 9 to 12 years, with diagnosed ADHD without comorbities according to DSM-IV criteria, $I Q \geq 89$, who had never been medicated for ADHD, who could read and write according to their level schooling and were being monitored in the outpatient clinic for ADHD at the Child Neurology Service of the Central Institute and the Children's Institute, Hospital das Clínicas, FMUSP, were selected and their neuropsychological test results were compared to the control group ( $n=15)$ which followed the same criteria as for gender, age and IQ. The SNAP-IV Rating Scale was also compared between patients and control group. RESULTS: 1$)$ There were significant differences $(p<0,05)$ between patients and control group as for the performance of attention and executive functions; 2 ) the patients presented higher scores for inattention, 
difficulties with the working memory, inadequate planning, longer execution time, longer reaction time, poorer inhibitory performance, higher errors per action and omission than the control group; 3)The neuropsychological tests that demonstrated higher sensitivity to asses attention and executives functions in order of importance were: a) TAVIS 3R (task 2- errors by action), b) TAVIS 3R (task 3- reaction time), c) TAVIS 3R (task 2- reaction time), d) TAVIS 3R (task 1- errors by action), e) Subtest Pictures Completion of WISC III- Third Edition and f) Trial Making Test, part B. CONCLUSIONS: According to the results, through most neuropsychological tests performed, it was possible to show changes in the executive and attentive functions in ADHD children. Also, it was possible to verify that the tests, in decreasing order of importance: TAVIS 3R (task 2- errors by action), TAVIS 3R (task 3reaction time), TAVIS $3 R$ (task 2- reaction time), TAVIS 3R (task 1- errors by action), Subtest Pictures Completion of WISC III- Third Edition and Trial Making Test, part B, showed a greater correlation with the ADHD diagnosis.

Descriptors: Attention Deficit Hyperactivity Disorder; Neuropsychological Tests; Attention; Executive Functions. 
INTRODUÇÃO 


\section{Introdução}

\subsection{Transtorno do Déficit de Atenção/Hiperatividade (TDAH)}

O Transtorno do Déficit de Atenção/Hiperatividade (TDAH) caracteriza-se pela combinação dos sintomas de déficit de atenção, hiperatividade e impulsividade, sendo o transtorno comportamental mais frequente em crianças. A incidência do TDAH em crianças e adolescentes de acordo com vários estudos realizados em diferentes regiões e culturas tanto no Brasil quanto internacionalmente, varia de 3 a $6 \%$, determinando prejuízos no âmbito familiar, escolar e social, bem como no desempenho acadêmico e no desenvolvimento emocional e afetivo. Acredita-se que esses comprometimentos estejam relacionados a um padrão de comportamento desatento, impulsivo e inquieto ${ }^{(1,2,3)}$.

O diagnóstico do TDAH é fundamentalmente clínico, baseando-se em critérios operacionais claros e bem definidos, provenientes de sistemas classificatórios como o Diagnostic and Statistical Manual of Mental Health Disorder, Fourth Edition, 2000 (DSM-IV). O TDAH pode ser subdividido segundo a presença ou ausência de hiperatividade/impulsividade e/ou déficit atencional, de acordo com os critérios do DSM-IV, que o classifica como 
combinado, predominantemente desatento e predominantemente hiperativo/impulsivo.

Para o diagnóstico do tipo predominantemente hiperativo/impulsivo, é necessária a presença de seis (ou mais) dos nove critérios de hiperatividade do DSM-IV, por um período de pelo menos seis meses, em grau de intensidade incompatível com o nível de desenvolvimento do portador. O mesmo deve ocorrer para o diagnóstico do tipo predominantemente desatento, respectivamente aos critérios de desatenção do DSM-IV. O tipo combinado deve preencher tanto os critérios de desatenção quanto os de hiperatividade. Os sintomas devem estar presentes em dois ou mais contextos da atividade da vida diária e determinar prejuízos significativos ${ }^{(1,4,}$ 5).

O TDAH ocorre isoladamente em $30-40 \%$ dos pacientes, e comumente se associa a outras comorbidades neuropsiquiátricas como: transtorno opositor desafiante, transtornos de conduta, depressão, ansiedade e outros transtornos do desenvolvimento, como atraso na fala e dificuldades no aprendizado ${ }^{(6)}$.

As causas desse transtorno, embora muito pesquisadas e atribuídas a uma combinação de fatores genéticos, biológicos e ambientais, ainda não foram completamente definidas, até mesmo pela frequência das comorbidades, o que dificulta a adoção de estratégias preventivas e curativas $^{(1,4,6,7,8)}$.

As variações clínicas do TDAH estão associadas entre outras etiologias, às variações dos processos biológicos implicados na origem 
de seus sintomas. Apesar de ainda não existir compreensão total a respeito dos mediadores bioquímicos envolvidos, as evidências obtidas através de estudos farmacológicos, de neuroimagem e de pacientes com lesões cerebrais sugerem que as catecolaminas, dopamina e noradrenalina tenham papel fundamental na fisiopatologia do transtorno ${ }^{(9,10)}$.

Nos últimos anos têm sido atribuídos papéis, de forma interacional, a outros neurotransmissores bioquímicos menos estudados como a serotonina, glutamina e acetilcolina. Mesmo não existindo resultados definitivos, uma série de estudos de neuroimagem, neuropsicologia, genética e bioquímica vêm confirmando essas hipóteses $^{(10,11)}$.

Pesquisas neuropsicológicas e de neuroimagem indicam comprometimento de funções do córtex pré-frontal (CPF) nos portadores de TDAH, ressaltando ainda mais a importância dessa região em relação aos sintomas apresentados por esses pacientes. Outras pesquisas de imagem cerebral demonstram áreas de tamanho reduzido no $\mathrm{CPF}$, núcleos da base, e cerebelo em pacientes com TDAH, regiões que sabidamente recebem múltiplas projeções de neurônios ricos em dopamina e noradrenalina, além da serotonina, glutamina e acetilcolina $^{(4,9,10,11)}$.

Estudos em animais e neurofarmacológicos indicam a importância das catecolaminas no adequado funcionamento das regiões pré-frontais e ainda evidenciam o fato de que mesmo pequenas lesões nessas áreas 
determinam alterações significativas no comportamento. O TDAH mostra evidências de alteração genética, incluindo genes relacionados com a neurotransmissão das catecolaminas ${ }^{(10,12,13)}$.

A fisiopatologia do TDAH, apesar de ainda não estar completamente compreendida parece relacionar-se a falhas nos circuitos que interligam áreas pré-frontais, cerebelo e núcleos da base. Acredita-se que os pacientes com TDAH do tipo combinado, apresentem dificuldade principalmente no controle inibitório, implicando em déficit na capacidade de controlar o comportamento motor e o próprio pensamento, além de não conseguir inibir os fatores distratores. Essa dificuldade inibitória parece estar associada a um déficit nos circuitos da região pré-frontal para os núcleos da base ${ }^{(12,13,}$ 14).

Nos últimos anos, uma forma de TDAH, com sintomas exclusivamente de déficit atencional tem sido identificada em pacientes com quadro de desatenção, tendência à desorganização mental e física, esquecimento, dificuldade em organizar e planejar seus afazeres e em sustentar a atenção por um período mínimo. Acredita-se que essa forma de TDAH está associada principalmente a um distúrbio nos circuitos que relacionam as áreas pré-frontais com o lobo parietal e que esses sintomas estariam associados às dificuldades de memória operacional (MO) e de motivação ${ }^{(15}$, 16)

O TDAH parece ser o resultado de uma combinação de fatores genéticos e ambientais que modificam o cérebro em desenvolvimento resultando em anomalias estruturais e funcionais. Além das alterações 
principais do controle atencional e do grau de atividade e impulsos, nos últimos anos, têm se enfatizado evidências de prejuízos em funções executivas (FEs) ${ }^{(11,13,14)}$.

A seguir iremos analisar, de modo um pouco mais detalhado, os conhecimentos sobre a atenção, FEs e suas implicações no TDAH. 


\subsection{Atenção}

Os estudos de Luria (1981) ${ }^{(17)}$ Mesulam (1985) ${ }^{(18)}$ e Posner (1990) ${ }^{(19)}$.são os mais evocados quando se analisa o mecanismo de manutenção da atenção. As interações bidirecionais entre o (CPF), o córtex parietal posterior, o neostriado, o sistema reticular ativador ascendente (SRAA), o giro do cíngulo, a ínsula, a amígdala e o hipocampo regulam os mecanismos de iniciação, sustentação e inibição das atividades motoras, do pensamento e controle atencional, obedecendo a motivações determinadas ${ }^{(2,17,18,19)}$.

A disfunção orgânica do mecanismo da atenção é comum para uma gama extensa de afecções em psiquiatria, neurologia e neuropsicologia, tanto em crianças como em adultos ${ }^{(15,20)}$.

Há evidências eletrofisiológicas de que a seletividade de reflexos orientados aperfeiçoa-se durante o desenvolvimento na infância, tem seu ponto máximo na adolescência, bem como na vida adulta e diminui na velhice. A quantidade de informações irrelevantes do meio ambiente que uma pessoa pode ignorar depende de uma série de fatores, entre eles idade, grau de vigília, habilidades de processamento visual, natureza do estímulo e presença de qualquer dificuldade atencional ${ }^{(21,22)}$.

O ser humano recebe um imenso número de estímulos, mas seleciona os mais importantes, ignorando os restantes. A atenção consiste na seleção da informação necessária, processamento dos programas seletivos de ação e manutenção de um controle permanente sobre tais 
processos. A forma mais primitiva de seleção atencional envolve o alinhamento dos receptores sensoriais ${ }^{(12,18)}$.

Atenção visual e reflexo orientado normalmente surgem quando um movimento súbito ou um som alto acontece no ambiente. $\mathrm{O}$ reflexo orientado

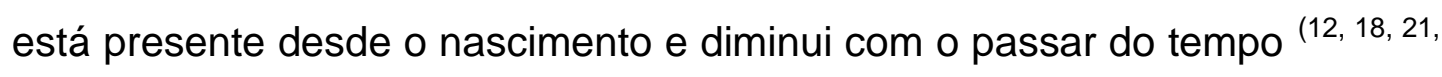
23)

O desenvolvimento da atenção passa pelo desenvolvimento de mecanismos cerebrais inibitórios. Tradicionalmente, as teorias do desenvolvimento enfatizam a importância das mudanças na capacidade de armazenar e processar informação durante o desenvolvimento cognitivo. Os processos inibitórios tornam-se mais eficientes ao longo do processo de maturação cerebral, possibilitando entrada menor de informação irrelevante para a MO e aumentando, assim, a capacidade funcional da criança ${ }^{(24,25,26)}$.

Essas mudanças na eficiência de processamento e inibição cerebral ao longo do desenvolvimento estariam ligadas à maturação do sistema nervoso e, mais notoriamente, à sinaptogênese, à reabsorção de sinapses e/ou neurônios supérfluos e, em última instância, à formação da mielina . O processo de mielinização é fator importante no entendimento do desenvolvimento cerebral e sua relação com a função neuropsicológica. A mielinização facilitaria a transmissão linear entre grupos de células nervosas e prejudicaria a transmissão lateral. Segundo essa hipótese, o efeito combinado do aumento na velocidade linear de transmissão de informação nervosa e a redução na interferência potencial entre outros grupamentos neurais, num dado processamento, vão resultar em melhor disponibilidade 
de armazenamento da $\mathrm{MO}$, de forma a se poder manipular outras informações ou mesmo executar outra tarefa ${ }^{(24,26)}$.

É sabido que o processo de maturação do encéfalo tem progressão póstero-anterior relacionada às funções sensoriais e às funções nervosas superiores, respectivamente. Em relação à sinaptogênese, após a maturação de áreas posteriores ocorre, em última instância, o desenvolvimento mais especializado das áreas pré-frontais. Sabemos que o maior número de sinapses nestas regiões, no ser humano, ocorre por volta dos quatro anos de idade e o processo de maturação cerebral determina a reabsorção de sinapses em uma fase posterior, que se estabiliza por volta dos 16 anos $(24,25,26)$.

Em relação ao processo de mielinização, que ocorre a partir do sexto mês da concepção e termina por volta do final da secunda década - meados da terceira, a evolução é, de certo modo, semelhante, ocorrendo, primeiramente, em áreas posteriores e por último no $\operatorname{CPF}^{(24,25)}$.

Do ponto de vista neuroevolutivo, normalmente a hiperatividade e a impulsividade diminuem de modo gradativo, permitindo maior autocontrole dos atos motores e do pensamento. Em crianças normais, isso pode ser evidenciado aos quatro e cinco anos de idade quando costumam ser mais impulsivas, comentando situações desagradáveis e esse comportamento desaparece dois ou três anos depois $(24,25,26,27)$.

A atenção é uma função cerebral essencial para o correto funcionamento das outras funções corticais superiores. Mesmo na literatura mais especializada, seja neurológica, ou psicológica, o uso do termo 
"atenção" torna-se inadequado porque ele é geralmente aplicado aos testes que necessitam de atenção e não aos processos envolvidos ${ }^{(26)}$.

A experiência clínica na avaliação de pacientes com distúrbios da atenção, estudos experimentais em primatas e por último exames de neuroimagem funcional têm permitido uma localização mais precisa das redes neurais relacionadas à atenção. A atenção não é mediada por uma única região cerebral ou mesmo pelo cérebro como um todo, mas realiza-se através de redes neuronais específicas, que se distribuem em diferentes áreas do parênquima encefálico ${ }^{(2,18,19,26,27)}$.

Pode-se dizer que existem duas redes neurais principais que regem aspectos complementares da atenção. Uma é mais difusa, relacionada à atenção mais global, incluindo estruturas talâmicas e os dois hemisférios cerebrais, estando particularmente envolvidas as regiões pré- frontais. A segunda rede neuronal corresponde a um sistema mais focal e vem relacionada aos aspectos de experiência espacial da atenção, estando mais lateralizada às regiões frontais e parietais do hemisfério direito. $\mathrm{O}$ sistema atencional mais difuso é responsável pela manutenção de um nível tônico da atenção, permitindo a monitorização de eventos sensoriais internos e externos. Os tálamos participam do controle da vigília pelas suas conexões com o SRAA, localizado na porção superior do tronco encefálico, e da atenção pelas suas conexões com os hemisférios cerebrais. De todas as regiões corticais, que recebem informações talâmicas pelo sistema difuso, as áreas pré-frontais parecem ser as mais importantes, apresentando papel fundamental no controle da atenção sustentada e seletiva $(24,25,26,28)$. 
Pacientes com lesões bilaterais em regiões pré-frontais dorsolaterais apresentam déficits de atenção em paralelo às alterações em FEs e na MO. As evidências experimentais ainda sugerem que o lobo frontal direito seria ainda mais especializado que o esquerdo, na manutenção da atenção, particularmente sustentada. As porções posteriores, principalmente o lobo parietal estão mais associadas à detecção da informação espacial enquanto as áreas pré-frontais teriam papel mais importante no controle das FEs e da ação motora. A porção dorsolateral do lobo frontal estaria mais especificamente associada a direções dos recursos necessários para uma resposta apropriada à informação agregada, enquanto o giro do cíngulo seria responsável por manutenção da motivação e esforço durante toda a execução do ato ${ }^{(18,19,26)}$.

A atenção é necessária porque o ambiente contém muito mais informações que o possível de serem processadas e compreendidas em um determinado momento. Os processos da atenção funcionariam como um fator de proteção do organismo do excesso de informação, selecionando apenas alguns estímulos e desprezando outros. A não compreensão desse conceito determina prejuízos na utilização, compreensão e interpretação dos diferentes testes utilizados na avaliação da atenção e no correto diagnóstico do paciente em análise. Por outro lado, a compreensão dessa idéia e a correta aplicação dos diferentes tipos de testes nos diversos pacientes, valorizam a avaliação neuropsicológica dos distúrbios de atenção, sejam eles provenientes das mais diferentes etiologias $(2,26,29)$. 
A atenção não é construída de forma única, envolvendo diferentes componentes, e, apesar de haver divergências quanto à terminologia, parecem existir três níveis de atenção mais consensualmente utilizados: seletiva, alternada e sustentada ${ }^{(30,31,32,33,34)}$.

A atenção seletiva corresponde à capacidade de responder a estímulos específicos. Esse termo refere-se à habilidade de selecionar estímulos relevantes, na presença de outros distratores e selecionar a informação para processamento consciente. Envolve a habilidade de filtrar uma informação particular e é mais fácil quando existem pistas que ajudam a salientar o estímulo alvo de outros distratores. A denominação seletiva é utilizada por muitos, também, como atenção focada, que se relaciona, mais especificamente à capacidade de percepção e resposta a um estímulo de cada vez ${ }^{(30,31,32,33,35)}$.

A atenção alternada refere-se à capacidade de mudar o foco de atenção entre tarefas com demandas cognitivas diferentes, determinandose, assim, à qual informação se prestará atenção, num dado momento. Esse termo é utilizado para se definir a capacidade de flexibilidade mental, permitindo-se mudar a atenção de um determinado teste para outro com diferentes solicitações cognitivas ${ }^{(30,31,32,33)}$.

A atenção sustentada envolve a capacidade de manter a atenção ao longo do tempo. Seria a capacidade de sustentar uma resposta comportamental consistente durante uma atividade contínua. Essa habilidade é crítica para o processamento de informações. Refere-se a dois 
aspectos do desempenho intimamente relacionados: quantidade de tempo, durante o qual determinado nível de desempenho pode ser mantido, e consistência do desempenho durante esse período. Refere-se à capacidade de se manter um adequado grau de vigília e respostas durante uma atividade repetitiva ou contínua. É particularmente dependente do controle mental e da MO sendo a forma mais caracteristicamente afetada em

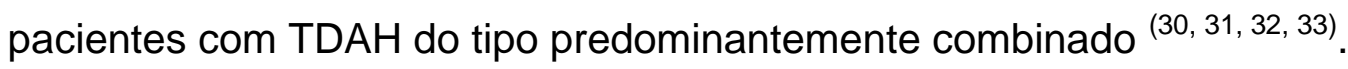

Outro aspecto relevante em relação à atenção diz respeito aos processos automáticos e voluntários. Alguns autores definem atenção voluntária como o direcionamento de recursos de processamento para dada fonte de informação intencionalmente, pela relevância do contexto momentâneo, porém há estímulos que atraem a atenção para si por serem inéditos. É o que acontece quando um estímulo distrator aparece inesperadamente no campo visual do sujeito e, antes que ele possa tomar a decisão consciente de atender ao estímulo, sua atenção é atraída por ele. Dessa forma não há esforço consciente e voluntário atencional, mas reação de captura da atenção gerada pelo estímulo, denominada de atenção automática. Em um segundo momento a atenção voluntária também pode ser deslocada para essa direção como forma de obter mais informações ${ }^{(12,}$ 23, 25, 36).

\subsection{FEs E TDAH}


O TDAH é visto como um distúrbio de base neurobiológica que mostra alterações entre algumas áreas cerebrais e seus circuitos associados. As principais regiões cerebrais alteradas são a pré-frontal, parietal, núcleos da base, cerebelo e seus circuitos associados. Essas alterações determinam que além dos sintomas cardinais (hiperatividade, impulsividade e déficit atencional), ocorram também prejuízos em funções mais complexas, que

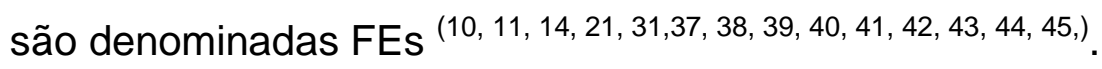

FEs são definidas como uma série de processos mentais que envolvem: planejamento, seleção, inibição de respostas, percepção, atenção, MO, entre outros. Essas funções maiores incluem as capacidades/habilidades de se antecipar, estabelecer objetivos, planejar, monitorar resultados, comparando-os com o objetivo inicial. São capacidades que permitem a um indivíduo perceber estímulos do seu ambiente, responder adequadamente, mudar de direção de modo flexível, antecipar objetivos futuros, considerar consequências e responder de modo integrado, utilizando todas essas capacidades para alcançar um objetivo final $^{(3,9,20,29,31,40,46,47,48)}$

Estudos neuropsicológicos demonstram que crianças com TDAH têm desempenho prejudicado na atenção e nas FEs, tais como: percepção, planejamento e organização, além de falhas na inibição comportamental, motora e do pensamento $(9,27,31,39,46,49,50,51,52)$.

Uma das teorias mais proeminentes da neuropsicologia do TDAH sugere que seus sintomas estão relacionados a prejuízos nas FEs do TDAH além de três importantes déficits associados a este transtorno: a 
impulsividade, hiperatividade e desatenção que estão relacionados diretamente com controle inibitório, resultando em erros pela ação ou pela omissão $^{(15,36,49,53,54,55,56,57,58,59) \text {. }}$

O CPF está muito associado a uma eficiente função executiva. Tem papel importante no controle dos comportamentos, pensamentos e da MO que é a habilidade de se manter em mente um evento que acabou de acontecer ou trazer à memória informações de longo prazo e usar esse conhecimento de representação para inibir ações ou pensamentos inapropriados e planejar ações futuras efetivas $(4,8,15,27,29,39,46,50,52,54,55,56$, $59,60$,$) .$

O sistema de MO está relacionado ao CPF dorso-lateral e suas conexões, denominado como depositário transitório de informações que depois poderão ser acessadas por outros circuitos neuronais, permitindo-se a representação transitória de informações relevantes para uma dada tarefa que estão armazenadas na memória de longo prazo de uma experiência passada ou podem estar no ambiente atual ${ }^{(9,40,46)}$.

Na MO, o CPF dorso-lateral é recrutado para realização de diversos e diferentes processos cognitivos envolvidos no desempenho em testes como os de tempo de reação em que ocorre a manutenção, manipulação e codificação da informação num curto período de tempo ${ }^{(58)}$.

Essas áreas estão envolvidas na chamada MO definida como uma modalidade que permite ao indivíduo manter, em seu sistema de atenção, uma quantidade de informações necessárias para as funções superiores e manipulá-las para alcançar um objetivo final. A MO está relacionada a 
diversos aspectos de outras FEs e é caracterizada como reserva dinâmica de informações disponíveis para a realização de operações imediatas, ou seja, o indivíduo necessita ter em mente aquilo que acabou de aprender para utilizar esse aprendizado posteriormente, em situações oportunas ${ }^{(18,27,}$ 48)

Um dos principais comprometimentos do TDAH está na inibição de resposta, que está incluída nas FEs e necessita de uma adequada capacidade de MO para ser executada. Esse tipo de dificuldade que pode ser observado diariamente em suas respostas dadas antes do término de perguntas ou em conseguir sustentar a atenção, mesmo diante de um estímulo externo importante. Tanto a falha no controle inibitório como a não sustentação da atenção causam déficit cognitivo uma vez que a recepção da informação é desorganizada, não sustentada e, consequentemente, ocorrem falhas no armazenamento e na estocagem de informação. Para executar esse resgate de informações pré-estocadas, bem como para manter determinada informação ativa durante a realização de uma tarefa, é necessário efetuar uma seleção das informações que são relevantes e, paralelamente, a inibição de outras informações irrelevantes àquela tarefa. Assim, a seleção de informações é um segundo componente que tem sido associado às FEs e ao $\operatorname{CPF}(9,19,21,23,31,46,54,55,56,57,60,61)$.

Pesquisas que utilizam testes de tempo de reação (o tempo decorrido entre o aparecimento do estímulo-alvo e a resposta motora), com estímulos de advertência e períodos de preparação, podem ser relevantes para o construto de antecipação apontando que os portadores de TDAH não usam 
o estímulo de advertência para se prepararem para o teste iminente, aumentando o tempo preparatório, e consequentemente tornando seu desempenho pior quando comparado aos que não apresentam o TDAH. As alterações no portador de TDAH variam desde a inibição do comportamento (motor e pensamento) como outras situações em que não consegue se preparar de modo adequado para o momento. Dados recentes informam também que déficits no controle oculomotor podem prejudicar 0 desempenho da organização da resposta motora e o controle inibitório nestas situações $(7,15,29,36,39,46,52,55,56,59,62)$.

No paciente com TDAH, a capacidade de responder, de forma adaptativa, a situações novas está comprometida já que ocorre uma disfunção na circuitaria fronto estriatal, comprometendo múltiplas FEs e a atenção (Figura 1), levando esse paciente a um baixo padrão de motivação, tornando-o irritado, "chateado" e talvez, por não conseguir terminar suas atividades, fica exausto perante as demandas acadêmicas e sociais.

A identificação de déficits neuropsicológicos, específicos ao TDAH, ajudaria a delinear a natureza exata da desordem e seu tratamento. Pesquisas realizadas com o objetivo de se comprovar a teoria da função executiva revelam que, uma disfunção nos domínios da manutenção de um tipo de atenção mais complexa (atenção sustentada), na inibição à interferência, na seleção e alternância de respostas, no monitoramento de comportamento e na $\mathrm{MO}$, tem papel importante na fisiopatologia do $\mathrm{TDAH}^{(35)}$. 


\begin{tabular}{|l|l|l|}
\hline Pré-frontal dorsolateral & $\begin{array}{l}\text { Memória operacional } \\
\text { Solução de problemas, } \\
\text { auto-controle, planejamento, } \\
\text { flexibilidade cognitiva }\end{array}$ \\
\hline Órbito-frontal & $\begin{array}{l}\text { Inibição de respostas } \\
\text { Regulação de emoções }\end{array}$ \\
\hline Cíngulo anterior & $\begin{array}{l}\text { Manutenção do objetivo } \\
\text { Escolha de resposta com } \\
\text { conflito } \\
\text { Controle da emoção } \\
\text { Atenção voluntária }\end{array}$ \\
\hline
\end{tabular}

Figura 1 - Principais áreas cerebrais relacionadas às FEs e ao TDAH 
OBJETIVOS 


\section{Objetivos}

Diante do fato de haver uma "certa" subjetividade no diagnóstico do TDAH, efetuamos este estudo com os seguintes objetivos:

1. Pesquisar alterações, através de testes neuropsicológicos, da atenção e das funções executivas em crianças portadoras do TDAH e

2. Avaliar quais os testes que podem apresentar maior correlação com o diagnóstico do TDAH 
Métodos 


\section{$3 \quad$ Métodos}

\subsection{Casuística}

Foram selecionados 23 pacientes do sexo masculino, de idade entre nove a 12 anos, com diagnóstico de TDAH, estabelecido segundo os critérios do DSM-IV, sem co-morbidades, com QI $\geq 89$, que não tivessem sido medicados para o TDAH e que estivessem em acompanhamento no Ambulatório de TDAH do Serviço de Neurologia Infantil do Instituto Central e do Instituto da Criança do Hospital das Clínicas da Faculdade de Medicina da USP. Esta pesquisa foi aprovada pela Comissão de Ética e pelos Conselhos dos Departamentos de Neurologia e Divisão de Psicologia do Instituto Central do Hospital das Clínicas da Faculdade de Medicina de São Paulo. (Anexos A e B)

O título da pesquisa foi modificado diante do novo desenho do estudo. (Anexo C).

O grupo controle foi composto de alunos da Escola Estadual Keizo Ishihara localizada na Rua Mario Gessulo, 60, Bairro do Butantã, São PauloSP, com a devida autorização da Diretora, mediante termo de consentimento livre e esclarecido. (Anexo D). 
Grupo controle seguiu os mesmos critérios em relação ao sexo, idade, QI, nível de escolaridade cursado e assinatura, pelos pais, do termo de consentimento livre e esclarecido. (Anexo E).

\subsubsection{Critérios de Inclusão}

> Pacientes do sexo masculino, com idade entre nove a 12 anos , que estivessem em acompanhamento pelo TDAH ;

Não tivessem sido medicados previamente para o TDAH ;

Apresentassem Q1 $\geq 89$;

Soubessem ler e escrever de acordo com o nível de escolaridade cursado;

$>$ Cujo os pais aceitassem a participação na pesquisa e assinassem o termo de consentimento livre e esclarecido. (Anexo F)

\subsubsection{Critérios de Exclusão}

$>$ Recusa em participar da pesquisa ou falta de colaboração para as avaliações;

Apresentassem comorbidades neuropsiquiátricas. 
Inicialmente foram avaliados 34 pacientes, dos quais quatro desistiram e sete foram excluídos por apresentarem co-morbidades neuropsiquiátricas (Síndrome de Asperger, Transtorno de Conduta, Transtorno da Ansiedade) além do TDAH.

\subsection{Material}

Foram utilizados os seguintes testes: ${ }^{* \#}$ Escala de Inteligência Wechsler para Crianças $3^{\underline{a}}$ Edição (WISC III) ${ }^{(63)}{ }^{*}{ }^{*}$ Teste de Desempenho Escolar (TDE) ${ }^{(64)}$, "Teste Computadorizado Psicofísico para a Atenção Visual Voluntária (TPAVV) do Departamento de Fisiologia e Biofísica do Instituto de Ciências Biomédicas da USP ${ }^{(23)}$ (Anexo G), " Teste de Cancelamento-quatro formas do Mesulam (Tc) ${ }^{(65)}$ (Anexo H), ${ }^{*}$ Teste das Trilhas (TMT) ${ }^{(67)}$ (Anexo I), Stroop Test (Anexo J), " Go-No Go ${ }^{(31)}$ e o *\# teste computadorizado para atenção visual TAVIS 3R ${ }^{(30)}$.

* Testes, na medida do possível, utilizados com dados normativos para a faixa etária selecionada (nove a 12 anos de idade).

\#Testes, na medida do possível, utilizados com tabelas padronizadas para amostragens em crianças brasileiras.

\subsection{Análise Estatística}


Devido ao tamanho amostral e devido à rejeição de normalidade dos dados, utilizou-se o teste não-paramétrico Mann-Whitney, aplicada para comparar a tendência central de duas amostras independentes: grupo de indivíduos portadores do TDAH e grupo controle.

A frequência do baixo desempenho em alguns testes neuropsicológicos nos portadores de TDAH foi comparada com aquela encontrada nos controles normais através do teste Exato de Fisher, pois foi necessária a categorização dos dados. No caso, os dados mostraram apenas alguns valores significantes, resultando em vários empates, o que inviabilizou o uso do teste de comparação da tendência central ${ }^{(67)}$.

A correlação de Pearson foi utilizada para avaliar a presença ou não de uma relação linear entre as variáveis quantitativas. A estatística resultando em 1 tem-se que existe uma correlação linear positiva perfeita e para o resultado igual a -1 tem-se uma relação negativa perfeita. Esta forma análise foi aplicada em alguns testes neuropsicológicos para verificar o comportamento conjunto das variáveis em estudo ${ }^{(68)}$.

A curva Receiver Operating Characteristic (ROC) foi utilizada para determinar o ponto de corte das variáveis estudadas que melhor poderiam correlacionar com o diagnóstico do TDAH. Nesta análise é possível obter uma ordem de eficiência dos testes estudados, aqueles que obtiveram maiores sensibilidade e especificidade (área sob a curva) ${ }^{(69)}$. Considerou-se como bons testes de correlação com o diagnóstico do TDAH aqueles com eficiência acima de 80\% conforme Tabela 14 . 
Em todas as análises efetuadas, a evidência estatística foi considerada significativa para o valor de $p$ abaixo de 0,05 .

\subsection{Procedimento}

Os pacientes foram inicialmente selecionados a partir de uma triagem através da utilização do questionário SNAP-IV, preenchido pelos respectivos pais e professores. A seguir, os pacientes foram avaliados pelo neurologista infantil do Ambulatório de Distúrbios do Aprendizado do Instituto da Criança do Hospital das Clínicas da Faculdade de Medicina de São Paulo (HCFMUSP). Aqueles que tiveram o diagnóstico confirmado, de acordo com os critérios do DSM-IV, foram selecionadas e, a partir disso, demos seguimento aos demais testes propostos.

Todos os pacientes foram avaliados individualmente pela própria pesquisadora, em uma sala reservada para esse fim, no Instituto da Criança do HCFMUSP no ambulatório de Distúrbios do Aprendizado com duração de duas a três sessões.

As crianças do grupo controle foram avaliadas pela própria pesquisadora em uma sala preparada especialmente para realização dos testes na própria escola, em horário escolar. Os alunos eram retirados individualmente e foram avaliados em duas ou três sessões, em horários previamente agendados. A ordem dos testes foi a mesma seguida pelo grupo experimental e o SNAP -IV foi preenchido pelos pais e professores.

A escala SNAP-IV é uma revisão de Swanson, Nolan e Pelham (SNAP) realizada em 1983 e validada no Brasil por Mattos et al. Os critérios 
do DSM-IV (1994) para diagnóstico de TDAH são incluídos em dois subconjuntos de sintomas: desatenção (itens de 1 a 9 ) e hiperatividade/impulsividade (itens de 11 a 19). Também são incluídos os critérios do DSM-IV para o Transtorno Opositor Desafiador (TOD) (itens de 21 a 28) uma vez que esse transtorno está frequentemente presente nas crianças com TDAH. Os itens 10 e 20 foram acrescentados nos domínios da desatenção e da hiperatividade/impulsividade, respectivamente. Finalmente, dois outros itens foram considerados: um do DSM-III-R (29) que não foi incluído na lista do DSM-IV para TOD e um artigo para se resumir o domínio do TOD (30) ${ }^{(70)}$.

A escala SNAP-IV possui quatro opções de resposta para cada artigo: nem um pouco = zero; um pouco $=$ um; bastante $=$ dois; demais $=$ três. Os escores das sub-escalas são calculados, somando-se a pontuação de cada item e dividindo-se pelo número de itens da sub-escala, ou seja, uma média para cada item. Esta escala avaliou a desatenção, a hiperatividade/impulsividade e o TOD. (Anexo K)

Ordem e descrição dos testes utilizados para a avaliação neuropsicológica da atenção e das funções executivas:

$\left.1^{\circ}\right)$ T.D.E. - Teste de Desempenho Escolar - Utilizado para escolares de 1a à 8 a série sendo composto de três subtestes: escrita, aritmética e leitura. A inclusão dos pacientes foi baseada no adequado rendimento para os subtestes de leitura e escrita.

$2^{\circ}$ ) WISC III - Escala de Inteligência Wechsler para Crianças- Terceira Edição. Foi desenvolvido para ser usado com crianças desde seis 
anos até 16 anos e 11 meses. É composto de 13 subtestes, os quais se subdividem em seis para escala verbal e sete para escala de execução. A cada subteste, o examinador diz que irá apresentar alguns jogos e fazer algumas perguntas para ver o que a criança já aprendeu na escola. É explicado, ainda, que algumas tarefas serão fáceis e outras, mais difíceis, e caso a criança não souber responder ou fazer alguma coisa, não faz mal, porque ela ainda pode não ter aprendido algumas coisas. O examinador também avisa que irá usar um relógio para marcar o tempo que a criança levará para responder e anotar as respostas para que não as esqueça. Neste estudo foram avaliados o QI total e o Perfil ACID (Aritmética, Código, Informação, Dígitos e Completar Figuras), objetivando analisar a atenção e a MO.

$3^{\circ}$ ) Teste Psicofísico para a Atenção Visual Voluntária- TPAVV- (uso autorizado pelo Professor Marcus Vinícius Baldo do Instituto de Ciências Biomédicas I da Faculdade de São Paulo). Analisamos nesta pesquisa o tempo de reação das crianças aos estímulos visuais apresentados. Em cada sessão de testes a criança sentava-se em uma cadeira com encosto, de modo que a distância entre seus olhos e a tela permanecia fixa em $50 \mathrm{~cm}$. Foi utilizado um microcomputador com processador Pentium (acoplado a um monitor de 15 polegadas) que gerou os estímulos e registrou as respostas. O experimento foi elaborado por meio de um programa 
específico chamado "Micro Experimental Labotatory-MEL" (Mel Professional v 2.01-Psychology Software Tools, Inc.).

$4^{\circ}$ ) Tc - Teste de Cancelamento - Foram utilizadas as quatro formas de Mesulam. A criança é instruída a trocar de lápis de cor ao comando do examinador. Em cada forma há 60 alvos e, a cada 12 alvos, ocorre o comando. Na primeira e terceira formas, os alvos estão dispostos de forma linear e, na segunda e quarta forma estão apresentados de forma não linear. A criança deve avisar quando achar que terminou. Avaliamos o tempo de execução.

$\left.5^{\circ}\right)$ TMT - Trail Making Test partes A e B - Denominado testes das trilhas em que a criança é instruída, na parte $\mathrm{A}$, a ligar os números em ordem crescente e avisar quando terminou e, na parte $B$, a ligar números e letras em ordem crescente e alfabética respectivamente. O objetivo do teste consistiu na avaliação da atenção sustentada na parte $A$, atenção alternada e flexibilidade mental na parte $B$.

$\left.6^{\circ}\right)$ Stroop Test - . Em nossa pesquisa, foi utilizada a versão Victoria. O teste compreende três cartões que medem $18 \times 11,5 \mathrm{~cm}$, contendo 24 estímulos cada, impressos sobre fundo branco. $\mathrm{O}$ cartão 1 compõe-se de 24 retângulos dispostos em seis carreiras de quatro itens, observando-se um espaçamento de $1 \mathrm{~cm}$ entre as carreiras e $2 \mathrm{~cm}$ entre os itens. Os retângulos são impressos nas cores, verde, rosa, azul e marrom, de modo a que cada cor 
apareça apenas uma vez por carreira e num arranjo aleatório. Nesse cartão a tarefa consiste em nomear as cores dos retângulos o mais rapidamente possível. O cartão 2 é similar ao 1, exceto pelos estímulos, quando, em lugar dos retângulos, encontram-se palavras não relacionadas a conceitos de cor (cada, nunca, hoje, tudo) impressas em letras maiúsculas, nas cores verde, rosa, azul e marrom dispostas aleatoriamente. Nesse cartão, a tarefa consiste em nomear as cores das palavras (ignorando a leitura das palavras) o mais rapidamente possível. O cartão 3 consiste no cartão interferência, em que os estímulos são nomes de cores (marrom, azul, rosa e verde), impressos em letras maiúsculas, nas cores verde, rosa, azul e marrom, de tal modo que a cor de tinta da impressão e o nome da cor nunca combinem (por exemplo, a palavra marrom aparece impressa nas cores rosa, verde e azul, mas nunca na cor marrom, e assim por diante). Nesse cartão, o sujeito é solicitado a nomear as cores de impressão (ignorando ler os nomes das cores) tão rápido quanto possível. Os três cartões são apresentados sempre na mesma ordem (retângulos, palavras comuns e nomes de cores). A exploração dos estímulos é feita através das linhas, da esquerda para a direita, de cima para baixo, conforme formato de leitura inglesa. Para cada cartão, o tempo gasto para se completar a tarefa é cronometrado, iniciando-se a cronometragem logo após o término das instruções dadas. Através da avaliação do tempo utilizado para completar as tarefas e dos 
erros cometidos foram avaliados a atenção sustentada, seletiva, o controle inibitório e a impulsividade.

$7^{\circ}$ ) Go-No Go - A criança é instruída a bater com a mão fechada contra a mesa duas vezes se o examinador bater uma e a bater uma vez se o examinador bater duas. A seguir, ela é instruída a bater duas vezes se o examinador bater uma, mas não fazer nada se o examinador bater duas vezes. São realizadas quatro, duas, duas e uma vezes, respectivamente, cada movimento. Esse teste analisa a capacidade de controle inibitório do indivíduo testado, ao avaliar a inibição da resposta prepotente.

8) TAVIS 3R - Teste de Atenção Visual - 3a. Revisão - Programa computadorizado que permite aplicar à criança ou ao adolescente três tarefas distintas (denominadas tarefas 1, 2 e 3), num tempo total inferior a 30 minutos. Na tarefa 1 a criança e/ou o adolescente são orientados a acionar o "joystick" quando o estímulo-alvo apresentado, no alto da tela, aparecer, dentre vários semelhantes; na tarefa 2 deve-se acionar o "joystick" quando aparecem na tela dois estímulos que obedeçam à regra solicitada. Para crianças, as regras que se alternam são "IGUAL" e "DIFERENTE". Para adolescentes, as regras que se alternam são "FORMA" e "COR". Na tarefa 4 deve-se acionar o "joystick" quando aparecer o estímulo-alvo em uma tela vazia, permanecendo-se atento por um tempo prolongado em uma tarefa propositalmente monótona. Para crianças, o estímulo alvo 
é a figura de um relógio e tem duração de 6 minutos. Para os adolescentes o estímulo alvo é um ponto vermelho e tem duração de 10 minutos. Maiores informações acessar http://www.neuropsicologia.net.

A seguir apresentamos resumidamente (Tabela 1) os testes aplicados e as funções avaliadas.

Tabela 1 - Testes utilizados e funções avaliadas

TESTES

FUNÇÕES AVALIADAS

WISC III - Perfil

Atenção e MO

$\mathrm{ACID+CF}$

TPAVV

Tempo de reação

Tc

Tempo de execução

TMT Parte A

Atenção Sustentada

TMT Parte B

Atenção alternada e flexibilidade mental

STROOP

Atenção sustentada, seletiva, controle inibitório e

impulsividade

Go-No Go Controle inibitório (inibição da resposta prepotente)

TAVIS 3R Tempo de reação. Atenção seletiva, alternada e sustentada 
RESULTADOS 
Para os experimentos descritos a seguir, foram incluídos 23 sujeitos diagnosticados como portadores do TDAH do tipo combinado, e 15 sujeitos controles, criteriosamente diagnosticados como não portadores do TDAH.

\subsection{Questionário SNAP-IV}

A diferença dos SNAP-IV professores entre os grupos TDAH e controle foi significativa, o que pode ser observado na Tabela 2. Pelos Gráficos 1 e 2 é possível verificar que, em todas as categorias, os resultados obtidos pelos questionários SNAP-IV para professores evidenciaram maiores alterações nos portadores de TDAH. O mesmo foi observado nos questionários apresentados para os pais. 


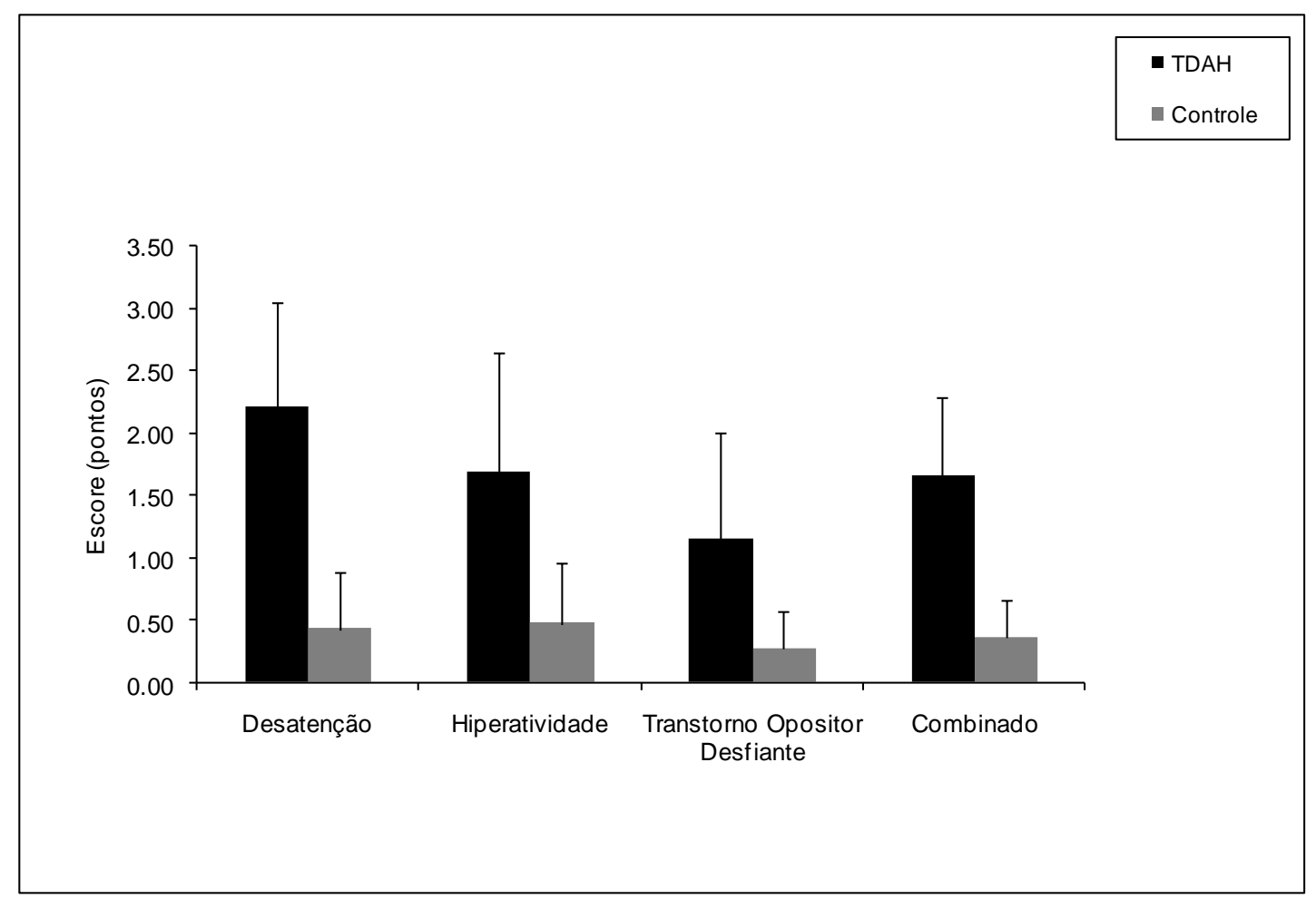

\section{Gráfico 1 - Perfis de Médias do SNAP-IV Professores}

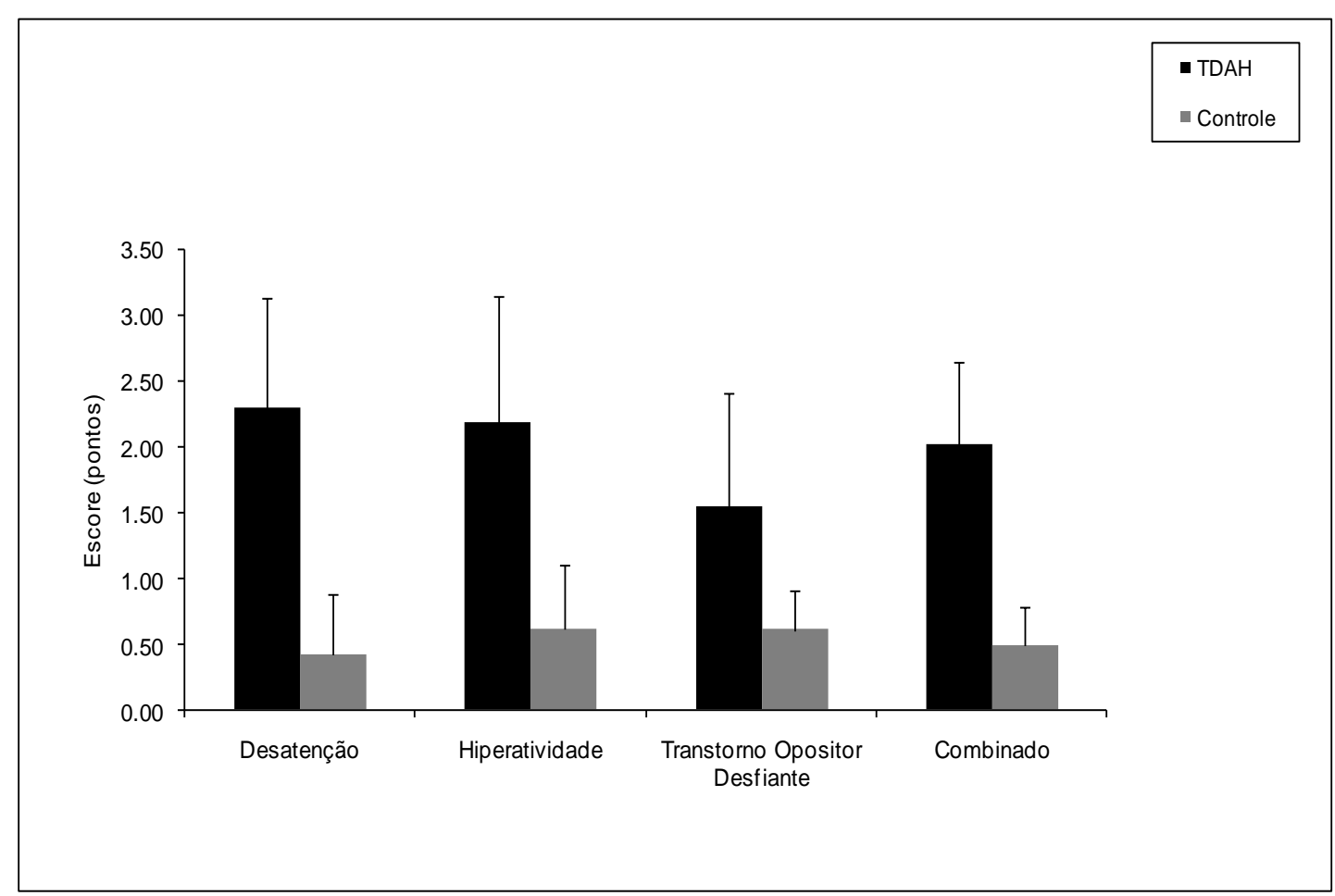

Gráfico 2 - Perfis de Médias do SNAP-IV Pais 
Tabela 2 - Teste de Mann-Whitney para o SNAP-IV entre os portadores de TDAH e os controles

\begin{tabular}{|c|c|c|c|c|c|c|c|c|c|}
\hline & & \multicolumn{4}{|c|}{ Snap Professores } & \multicolumn{4}{|c|}{ Snap Pais } \\
\hline & & Desatençã & Hiperatividade & TOD & Combinado & Desatenção & Hiperatividade & TOD & Combinado \\
\hline & Ponto de Corte & 2.56 & 1.78 & 1.38 & 2 & 1.78 & 1.44 & 1.88 & 1.67 \\
\hline \multirow{2}{*}{ TDAH } & Média & 2.20 & 1.68 & 1.15 & 1.66 & 2.29 & 2.18 & 1.55 & 2.01 \\
\hline & Desv. Pad & 0.83 & 0.96 & 0.86 & 0.62 & 0.58 & 0.66 & 0.64 & 0.49 \\
\hline \multirow{2}{*}{ Controle } & Média & 0.43 & 0.47 & 0.27 & 0.36 & 0.43 & 0.69 & 0.43 & 0.50 \\
\hline & Desv. Pad & 0.45 & 0.49 & 0.30 & 0.30 & 0.42 & 0.61 & 0.61 & 0.49 \\
\hline \multirow{2}{*}{\multicolumn{2}{|c|}{$\begin{array}{c}\text { Mann-Whitney } \\
\text { p-valor Mann-Whitney }\end{array}$}} & -4.44 & -3.25 & -2.94 & -4.33 & -4.90 & -4.71 & -4.56 & -4.95 \\
\hline & & $<0,001$ & 0.001 & 0.003 & $<0,001$ & $<0,001$ & $<0,001$ & $<0,001$ & $<0,001$ \\
\hline
\end{tabular}

FONTE: Hospital das Clínicas e Escola Estadual Keizo Ishihara

NOTA: Pacientes do Ambulatório do Distúrbio do Aprendizado do grupo controle da Escola Estadual Keizo Ishihara

$\mathrm{Na}$ análise seguinte, verificou-se a existência da relação linear entre as variáveis do SNAP-IV para professores e pais através da correlação de Pearson (Tabela 3). Em todas as características (desatenção, hiperatividade, TOD e combinado) existiu correlação positiva significativa entre o SNAP-IV dos dois grupos (professores e pais), ou seja, quanto maior o SNAP-IV dos pais, maior é o SNAP-IV dos professores. Observar Gráficos 3, 4, 5 e 6. 


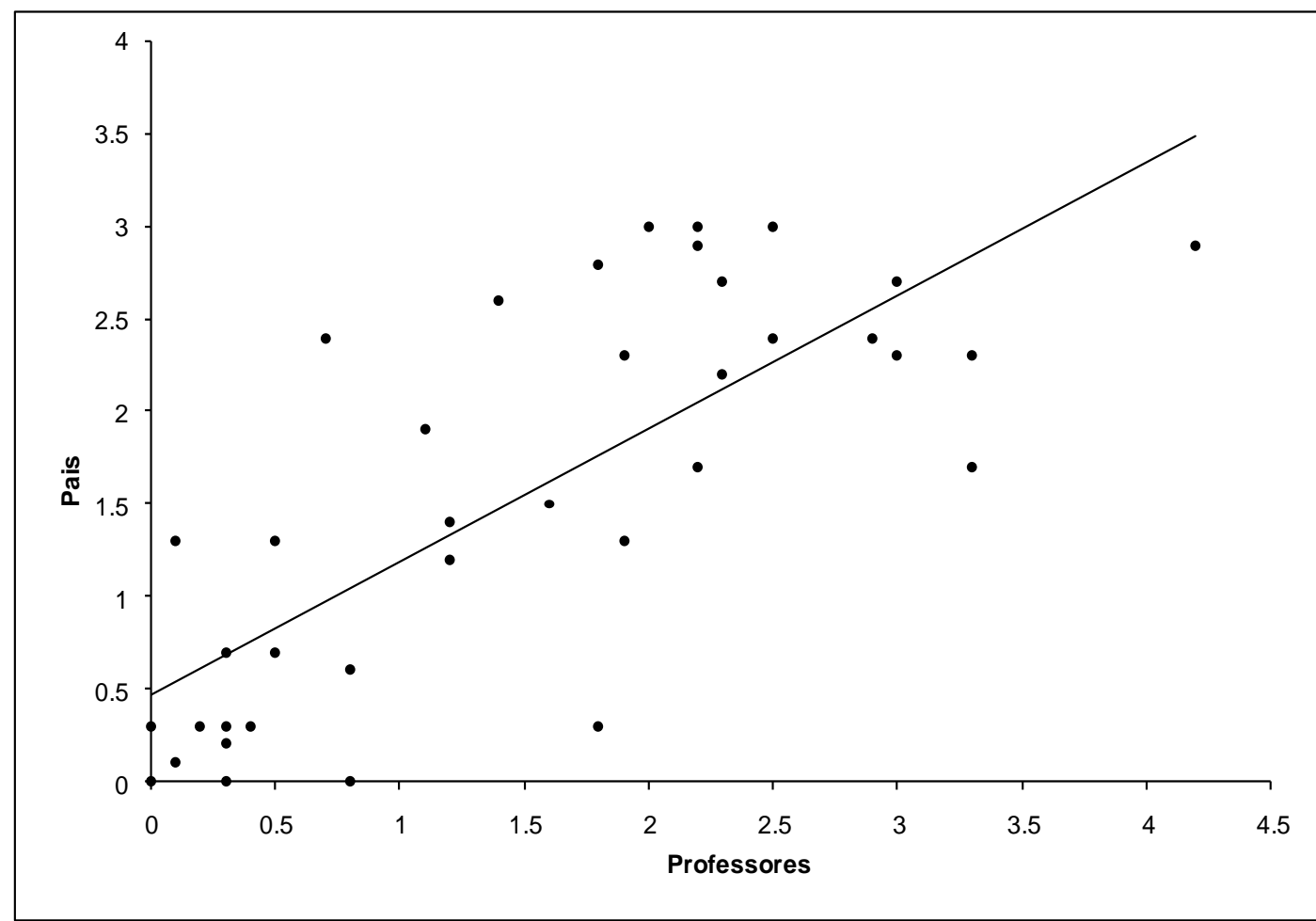

Gráfico 3 - Dispersão entre SNAP-IV professores e pais DESATENÇÃO 


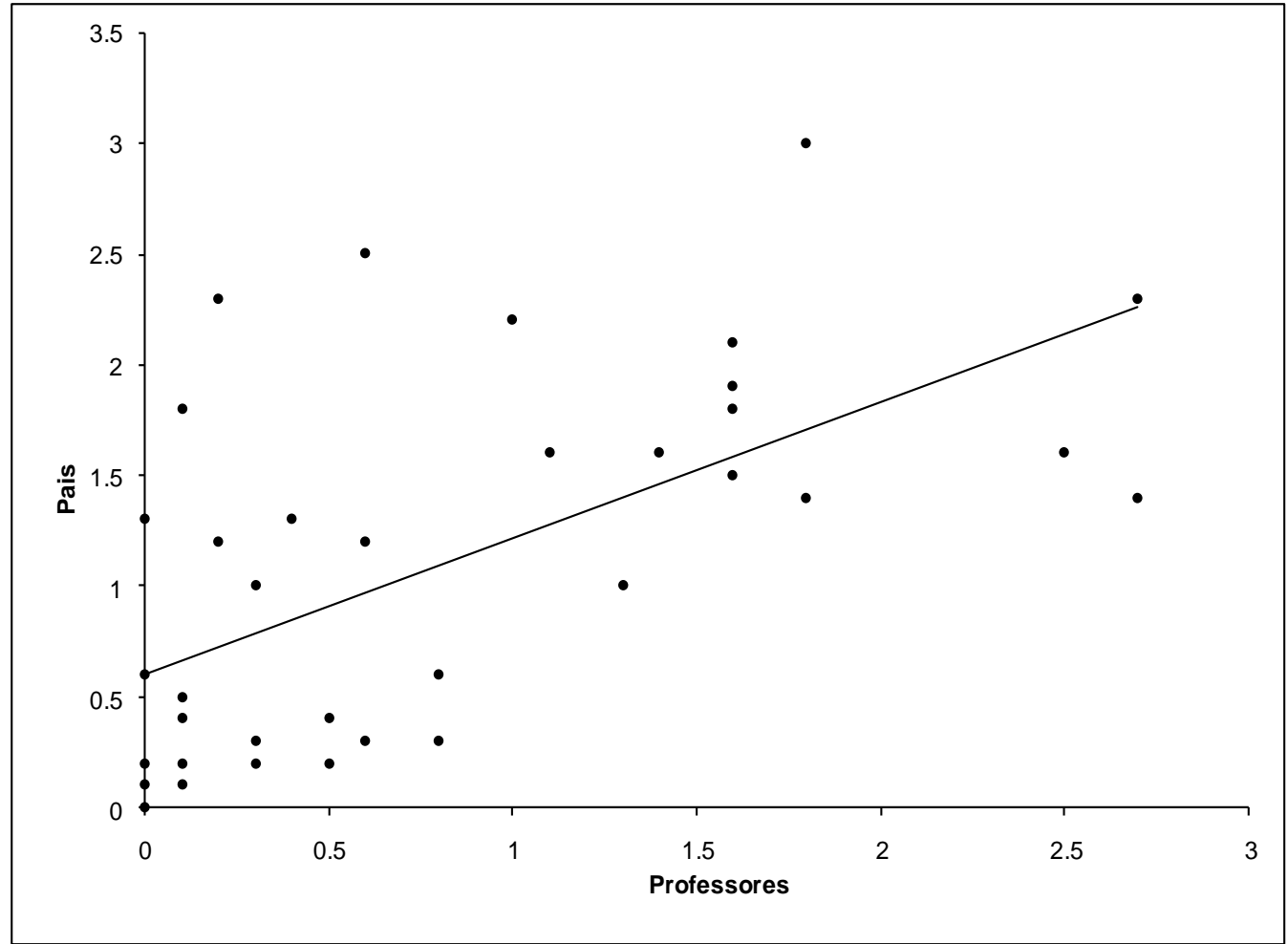

Gráfico 4 - Dispersão entre SNAP-IV professores e pais HIPERATIVIDADE

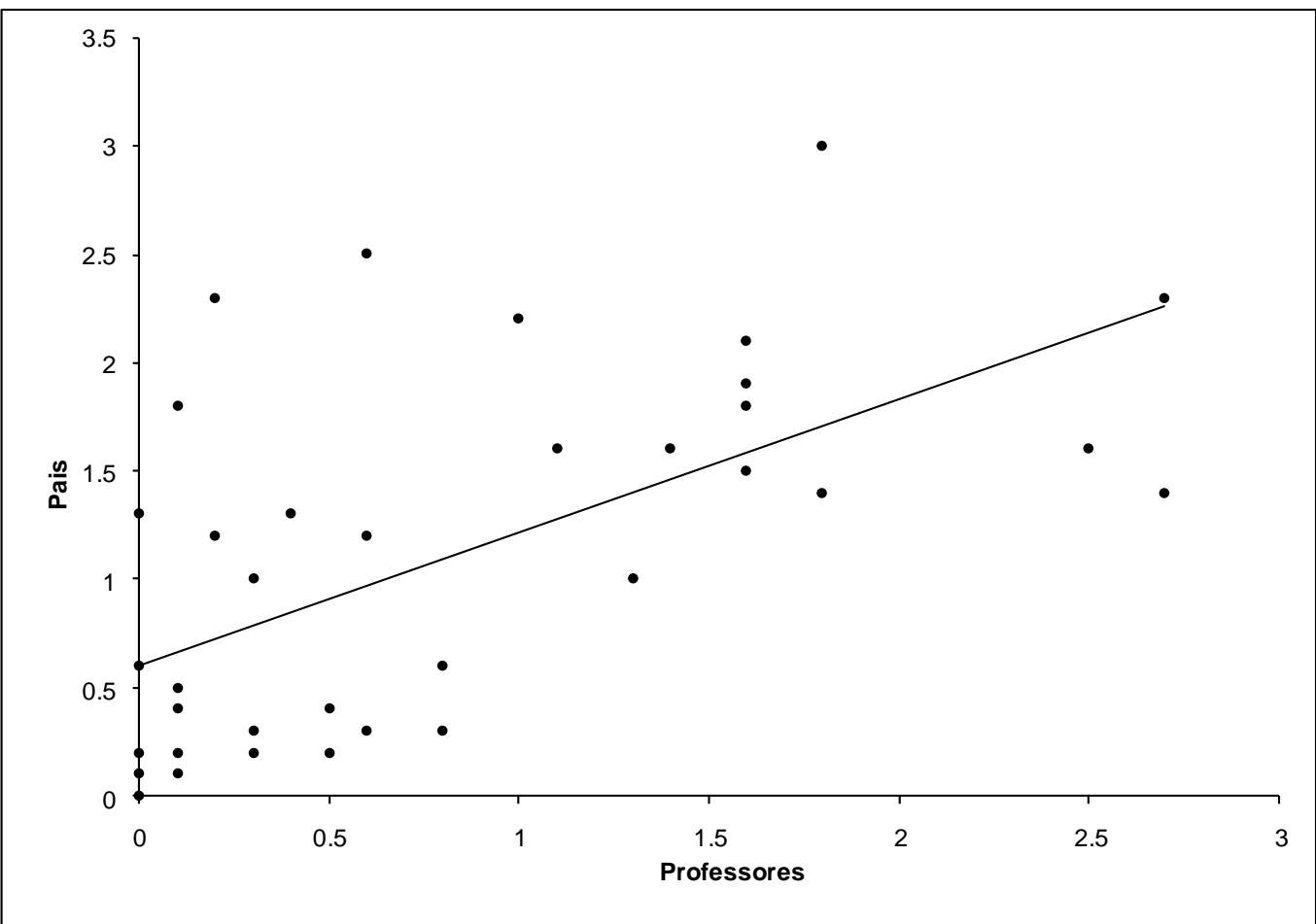

Gráfico 5 - Dispersão entre SNAP-IV professores e pais TOD 


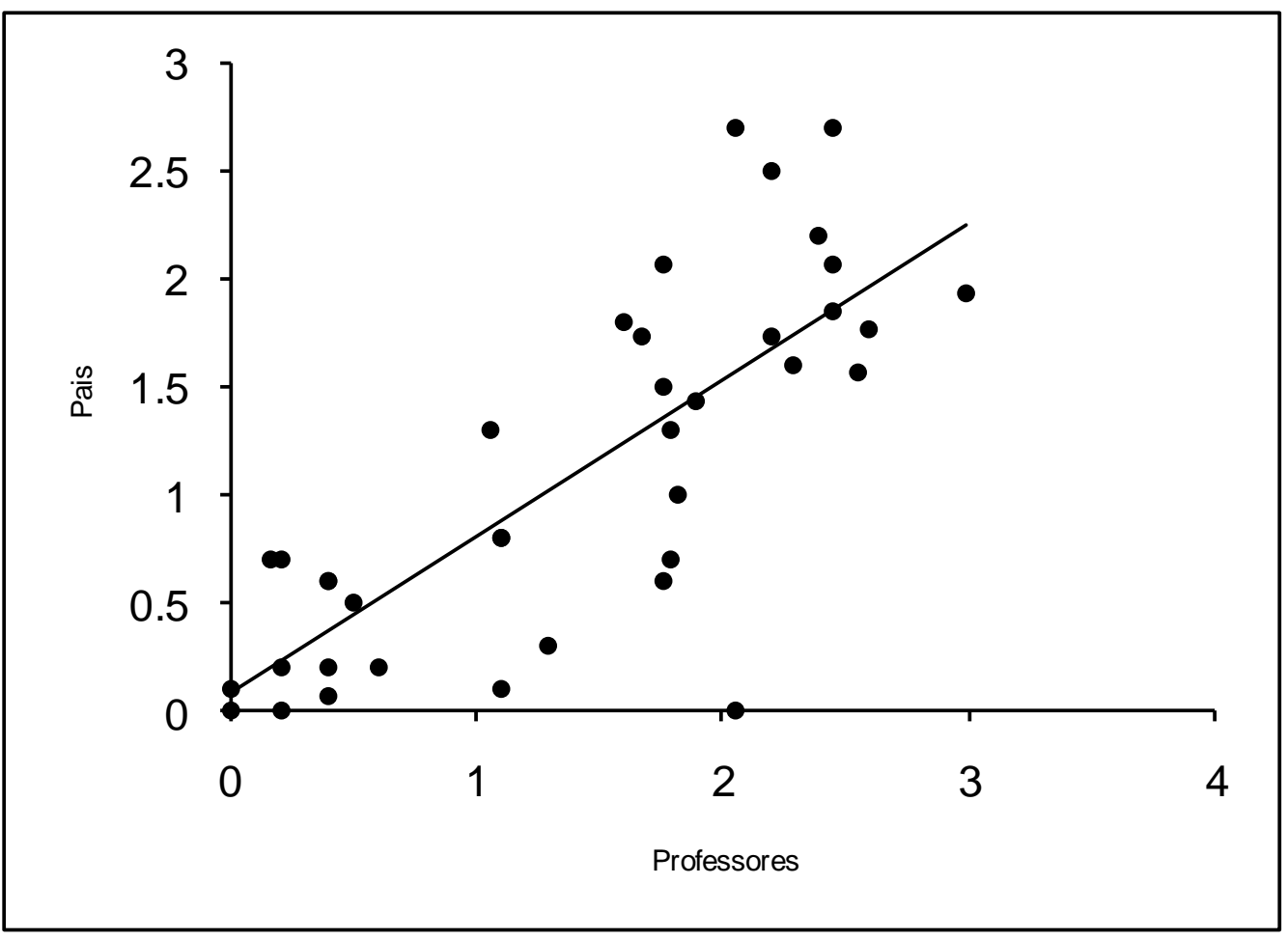

Gráfico 6 - Dispersão entre SNAP-IV professores e pais COMBINADO

Tabela 3 - Correlação de Pearson entre os SNAP-IV Pais e Professores

\begin{tabular}{c|cccc}
\cline { 2 - 5 } & Desatenção & Hiperatividade & TOD & Combinado \\
\hline Correlação & 0.766 & 0.768 & 0.597 & 0.833 \\
pvalor & $<0,001$ & $<0,001$ & $<0,001$ & $<0,001$ \\
\hline
\end{tabular}

FONTE: Hospital das Clínicas e Escola Estadual Keizo Ishihara

NOTA: Pacientes do Ambulatório do Distúrbio do Aprendizado e do grupo controle da Escola Estadual Keizo Ishihara 


\subsection{WISC III (Perfil ACID+CF) - Escala de Inteligência Wechsler para Crianças-Terceira Edição}

A tendência central do grupo controle foi significantemente maior que a tendência central dos portadores do TDAH no perfil ACID +CF (Aritmética, Código, Informação, Dígitos e Completar Figuras) com os respectivos valores: $p<0,01 ; p<0,01, p<0,009 ; p<0,001$ e $p<0,001$. O Gráfico 7 e a Tabela 4 apresentam claramente as diferenças significativas encontradas. $\mathrm{O}$ máximo de dígitos memorizados na $\mathrm{OD}$ e na $\mathrm{OI}$, tanto pelo grupo controle como pelo grupo TDAH, demonstrou diferença significativa somente na OI. Esta diferença é encontrada na Tabela 4.

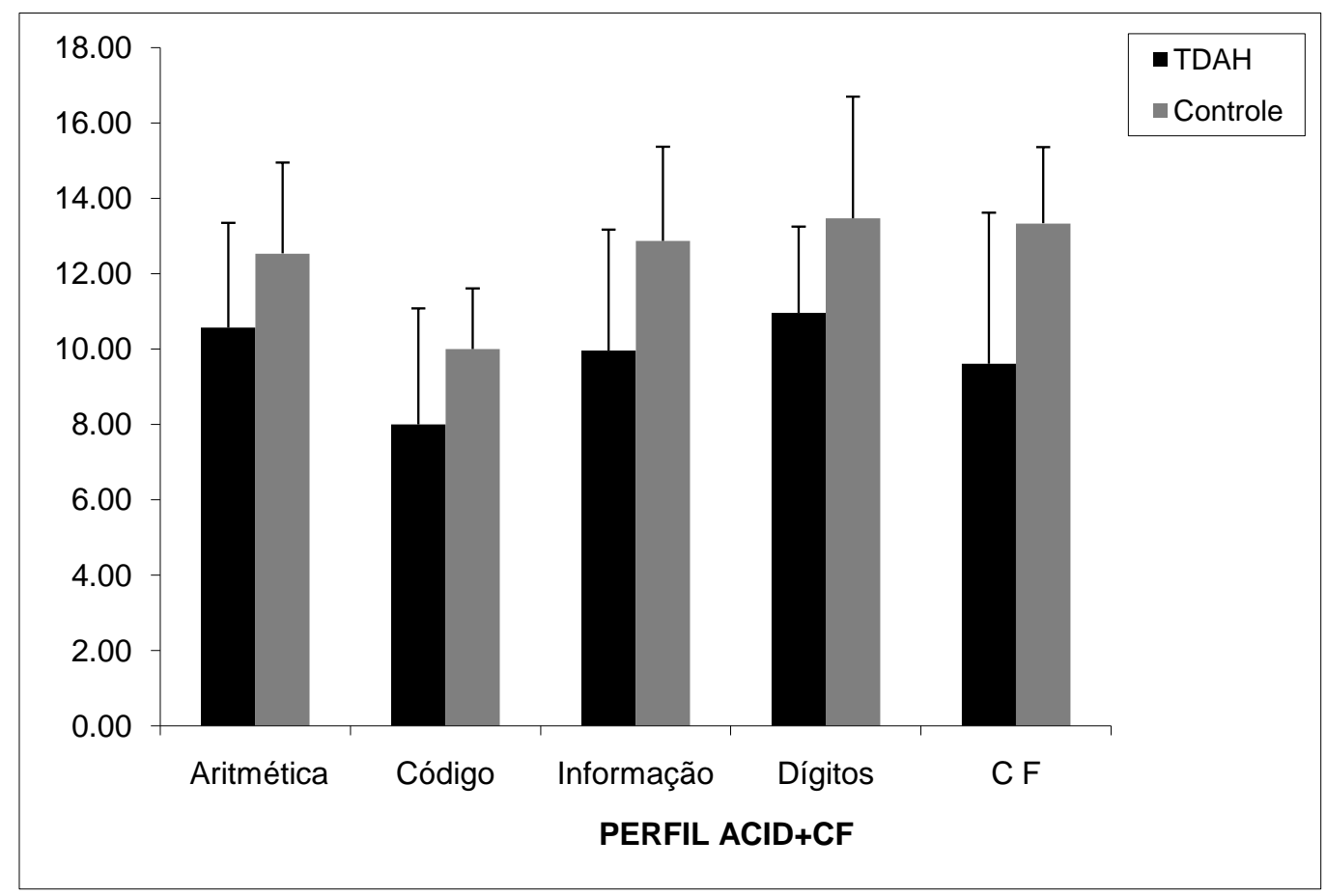

Gráfico 7 - Perfis de Médias do Perfil ACID+CF 
Tabela 4 - Teste de Mann-Whitney para as médias do Perfil ACID+CF e máximo de dígitos, memorizados, na OD e OI.

\begin{tabular}{|c|c|c|c|c|c|c|c|c|}
\hline & & \multicolumn{7}{|c|}{ PERFIL ACID +CF } \\
\hline Grupo & & Aritmética & Código & Informação & Dígitos & OD & OI & C F \\
\hline \multirow{2}{*}{ TDAH } & Média & 10.57 & 8.00 & 9.96 & 10.96 & 5.91 & 3.17 & 9.61 \\
\hline & Desv.Pad & 2.78 & 3.07 & 3.21 & 2.29 & 1.53 & 0.89 & 4.01 \\
\hline \multirow{2}{*}{ Controle } & Média & 12.53 & 10.00 & 12.87 & 13.47 & 6.00 & 4.20 & 13.33 \\
\hline & Desv.Pad & 2.42 & 1.60 & 2.50 & 3.23 & 0.85 & 1.15 & 2.02 \\
\hline \multirow{2}{*}{\multicolumn{2}{|c|}{$\begin{array}{c}\text { Mann-Whitney } \\
\text { valor } p\end{array}$}} & -2.443 & -2.371 & -2.609 & -2.495 & -0.699 & -2.713 & -3.334 \\
\hline & & 0.016 & 0.018 & 0.009 & 0.013 & 0.516 & 0.011 & 0.001 \\
\hline
\end{tabular}

FONTE: Hospital das Clínicas e Escola Estadual Keizo Ishihara

NOTA: Pacientes do Ambulatório do Distúrbio do Aprendizado e do grupo controle da Escola Estadual Keizo Ishihara

\subsection{Teste Psicofísico para Atenção Visual Voluntária (TPAVV)}

A significância das diferenças entre os grupos TDAH e controle, em cada uma das tarefas está descrita no Gráfico 8. Com exceção da seta direita válida, nas demais categorias se constatou diferença entre esses grupos (Tabela 5). No Gráfico 8 observa-se que tanto os controles quanto o grupo portador do TDAH apresentaram pior desempenho na Condição Inválida do TPAVV (seta e quadrado aparecem em lados opostos). 


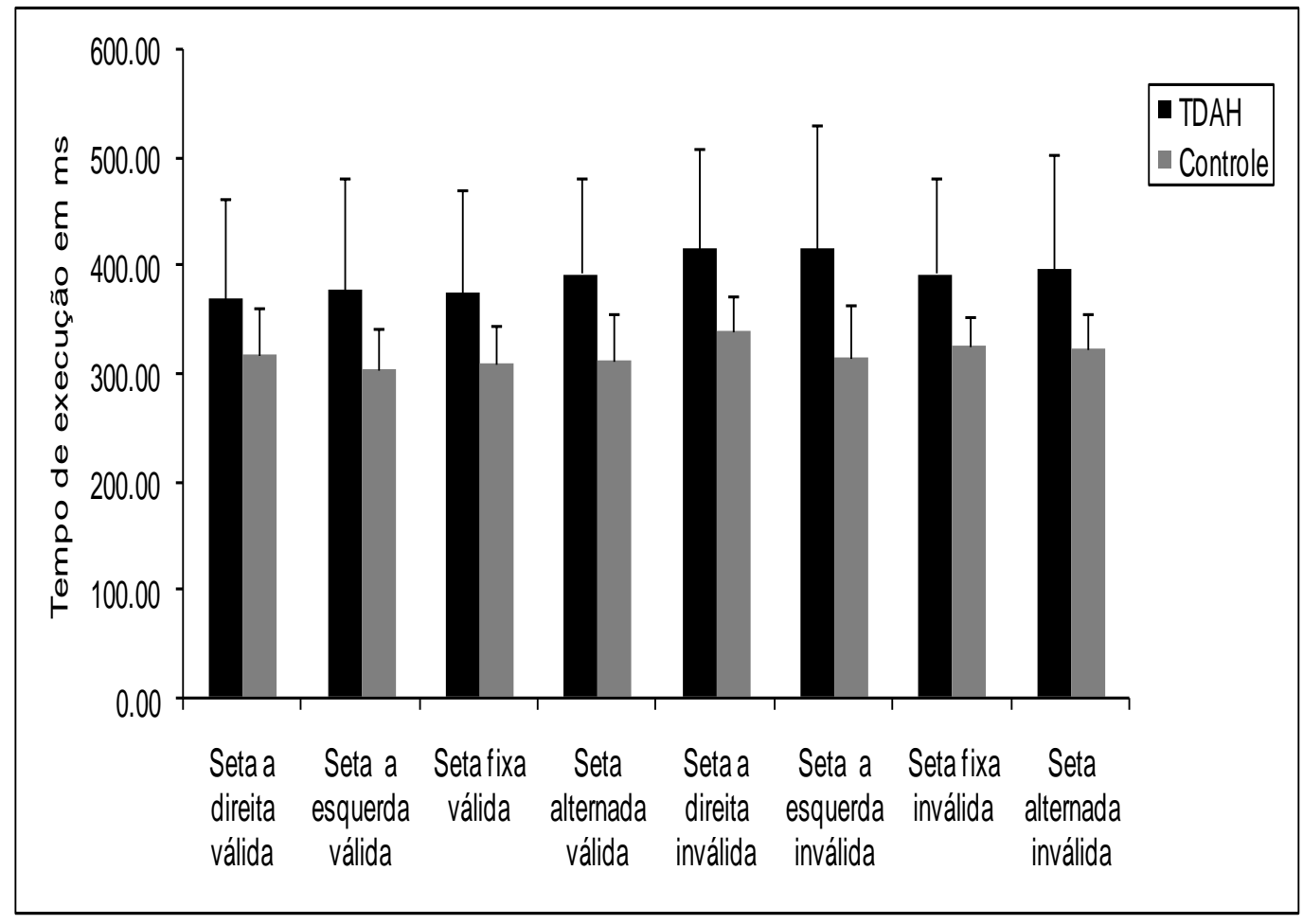

Gráfico 8 - Perfis de Médias do TPAVV 
Tabela 5 - Teste de Mann-Whitney para as Médias do Tempo de Reação do TPAVV

\begin{tabular}{|c|c|c|c|c|c|}
\hline & & Seta a direita válida & Seta a esquerda válida & Seta fixa válida & Seta alternada válida \\
\hline TRAH & Média & 368.67 & 377.50 & 375.04 & 392.85 \\
\hline IDAП & Desv. Pad & 93.85 & 104.25 & 96.28 & 89.15 \\
\hline Cantrola & Média & 317.35 & 303.67 & 310.53 & 311.68 \\
\hline Comitivie & Desv. Pad & 42.77 & 37.37 & 33.40 & 43.48 \\
\hline Mann & -Whitney & -1.63 & -2.40 & -2.27 & -3.03 \\
\hline p-valor M & ann-Whitney & 0.107 & 0.016 & 0.022 & 0.002 \\
\hline & & Seta a direita inválida & Seta a esquerda inválida & Seta fixa inválida & Seta alternada inválida \\
\hline$T \mathrm{TAH}$ & Média & 417.03 & 417.26 & 392.85 & 397.38 \\
\hline & Desv. Pad & 92.60 & 114.21 & 89.15 & 106.55 \\
\hline Controlo & Média & 338.57 & 313.97 & 326.41 & 323.32 \\
\hline Controle & Desv. Pad & 33.52 & 50.23 & 25.98 & 31.35 \\
\hline Manr & -Whitney & -2.64 & -2.60 & -2.58 & -2.20 \\
\hline p-valor $N$ & lann-Whitney & 0.007 & 0.008 & 0.009 & 0.028 \\
\hline
\end{tabular}

FONTE: Hospital das Clínicas e Escola Estadual Keizo Ishihara

NOTA: Pacientes do Ambulatório do Distúrbio do Aprendizado e do grupo controle da Escola Estadual Keizo Ishihara

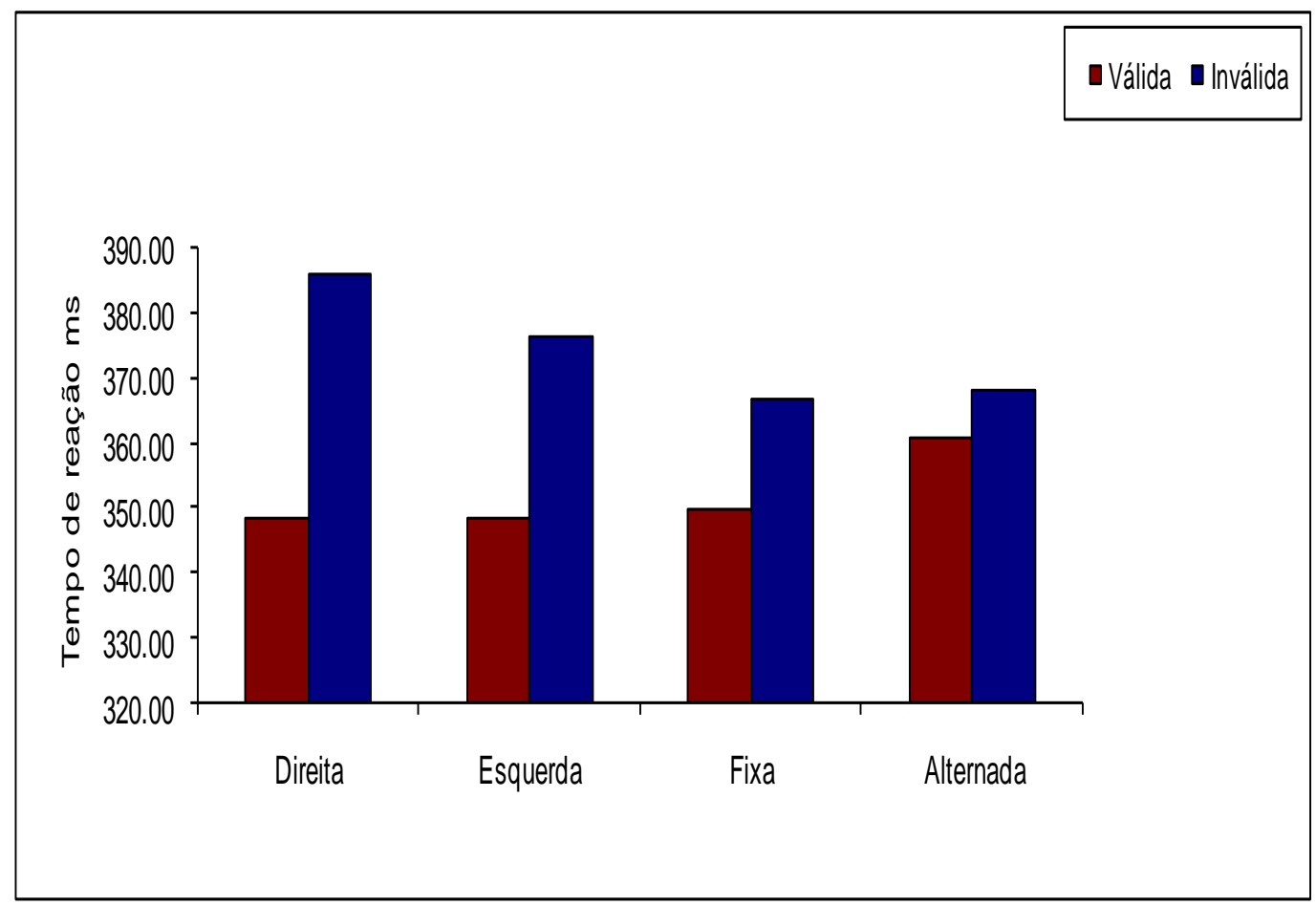

Gráfico 9 - Perfis de Médias para Condição Válida e Condição Inválida 


\subsection{Teste de Cancelamento (Tc)}

A média do Tempo de Execução das formas um, dois, três e quatro do teste de cancelamento do grupo TDAH é significativamente maior que o do grupo controle demonstrado no Gráfico 10 e Tabela 6.

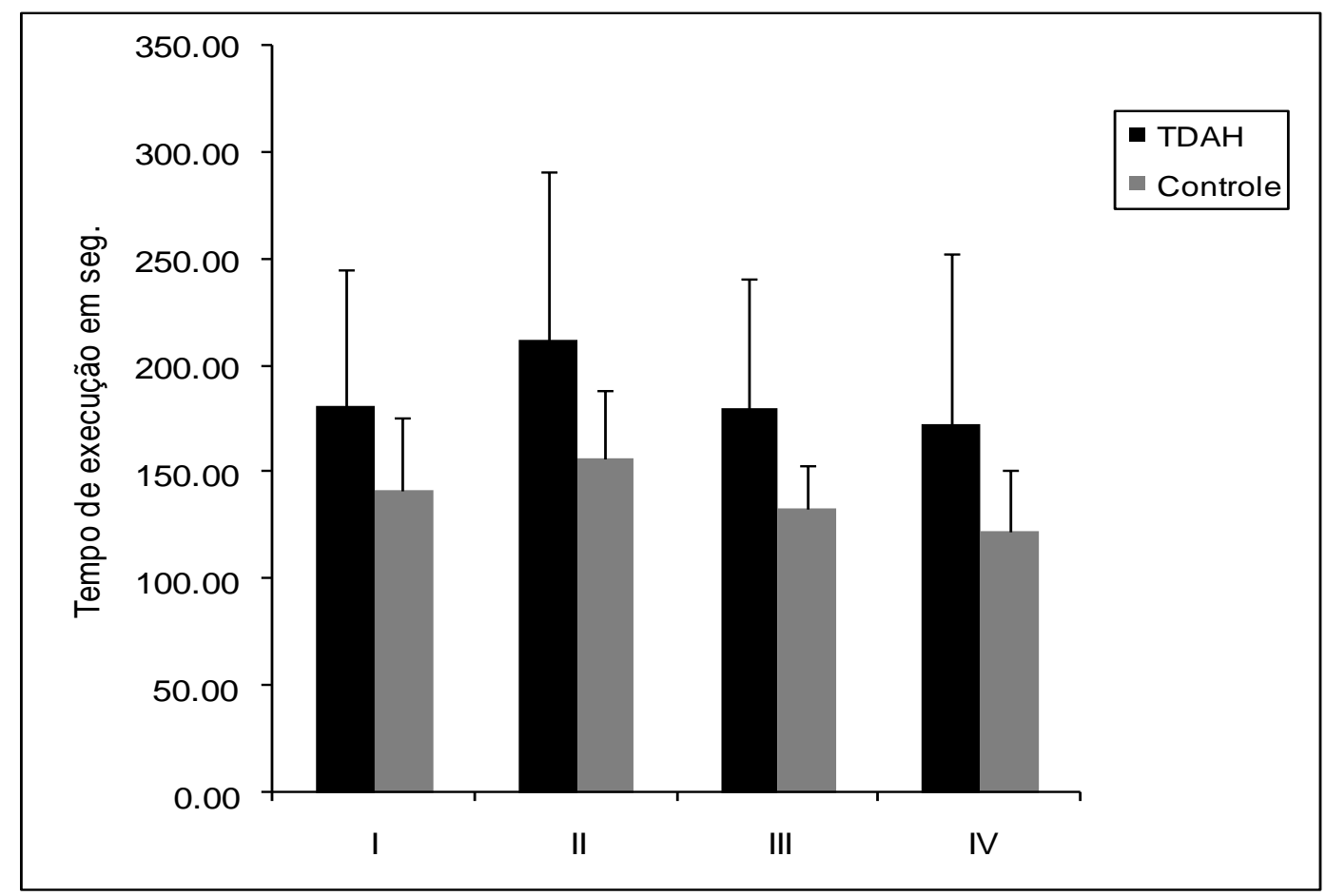

Gráfico 10 - Perfis de Médias do Tc

Tabela 6 - Teste de Mann-Whitney para as Médias do Tempo de Execução do Tc

\begin{tabular}{c|c|cccc}
\cline { 3 - 5 } \multicolumn{2}{c|}{} & \multicolumn{4}{c}{ Teste de Cancelamento- Tempo } \\
\hline \multirow{2}{*}{ Grupo } & & I & II & III & IV \\
\hline \multirow{2}{*}{ TDAH } & Média & 181.35 & 212.57 & 180.43 & 173.17 \\
& Desv. Pad & 64.05 & 78.42 & 60.55 & 79.03 \\
\hline \multirow{2}{*}{ Controle } & Média & 141.40 & 156.80 & 133.07 & 122.47 \\
& Desv. Pad & 34.21 & 31.81 & 20.64 & 28.83 \\
\hline \multicolumn{2}{c}{ Mann-Whitney } & -2.061 & -2.271 & -2.524 & -2.091 \\
\multicolumn{2}{c}{ p-valor Mann-Whitney } & 0.038 & 0.022 & 0.011 & 0.035 \\
\hline
\end{tabular}

FONTE: Hospital das Clínicas e Escola Estadual Keizo Ishihara

NOTA: Pacientes do Ambulatório do Distúrbio do Aprendizado e do grupo controle da Escola Estadual Keizo Ishihara 


\subsection{Teste das Trilhas (TMT)}

Foi detectada diferença estatisticamente significativa entre os grupos

TDAH e controle dos tempos da parte $A$ e $B$, com $p<0,044$ e $p<0,001$

respectivamente. Apresentada através do Gráfico 11 e da Tabela 7.

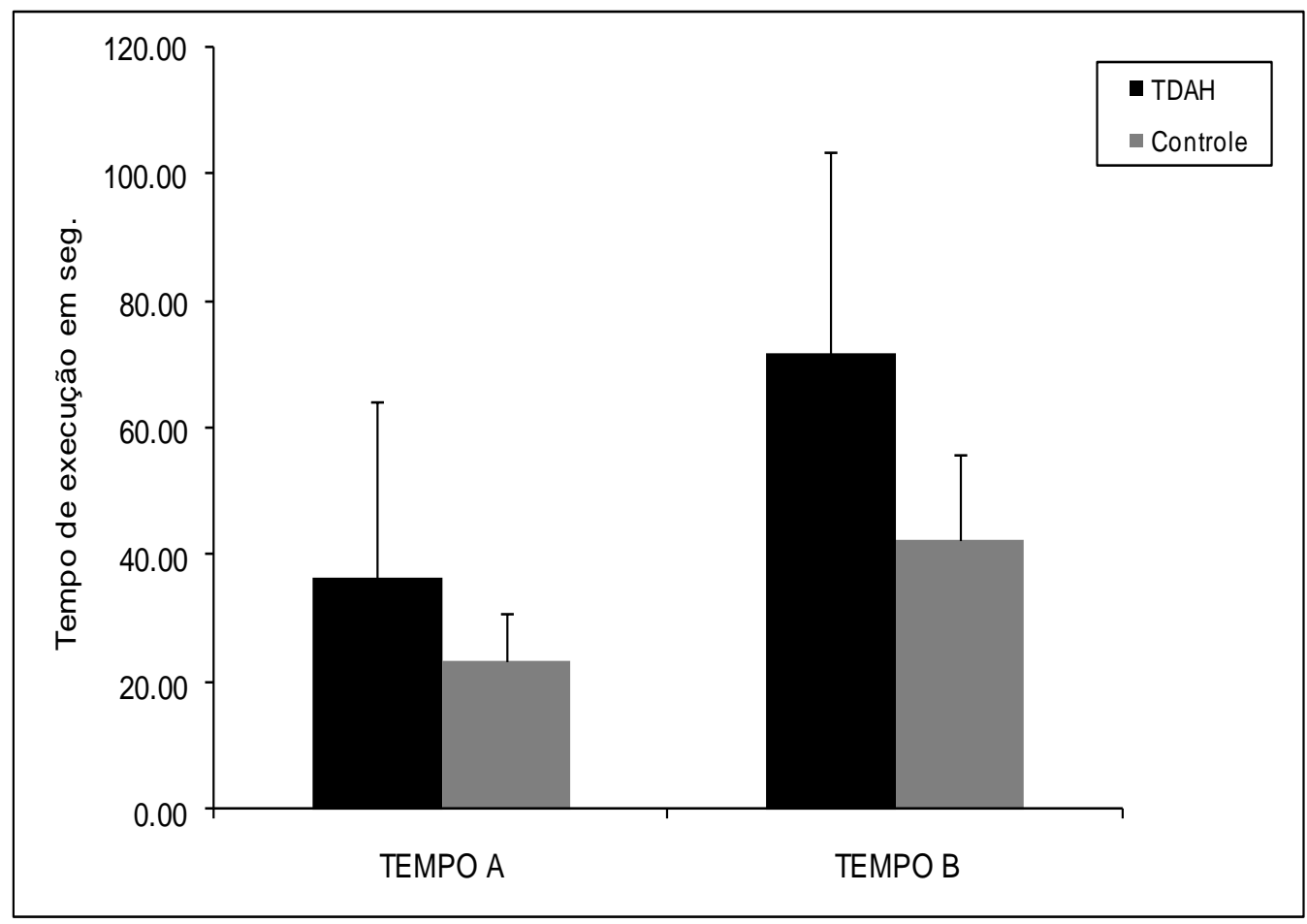

Gráfico 11 - Perfis de Médias do Tempo do Teste da Trilhas partes A e B

Tabela 7 - Teste de Mann-Whitney para as Médias dos Tempos das Partes A e B do Teste das Trilhas

\begin{tabular}{|c|c|c|c|}
\hline & \multicolumn{2}{|c|}{ Trail Making Test } \\
\hline & & TEMPO A & EMPO B \\
\hline \multirow{2}{*}{ TDAH } & Média & 36.52 & 72.00 \\
\hline & Desv. Pad & 27.73 & 31.64 \\
\hline \multirow{2}{*}{ Controle } & Média & 23.27 & 42.53 \\
\hline & Desv. Pad & 7.50 & 13.35 \\
\hline \multicolumn{2}{|c|}{ Mann-Whitney } & $\begin{array}{c}-2.003 \\
0.044\end{array}$ & $\begin{array}{c}-3.316 \\
0.001\end{array}$ \\
\hline
\end{tabular}

FONTE: Hospital das Clínicas e Escola Estadual Keizo Ishihara

NOTA: Pacientes do Ambulatório do Distúrbio do Aprendizado e do grupo controle da Escola Estadual Keizo Ishihara 


\subsection{Stroop Test}

Os tempos do Stroop Test palavras possuem diferenças estatisticamente significantes entre os grupos TDAH e controle com o valor de $p=0,043$.

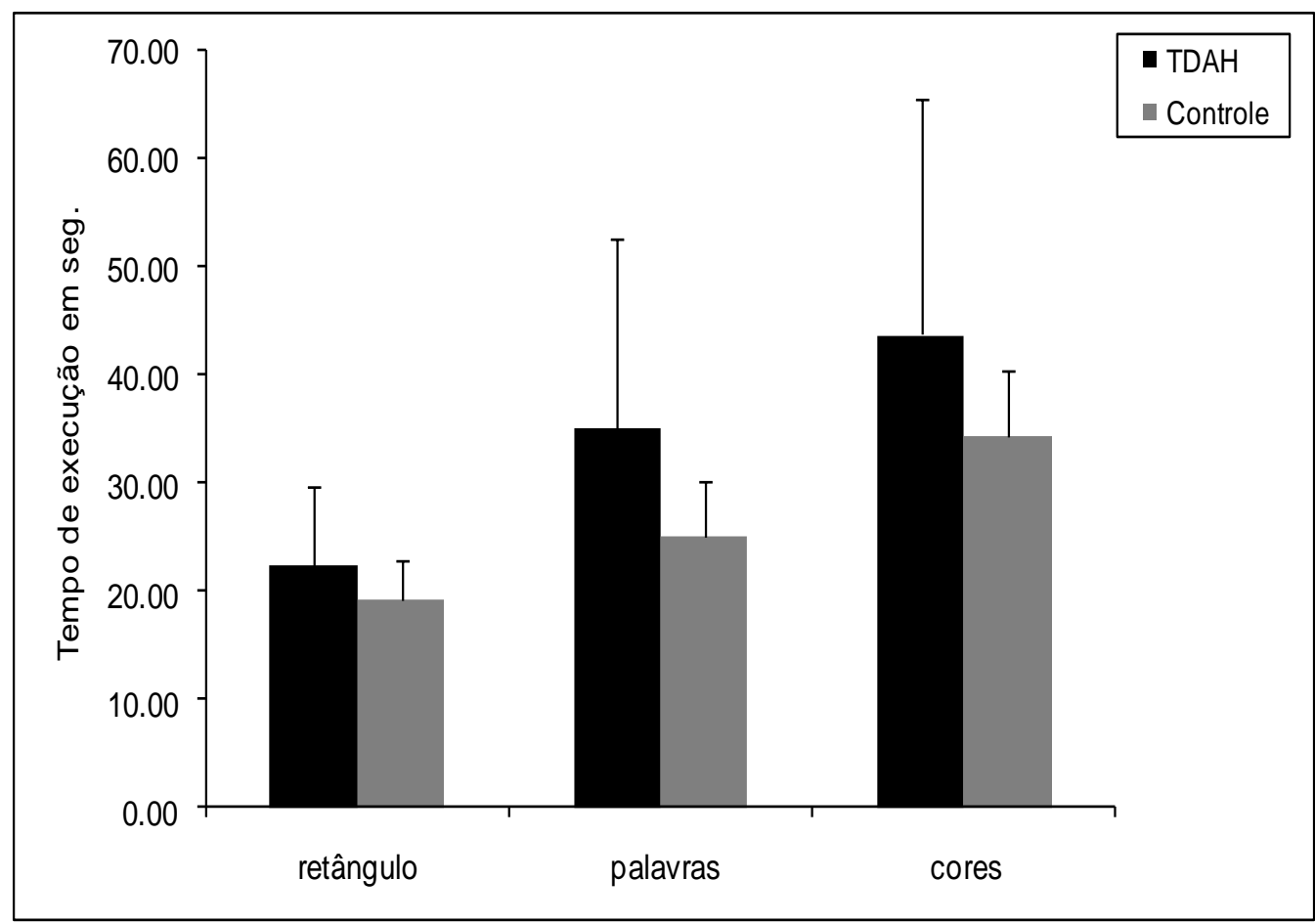

Gráfico 12 - Perfis de Médias do Tempo do Stroop Test

Tabela 8 - Teste de Mann-Whitney para as Médias do Tempo de Execução do Stroop Test

\begin{tabular}{|c|c|c|c|c|}
\hline & & \multicolumn{3}{|c|}{ Stroop Test - Tempo } \\
\hline & & retângulo & palavras & cores \\
\hline \multirow{2}{*}{ TDAH } & Média & 22.39 & 35.04 & 43.74 \\
\hline & Desv. Pad & 7.22 & 17.64 & 21.88 \\
\hline \multirow{2}{*}{ Controle } & Média & 19.33 & 25.20 & 34.40 \\
\hline & Desv. Pad & 3.68 & 5.09 & 6.05 \\
\hline \multicolumn{2}{|l|}{ Mann } & 1.72 & 2.10 & 1.94 \\
\hline \multicolumn{2}{|c|}{ p-valor Mann-Whitney } & 0.095 & 0.043 & 0.063 \\
\hline
\end{tabular}

FONTE: Hospital das Clínicas e Escola Estadual Keizo Ishihara

NOTA: Pacientes do Ambulatório do Distúrbio do Aprendizado e do grupo controle da Escola Estadual Keizo Ishihara 
O teste Exato de Fisher foi utilizado para verificar se a proporção de erros (nos cartões retângulo, palavras e cores) no Stroop Test foi a mesma nos dois grupos. Agruparam-se as categorias entre aqueles que erraram e aqueles que não erraram para se alcançar as condições de se efetuar o teste. Concluiu-se que não foi possível verificar diferença entre as proporções de erros nos dois grupos nos critérios retângulo e palavras. Finalmente, observou-se diferença estatisticamente significativa nas proporções de erros dos dois grupos no critério cores.

Tabela 9 - Teste Exato de Fisher para verificar a homogeneidade de proporções de erros entre os grupos TDAH e controle do Stroop Teste

\begin{tabular}{c|ccc}
\cline { 2 - 4 } & \multicolumn{3}{|c}{ Stroop Test - Erros } \\
\cline { 2 - 4 } & retângulo & palavras & cores \\
\hline p-valor & 0.509 & 0.063 & $<0,001$ \\
\hline
\end{tabular}

FONTE: Hospital das Clínicas e Escola Estadual Keizo Ishihara

NOTA: Pacientes do Ambulatório do Distúrbio do Aprendizado e do grupo controle da Escola Estadual Keizo Ishihara

\subsection{Go-No Go}

Utilizando teste Exato de Fisher, verificou-se a proporções de erros do teste Go-No Go entre os grupos Controle e portadores de TDAH, não se verificando diferenças significativas entre eles. 
Tabela 10 - Teste Exato de Fisher para verificar a proporção de erros entre os grupos TDAH e controle do Go-No Go

\begin{tabular}{c|cc|c}
\hline Go-no-Go & Controle & Paciente & pvalor- Fisher \\
\hline $\mathbf{2} / \mathbf{1}(\mathbf{4})$ & 0.933 & 0.957 & 0.640 \\
$\mathbf{1 / 2}(\mathbf{2})$ & 0.933 & 0.870 & 0.480 \\
$\mathbf{2} / \mathbf{1}(\mathbf{2})$ & 0.867 & 0.609 & $\mathbf{0 . 0 8 7}$ \\
$\mathbf{0 / 2}(\mathbf{1})$ & 0.800 & 0.696 & 0.373 \\
\hline
\end{tabular}

FONTE: Hospital das Clínicas e Escola Estadual Keizo Ishihara

NOTA: Pacientes do Ambulatório do Distúrbio do Aprendizado e do grupo controle da Escola Estadual Keizo Ishihara

\subsection{TAVIS $3 R$}

Compararam-se os resultados das tarefas T1, T2 e T3 entre os grupos TDAH e controle. A diferença é altamente significativa entre esses grupos nas Tarefas 2 e 3 com $p<0,001$ evidenciada no Gráfico 13 e na Tabela 11.

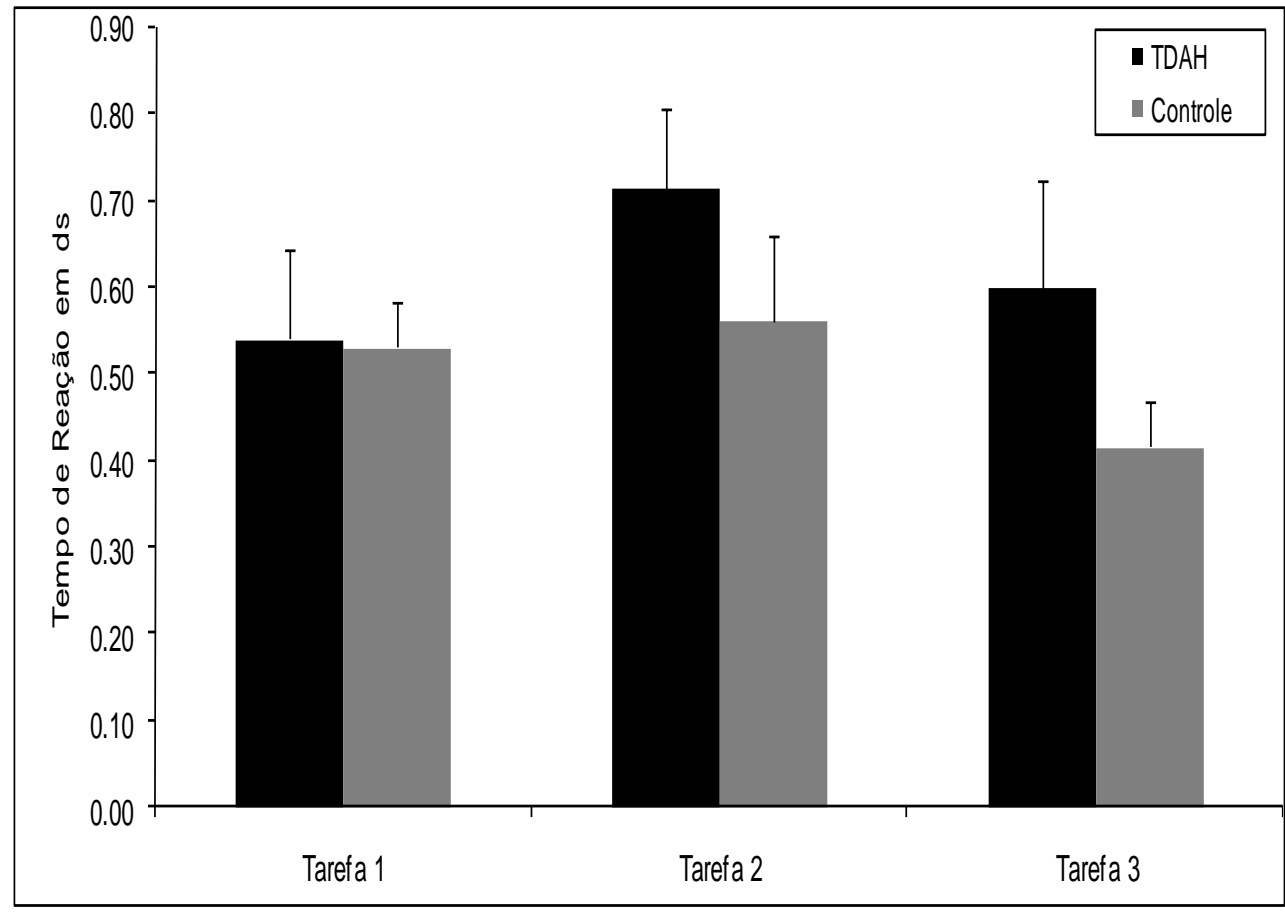

Gráfico 13 - Perfis de Médias do Tempo de reação do TAVIS 3R 
Tabela 11 -. Teste de Mann-Whitney para as Médias do Tempo de Reação das tarefas 1, 2, e 3 do TAVIS 3R

\begin{tabular}{|c|c|c|c|c|}
\hline & & \multicolumn{3}{|c|}{ TAVIS } \\
\hline & & Tarefa 1 & Tarefa 2 & Tarefa 3 \\
\hline \multirow{2}{*}{ TDAH } & Média & 0.54 & 0.71 & 0.60 \\
\hline & Desv. Pad & 0.10 & 0.09 & 0.13 \\
\hline \multirow{2}{*}{ Controle } & Média & 0.53 & 0.56 & 0.42 \\
\hline & Desv. Pad & 0.05 & 0.10 & 0.05 \\
\hline \multicolumn{2}{|c|}{ Mann-Whitney } & -1.40 & -3.79 & -4.46 \\
\hline \multicolumn{2}{|c|}{ p-valor Mann-Whitney } & 0.162 & $<0,001$ & $<0,001$ \\
\hline
\end{tabular}

FONTE: Hospital das Clínicas e Escola Estadual Keizo Ishihara

NOTA: Pacientes do Ambulatório do Distúrbio de Aprendizagem e do grupo controle da Escola Estadual Keizo Ishihara

As diferenças entre os grupos TDAH e Controle em relação a presença de erros por ação das Tarefas 1 e 2 são estatisticamente significativas com $p<0,001$. A Tarefa 3 não apresentou diferença significativa, o que pode ser evidenciado no Gráfico 14 e Tabela 12.

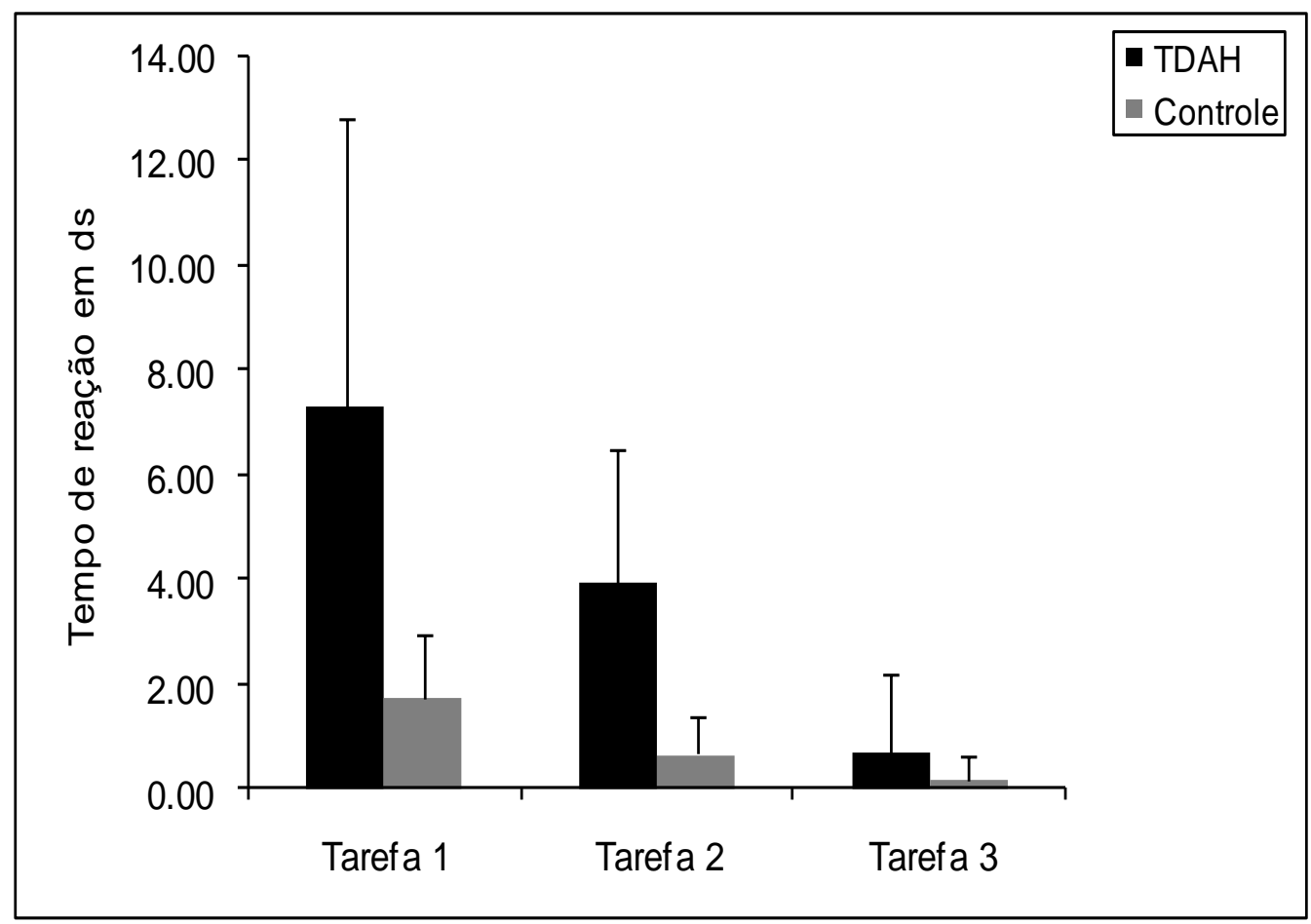

Gráfico 14 - Perfis de Médias dos erros por ação do TAVIS 3R 
Tabela 12 - Teste de Mann-Whitney para as Médias de Erros por ação das Tarefas 1, 2, e 3 do TAVIS 3R

\begin{tabular}{c|c|ccc}
\cline { 3 - 5 } \multicolumn{2}{c|}{} & \multicolumn{3}{c}{ Ação } \\
\cline { 3 - 5 } TDAH & Marefa 1 & Tarefa 2 & Tarefa 3 \\
\hline \multirow{2}{*}{ Controle } & 7.30 & 3.96 & 0.70 \\
& Desv. Pad & 5.51 & 2.55 & 1.49 \\
\hline \multirow{2}{*}{ Mann-Whitney } & Média & 1.73 & 0.67 & 0.20 \\
& Desv. Pad & 1.22 & 0.72 & 0.41 \\
\hline \multicolumn{2}{c|}{ p-valor Mann-Whitney } & -3.83 & -4.65 & -0.66 \\
\hline
\end{tabular}

FONTE: Hospital das Clínicas e Escola Estadual Keizo Ishihara

NOTA: Pacientes do Ambulatório do Distúrbio do Aprendizado e do grupo controle da Escola Estadual Keizo Ishihara

Utilizou-se o teste Exato de Fisher para verificar se a proporção de indivíduos que apresentaram omissões em cada uma das três tarefas eram significativamente diferentes entre os grupos TDAH e controle. Concluiu-se que existe diferença entre as proporções de indivíduos que apresentaram omissões nas tarefas 1 e 2, com o $p<0,001$ e $p<0,039$. Já para a tarefa 3 o valor de $p$ foi sem significância $(0,509)$. Estas análises podem ser observadas na Tabela 13.

Tabela 13 - Teste Exato de Fisher para verificar a proporção de erros por omissão entre os grupos TDAH e Controle nas tarefas 1, 2, e 3 do TAVIS 3R

\begin{tabular}{c|ccc}
\cline { 2 - 4 } & \multicolumn{3}{c}{ Omissão } \\
& Tarefa 1 & Tarefa 2 & Tarefa 3 \\
\hline p-valor & 0.001 & 0.039 & 0.509 \\
\hline
\end{tabular}

FONTE: Hospital das Clínicas e Escola Estadual Keizo Ishihara

NOTA: Pacientes do Ambulatório do Distúrbio do Aprendizado e do grupo controle da Escola Estadual Keizo Ishihara 
A curva ROC determinou o ponto de corte das variáveis estudadas e evidenciou diferenças quanto ao grau de importância de cada teste analisado em relação à presença ou não, da correlação com o diagnóstico do TDAH (Gráficos 15, 16, 17 e 18).

$\mathrm{Na}$ Tabela 14 apresentam-se os testes que se mostraram mais eficientes na possível correlação com o TDAH, incluindo-se os valores de sensibilidade e especificidade para cada teste.

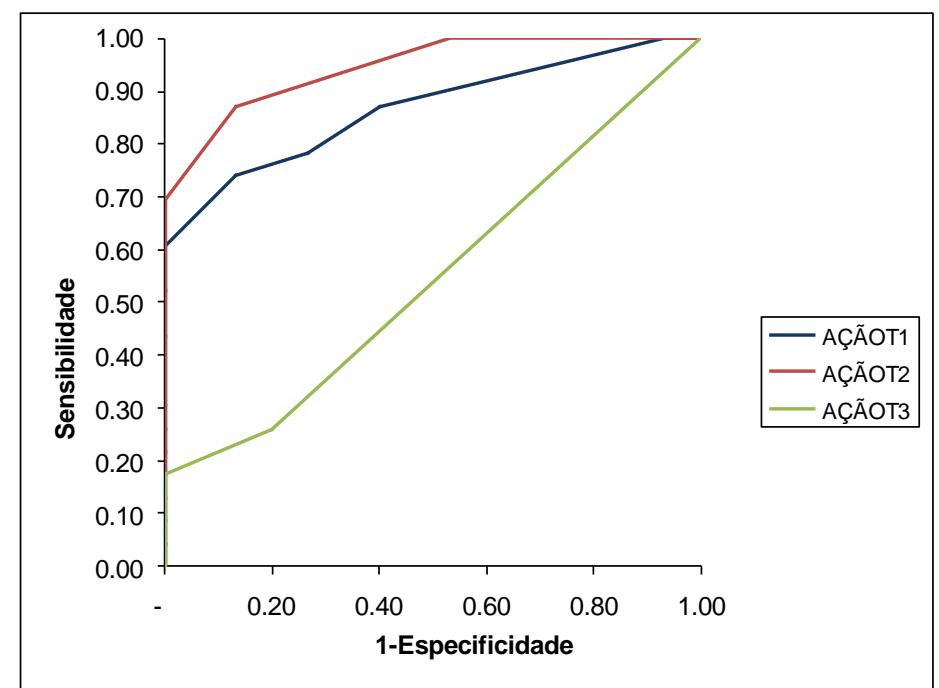

Gráfico 15 - Curva ROC Tarefas 2 e 1 (erros por ação) do TAVIS 3R

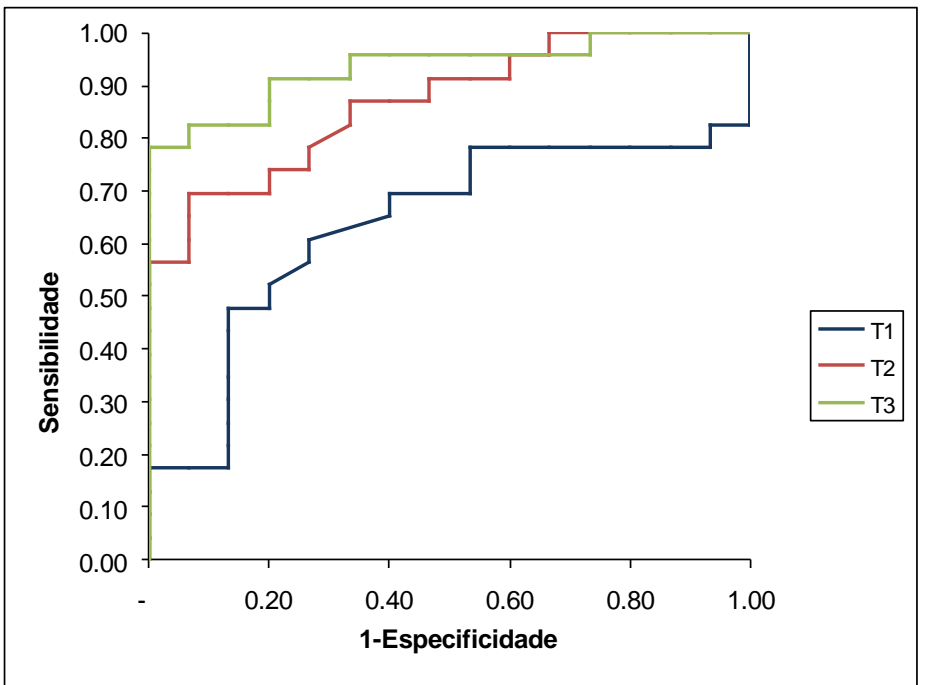

Gráfico 16 - Curva ROC Tarefas 3 e 2 (tempo de reação) do TAVIS 3R 


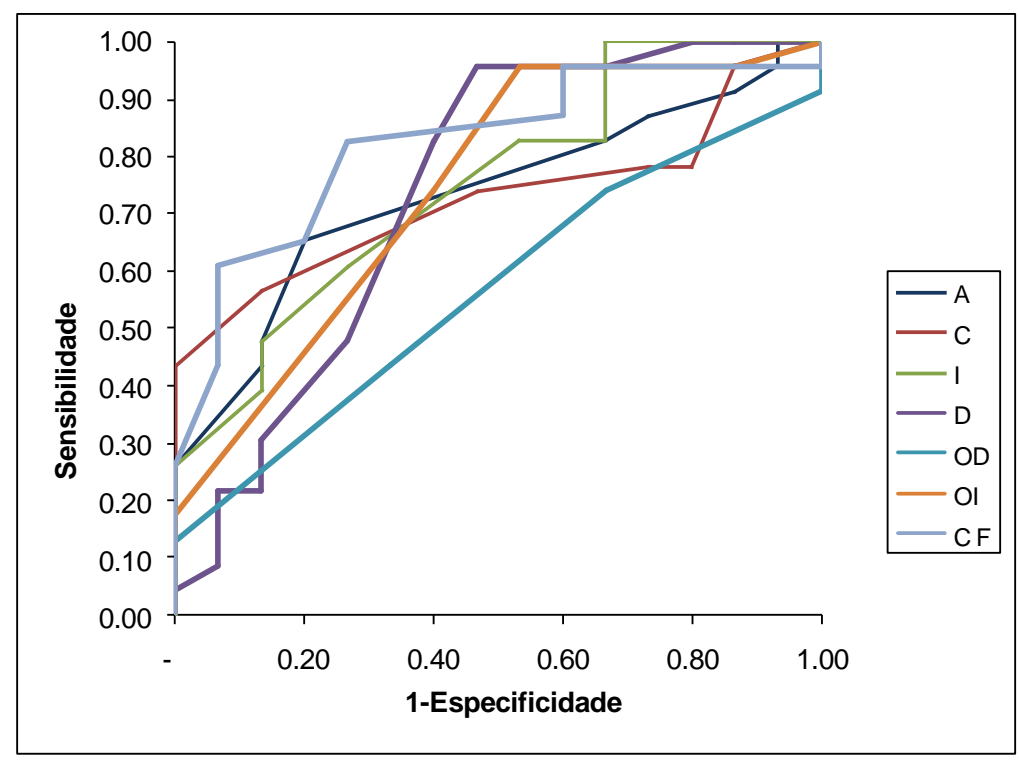

Gráfico 17 - Curva ROC perfil ACID+CF

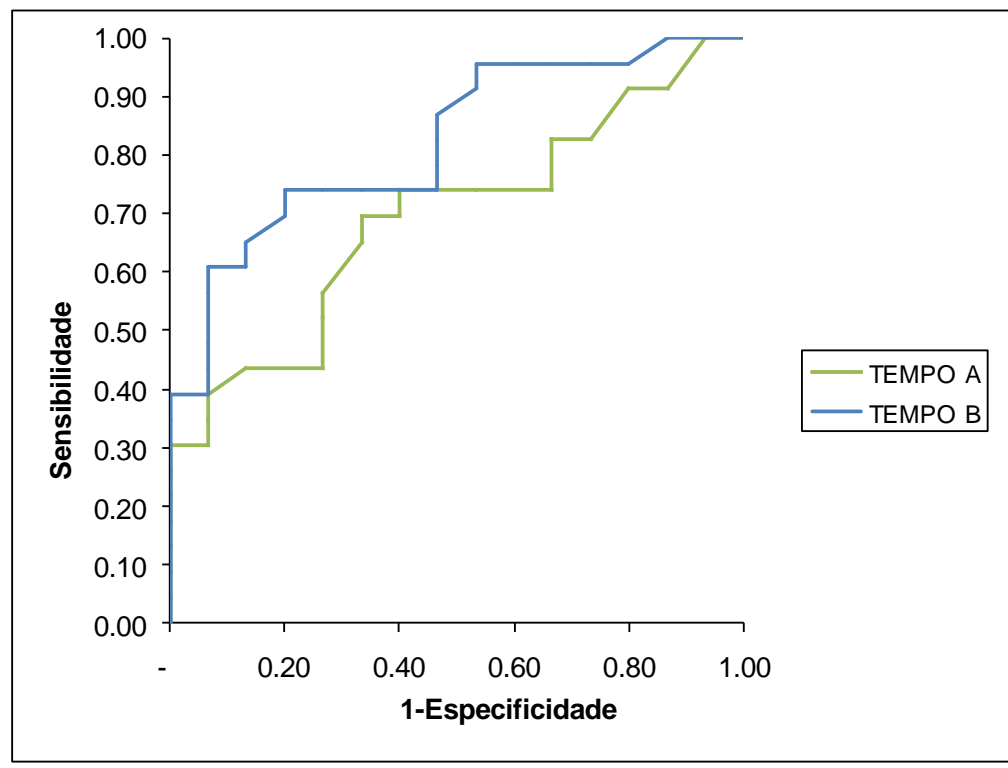

Gráfico 18 - Curva ROC teste das trilhas TMT parte B 
Tabela 14 - Resultados dos testes que apresentaram Sensibilidade e Especificidade

\begin{tabular}{|c|c|c|c|c|}
\hline \begin{tabular}{l}
\multicolumn{1}{c}{ Teste } \\
Completar Figuras \\
TMT parte B \\
\end{tabular} & $\begin{array}{c}\text { Área sob a curva } \\
0.822 \\
0.822 \\
\end{array}$ & $\begin{array}{c}\text { Limiar superior } \\
12.50 \\
41.5 \\
\end{array}$ & $\begin{array}{c}\text { Sensibilidade } \\
0.83 \\
0.83 \\
\end{array}$ & $\begin{array}{c}\text { Especificidade } \\
0.73 \\
0.53 \\
\end{array}$ \\
\hline Teste & Área sob a curva & Limiar inferior & Sensibilidade & Especificidade \\
\hline $\begin{array}{l}\text { erros ação tarefa } 2 \text { TAVIS 3R } \\
\text { tarefa } 3 \text { TAVIS 3R } \\
\text { tarefa } 2 \text { TAVIS 3R } \\
\text { erros ação tarefa } 1 \text { TAVIS 3R }\end{array}$ & $\begin{array}{l}0.945 \\
0.933 \\
0.868 \\
0.867\end{array}$ & $\begin{array}{l}1.50 \\
0.48 \\
0.64 \\
2.50\end{array}$ & $\begin{array}{l}0.87 \\
0.83 \\
0.83 \\
0.78\end{array}$ & $\begin{array}{l}0.87 \\
0.93 \\
0.67 \\
0.73\end{array}$ \\
\hline
\end{tabular}

FONTE: Hospital das Clínicas e Escola Estadual Keizo Ishihara

NOTA: Pacientes do Ambulatório do Distúrbio do Aprendizado e do grupo controle da Escola Estadual Keizo Ishihara 
Discussão 


\section{$5 \quad$ Discussão}

Procuramos priorizar neste estudo pesquisar a atenção e as FEs através de testes neuropsicológicos em crianças portadoras do TDAH e, com isso, avaliar quais podem apresentar maior correlação com o diagnóstico do TDAH.

A análise estatística dos resultados mostrou que a comparação entre os dois grupos apresentou diferença significante nas funções avaliadas através dos testes neuropsicológicos, o que representa um ponto essencial para a validade do trabalho.

Vários estudos se referem ao TDAH como um distúrbio também das FEs, porém com formas diferentes para explicar esse transtorno. Para alguns estudiosos nem todo portador do TDAH apresenta prejuízos significativos em testes que analisam as FEs, e está claro que a disfunção executiva não é patognomônica nem necessária para o diagnóstico do $\operatorname{TDAH}^{(8,11,38,50,71)}$.

Por outro lado, Brown (2006) ${ }^{(13)}$ ressalta a importância das alterações da FEs nas atividades diárias dos portadores do TDAH e salienta que a avaliação, através de testes neuropsicológicos, pode resultar em falsos negativos pelo fato de que, durante esse tipo de investigação, principalmente 
em pacientes de maior capacidade cognitiva, possa ocorrer menor influência das múltiplas variáveis que normalmente atrapalham muito estes pacientes (13).

As alterações estruturais e/ou funcionais dos circuitos cerebrais que interligam as regiões pré-frontais com o cerebelo, lobo parietal e núcleos da base, demonstradas repetidamente em estudos científicos na última década, permitem a compreensão das dificuldades para um adequado funcionamento executivo dos pacientes com TDAH, prejudicando-os, de forma muito mais relevante, nas alterações primárias do controle atencional e dos impulsos motores ${ }^{(24,38)}$

No período de planejamento deste estudo, optamos por realizar uma bateria específica de testes neuropsicológicos, objetivando avaliar, em nossos pacientes, além das três modalidades da atenção (seletiva, alternada e sustentada), algumas FEs que acreditamos estarem mais prejudicadas nos portadores do TDAH, que são: MO, controle inibitório e tempo de reação.

O questionário SNAP-IV foi utilizado para a seleção dos pacientes e se mostrou estatisticamente útil para a averiguação, tanto por parte dos pais quanto dos professores, da intensidade dos sintomas nele avaliados: desatenção, hiperatividade e do tipo opositor-desafiante.

Vários estudos já demonstraram alterações da capacidade atencional e da FEs em portadores do TDAH, porém o mesmo tipo de teste, que foi alterado em uma pesquisa, nem sempre foi anormal em outra ${ }^{(3,22,38,46,52,54)}$.

Acreditamos que muitas destas disparidades estão relacionadas com o tipo de teste escolhido, mas também com a população avaliada, 
frequentemente, com co-morbidades associadas, variações de faixa etária e sexo. Devido a esses problemas, optamos por efetuar uma seleção mais homogênea do nosso grupo de estudo, tornando-o mais adequado, ou seja, analisamos somente crianças do sexo masculino, sem co-morbidades e entre nove e 12 anos de idade.

Durante a escolha dos testes utilizados, baseamo-nos no conhecimento de que determinados testes estariam sendo aplicados para se avaliar prioritariamente determinada função. Todavia, destacamos que, apesar dos testes neuropsicológicos serem desenvolvidos a partir de um paradigma que envolva uma determinada função, de modo geral esses testes não avaliam uma única atividade executiva isoladamente, até mesmo porque exigem a integração dos diferentes sistemas neuronais para serem realizados.

A seguir, vamos abordar, separadamente, as alterações encontradas em relação à atenção e às FEs estudadas de acordo com os vários testes utilizados.

Inicialmente abordaremos a atenção, que consideramos 0 mais importante pré-requisito para a manifestação de outras funções cognitivas e, como termo genérico, para designar uma família de mecanismos que selecionam parte dos estímulos, capturando-os para o centro da consciência, enquanto mantêm outros estímulos ao redor.

A atenção, como um todo, mostrou-se nitidamente alterada nos indivíduos com TDAH através da análise dos resultados do perfil atentivo: ACID+CF (subtestes Aritmética, Código, Informação, Dígitos e Completar Figuras) do teste de inteligência WISC III. A ausência de significância 
estatística no subteste dígitos de ordem direta está associada, em nosso modo de ver, ao fato de que é utilizado menor esforço atencional por tratarse de processo passivo, o que está de acordo com alguns estudos ${ }^{(46,63)}$.

A atenção seletiva, que consiste na capacidade de se manter o foco mesmo na presença de distratores, relacionada principalmente com os circuitos neuronais de áreas pré-frontais, foi avaliada por nós através dos testes, cartão-palavras do Stroop e a Tarefa 1 do TAVIS 3R. As alterações nesses testes (erros no Stroop e Tempo de Reação do TAVIS 3R) não foram significantes nos portadores do TDAH combinado em relação aos pacientes do grupo controle, corroborando com outras pesquisas já existentes ${ }^{(8,34,35)}$. Uma possibilidade, aventada por nós a respeito do resultado, consiste em que em relação ao Stroop Test, utilizaram mais tempo para realização do cartão-palavras, e por isso erraram menos e no TAVIS 3R, na pouca dificuldade e duração do teste.

A atenção alternada refere-se à capacidade em manter uma flexibilidade mental, permitindo-se desviar repetidamente a atenção de um assunto para outro, com diferentes necessidades cognitivas, sem perda significativa do conteúdo dos dois itens. Ela foi avaliada pelos testes das trilhas Parte B e pela Tarefa 2 do TAVIS 3R. Os pacientes com TDAH apresentaram piores resultados em relação aos tempos de execução e de reação, observando-se ainda mais erros por ação e omissão. A atenção alternada está correlacionada, principalmente, com circuitos que inter-relacionam áreas préfrontais e parietais, alterados nos pacientes com $\operatorname{TDAH}^{(30,33,34,43,46)}$. Esse tipo de dificuldade pode ser observado quando os portadores do TDAH 
distraem-se facilmente estudando e, simultaneamente, ouvem um barulho, desviando sua atenção ao que está acontecendo, ou, então, em sala de aula, o aluno copia o que está no quadro, e ouve o que o professor está explicando. Outro exemplo é quando não conseguem falar ao celular e escrever ao mesmo tempo. O portador do TDAH do tipo combinado apresenta maior dificuldade para realizar as duas tarefas ao mesmo tempo, não conseguindo alternar o foco de atenção entre tarefas diferentes, de modo eficiente.

A atenção sustentada é a capacidade de se manter um adequado grau de vigília e qualidade de respostas durante uma atividade contínua ou repetitiva. Foi avaliada pelos testes Códigos (subteste do WISC III), Tc e Tarefa 3 do TAVIS 3R. É mensurada através dos tempos de execução e de reação, observando-se, ainda, decréscimo no desempenho durante o período de tempo do teste. Os pacientes com TDAH apresentaram piores resultados em relação aos do grupo-controle, evidenciando-se a dificuldade, nesses indivíduos, em manter adequado rendimento em situações mais prolongadas. Os circuitos mais correlacionados com esse tipo de atenção parecem estar mais relacionados às regiões pré-frontais do hemisfério direito $(33,34,50,64)$. Na prática diária, um exemplo de dificuldade com a atenção sustentada pode ser observado durante a leitura de um simples texto. A criança portadora de TDAH não consegue manter eficiência atencional adequada até o final, prejudicando, obviamente, a interpretação do texto. Diante dos testes aplicados, ficou evidente a dificuldade nesse tipo de atenção já que, antes de terminar o teste, o paciente "reclamava", dizendo 
que estava demorando e perguntava quando iríamos terminar porque era muito chato ou usava o tempo, além do esperado, para terminar a tarefa.

Utilizamos o Teste Psicofísico para Atenção Visual Voluntária, com o objetivo de pesquisar o tempo de reação aos estímulos. Psicofísica é um ramo quantitativo de estudo da percepção, que avalia as relações entre estímulos observados e resposta. Métodos psicofísicos são utilizados para se determinar limiares, incluindo a análise do campo visual. Uma das formas de medição mais empregadas em estudos psicofísicos é através de tempo de reação. Nessa tarefa, o voluntário tem que comparar a ordem de apresentação de dois estímulos apresentados no campo visual em diferentes intervalos. Apesar de envolver resposta motora, essa tarefa é principalmente perceptiva, pois a velocidade da resposta não é relevante e, sim, a acurácia ${ }^{(72)}$.

O tempo de reação para a realização das respostas corretas foi maior nos portadores de TDAH em relação aos do grupo controle em quase todos os tipos de avaliações pesquisadas. Esse tipo de teste envolve processos amplos, como processamento da informação, armazenamento transitório, seleção, sustentação e emissão da resposta. Este estudo permitiu detectar a presença de um déficit na atenção voluntária nos pacientes analisados.

De acordo com Stuss e colaboradores ${ }^{(73)}$, durante esse tipo de procedimento ocorreria participação de três áreas associadas do sistema atencional. Relacionado ao potencial de prontidão para a resposta, ocorre ativação da região frontal média superior, que estaria diretamente correlacionada à velocidade do tempo de resposta. A capacidade de 
percepção do estímulo estaria relacionada à ativação de circuitos da região pré-frontal dorsolateral com áreas parietais e a habilidade de apresentar uma atenção sustentada estaria associada com a região pré-frontal dorsolateral, principalmente do hemisfério direito.

Acreditamos que, durante a avaliação do tempo de reação através do TPAVV, na verdade estamos analisando simultaneamente o funcionamento de um sistema atencional anterior e posterior. O sistema anterior, incluindo o giro do cíngulo anterior e o córtex pré-frontal, atuaria no controle inibitório, na flexibilidade cognitiva, na memória operacional, no planejamento e, através de conexões com estruturas subcorticais, particularmente o striatum atuaria, controlando a resposta motora. Por outro lado, o sistema posterior, incluindo córtex parietal, estruturas mesencefálicas e talâmicas, controlaria os processos perceptuais automáticos, incluindo a orientação visual a um novo estímulo $^{(74,75)}$. Durante o procedimento da atenção voluntária, é importante a integração de todas essas estruturas.

O modelo cognitivo-energético de Sergeant (2005) salienta a importância de processos relacionados à manutenção do "despertar" e da "capacidade de ativação", os quais controlam a captação e a produção de resposta, respectivamente. De acordo com esse autor, esses dois processos são mantidos e modulados por um terceiro processo denominado "capacidade de esforço", que é definido como a energia necessária para a realização das demandas e estaria muito relacionado à motivação do indivíduo. O "despertar" estaria associado ao processamento do estímulo e seria muito influenciado pela intensidade e novidade do mesmo. A 
"capacidade de ativação" estaria mais relacionada à prontidão da resposta e seria muito influenciada por variáveis do tipo preparação, alerta, hora do dia e duração do teste ${ }^{(76)}$.

Déficits na prontidão, organização e monitorização das respostas estariam mais evidentes nas crianças com TDAH combinado e, associados à dificuldade com o sistema de ativação, enquanto que prejuízos na capacidade de detecção e orientação para os estímulos estariam relacionados ao sistema de despertar, e mais alterados nas crianças com TDAH de predomínio desatento. Em nosso modo de ver o paciente com TDAH combinado apresenta dificuldades com os dois sistemas, anterior e posterior e isso nos permite compreender a dificuldade em se separar os subtipos de TDAH combinado e predominantemente desatento, constatada por diversos autores $(77,78,79)$. Esses resultados estão associados a dificuldades com o sistema atencional prejudicado nos pacientes que apresentam déficits na manutenção de um adequado estado de prontidão para perceber os estímulos e/ou na capacidade de efetuar as respostas de modo consistente, durante uma atividade contínua ou repetitiva.

Na verdade, a avaliação através do TPAVV, que serviu em nosso estudo para se analisar a capacidade do tempo de reação, não está mensurando exclusivamente a atenção, mas, em paralelo, avalia também funções executivas do indivíduo, já que envolve uma série de controles simultâneos para uma adequada resposta.

A partir daqui daremos ênfase à avaliação mais específica das FEs destacando aquelas que se mostraram comprometidas de acordo com os 
testes por nós utilizados e que representaram evidências de correlação com o diagnóstico de TDAH.

Considerando as FEs como um conjunto de funções cognitivas que inclui manutenção da atenção, inibição à interferência, seleção e alternância de respostas, monitoração do comportamento e MO, acreditamos que os portadores do TDAH apresentam uma gama de dificuldades o que determina um pior desempenho em relação aos indivíduos sem TDAH.

Daremos início à análise de uma das FEs mais prejudicadas nos portadores do TDAH, que é a MO, associada ao córtex pré-frontal dorsolateral e seus circuitos neuronais os quais realizam diversos e diferentes processos cognitivos, mantendo e manipulando a informação num curto espaço de tempo e facilitando a eficiência na codificação da informação ${ }^{(46,52,58)}$.

MO é uma modalidade mnemônica que facilita a pessoa manter, no seu sistema de atenção, quantidade de informação relevante para chegar a um objetivo final. A MO aborda diversos aspectos das FEs, podendo-se considerá-la como parte dessas, e, quando comprometida, interfere diretamente em outras FEs, tais como na inibição de ações motoras ou pensamentos, não permitindo, assim, avaliação adequada das situações, como, por exemplo, a adaptação social, o controle das emoções e o uso de conteúdo informativo em momento oportuno. Algumas atitudes desse tipo podem ser observadas nos locais de trabalho e na escola onde o portador de TDAH é sempre visto como inconveniente diante de suas respostas e conversas sem sentido para o que está acontecendo. Ou então como aquele 
sujeito que nunca planeja, subestimando o tempo e deixando para fazer tudo de última hora.

Em nosso estudo, os portadores do TDAH obtiveram escores significativamente inferiores, através do subteste dígitos de ordem inversa do Teste WISC III, àqueles de indivíduos do grupo controle, corroborando com os achados de outros estudos e confirmando tal área, alterada nos TDAH ${ }^{(15}$, $22,52,58,59)$.

Outra função executiva é o controle inibitório, no qual o indivíduo deve realizar inibição à interferência, e que pode ser mensurado por exemplo pela presença de erros por ação computadorizados e/ou testes que usam lápis e papel. Essa é uma das FEs que requer controle em tarefas cotidianas e exigem flexibilidade para mudanças nas atividades, resultando na possibilidade da sustentação da atenção. Os portadores de TDAH apresentam esse comportamento quando fica evidente a sua incapacidade de alterar o curso das ações ou dos pensamentos e, com isso, a sua dificuldade em aprender com erros. Um bom exemplo é aquele em que a pessoa portadora de TDAH persevera erroneamente numa atividade mesmo sendo aconselhada a mudar a forma de fazê-la e isso, no caso do TDAH, não ocorre por uma questão de "teimosia", mas sim por uma questão de não conseguir inibir e perceber a necessidade de alternar o modo de execução da tarefa. Alterações nesse tipo de tarefa associada ao córtex pré-frontaldorsolateral e à região órbito-frontal (Tempo e Erros do Stroop cartão cores, Teste da trilhas parte B, TAVIS 3R-erros por ação e omissão) foram 
pronunciadas de forma mais evidente no grupo dos indivíduos com TDAH $(21,37,43,49,55,56,57)$

Nos testes aplicados, a análise estatística nos mostrou que alguns deles são mais sensíveis na correlação para o diagnóstico do TDAH, sendo eles, em ordem de importância: a Tarefa 2 (erros por ação) do TAVIS 3R, a Tarefa 3 (tempo de reação) do TAVIS 3R, a Tarefa 2 (tempo de reação) do TAVIS 3R, a Tarefa 1 (erros por ação) do TAVIS 3R, o subteste Completar Figuras do Teste WISC III e o teste das trilhas TMT Parte B. Tanto a Tarefa 3 como a 2 do TAVIS $3 R$ foram prejudicadas pelo fato de que, no portador do TDAH do tipo combinado, o preparo do ato motor, o controle oculomotor, a percepção visual, o processamento e a manutenção da informação, interferiram negativamente no desempenho da organização para a emissão da resposta motora, aumentando o número de erros por ação e consequentemente o tempo de reação. No subteste Completar Figuras pudemos inferir que os meninos com TDAH do tipo combinado obtiveram baixo desempenho pela impulsividade diante da tarefa, ou seja, não conseguiram inibir o pensamento para apontar corretamente o que faltava na gravura. Dessa forma, é de suma importância ressaltar que esses resultados deram-se em favor de a atenção e de as FEs estarem comprometidas no TDAH, principalmente a MO, o controle inibitório e o tempo de reação. No teste das trilhas Parte $B$, o tempo de execução também foi maior que o dos controles porque os portadores do TDAH não conseguem alterar, adequadamente, o curso das ações e, com isso, demonstram déficits na flexibilidade mental ${ }^{(80,81,82,83)}$. 
No nosso estudo, os testes que explicam as dificuldades do funcionamento do dia-a-dia do portador do TDAH evidenciaram respostas alteradas, demonstrando déficit atencional e executivo. Acreditamos que a presença de alterações em maior frequência que a observada em outros estudos com adultos possa estar relacionada ao fato de avaliarmos apenas crianças e que talvez haja relação com o fato de que a maturação cerebral esteja ainda em desenvolvimento e as diferenças com os controles sejam maiores ainda, nesse momento ${ }^{(24,28,34,35,38,41,45)}$. 
Conclusões 
1. Foi possível evidenciar alterações da atenção e das FEs em crianças portadoras do TDAH, através da maioria dos testes neuropsicológicos utilizados e

2. Os seguintes testes demonstraram maior correlação com o diagnóstico do TDAH em ordem decrescente de importância:

$1^{\circ}$ ) Tarefa 2 (erros por ação) do TAVIS 3R

$2^{\circ}$ ) Tarefa 3 (tempo de reação) do TAVIS 3R

3ํ) Tarefa 2 (tempo de reação) do TAVIS 3R

4ํ) Tarefa 1 (erros por ação) do TAVIS 3R

$5^{\circ}$ ) subteste Completar Figuras do teste WISC III - Terceira Edição e

6으 ) Teste das Trilhas, parte B. 
ANEXos 


\section{Anexo A}

\section{Cód.: $80 / 05$ \\ COMISSÃO SETORIAL DE ÉTICA DA DIVISÃO DE PSICOLOGIA DO INSTITUTO CENTRAL DO HCFMUSP Relatório da Análise de Projetos de Pesquisa}

NOME do PESQUISADOR RESPONSÁvel: Cristiana Pacheco Martini

TítULO DO PROJETO: O perfil do nível de atenção antes e depois do uso do metilfenidato em crianças com transtorno do déficit de atenção/hiperatividade

PARECER QUANTO AOS PRINCIPAIS ELEMENTOS DO TEXTO:

1. Título:

Adequado.

2. Introdução:

Adequada e pertinente.

3. Objetivo:

Presente ao início da p. 07, justifica a execução do projeto baseado na literatura apresentada. Seria mais adequado destacar o objetivo como um item em separado.

4. Justificativa:

Bem estabelecida na revisão da literatura.

5. Revisão da Literatura:

Bem fundamentada, incluindo produção recente relativa ao tema e demonstrando envolvimento da pesquisadora com o assunto.

6. Método:

O método seria mais claro se definisse os itens abaixo separadamente, deixando o cronograma para o final do exposto.

a) Amostra: adequada e de acordo com o cronograma proposto.

b) Instrumentos: compativeis com as funções envolvidas no TDA-H

c) Procedimento: adequado

d) Análise dos dados: sugere-se cuidado para utilização de testes paramétricos em dimensões subjetivas que, porventura, podem não obedecer à distribuição normal.

7. Referências:

Adequadas. 
Cód.:

8. Anexos:

Deve-se evitar inclusão de instrumentos de uso reconhecido e bem difundido, incluindo apenas aqueles não disponíveis no mercado e/ou não padronizados.

\section{Cadastro CAPPesq:}

Adequado.

\section{Comentários Gerais:}

Nada a acrescentar.

\section{Parecer:}

X Aprovado.

Aprovado, mas necessita efetuar as mudanças comentadas no(s) item(ns) assinalados antes do início do projeto. Reencaminhar à COSEPE após correções.

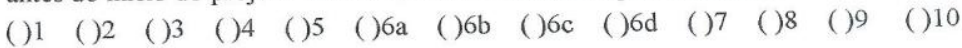

Aprovado como projeto-piloto.

Após seu término, encaminhar a forma final à COSEPE para envio à CAPPesq

Aprovado como projeto-piloto, mas necessita efetuar as mudanças comentadas no(s)

item(ns) assinalados antes do início do projeto. Reencaminhar à COSEPE após correções.

()1 ()2 ()3 ()4 ()5 ()6a ()6b ()6c ()6d ()7 ()8 ()9 ()10

Não aprovado. Verificar comentários no(s) item(ns):

()1 ()2 ()3 ()4 ()5 ()6a ()6b ()6c ()6d ()7 ()8 ()9 ()10

Sugerimos agendar reunião com membro da COSEPE para orientação.

Outro: 
Anexo B 


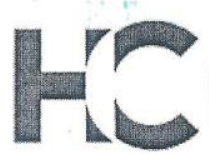

MOSPINAL DAS GuWHens

\section{APROVAÇÃO}

A Comissão de Ética para Análise de Projetos de Pesquisa - CAPPesq da Diretoria Clínica do Hospital das Clínicas e da Faculdade de Medicina da Universidade de São Paulo, em sessão de 09.11.05, APROVOU o Protocolo de Pesquisa $n^{\circ}$ 889/05, intitulado: "O perfil do nível de atenção antes e depois do uso do metilfenidato em crianças com transtorno do déficit de atenção/hiperatividade" apresentado pelo Departamento de NEUROLOGIA, inclusive o Termo de Consentimento Livre e Esclarecido.

Cabe ao pesquisador elaborar e apresentar à CAPPesq, os relatórios parciais e final sobre a pesquisa (Resolução do Conselho Nacional de Saúde $n^{\circ} 196$, de 10.10.1996, inciso IX. 2, letra "c")

Pesquisador(a) Responsável: Profa. Dra. Umbertina Conti Reed Pesquisador (a) Executante: Sra. Cristiana Pacheco Martini

CAPPesq, 09 de Novembro de 2005.

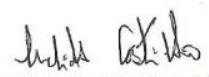

PROF. DR. EUCLIDES AYRES DE CASTILHO

Presidente da Comissão de Ética para Análise de Projetos de Pesquisa

\footnotetext{
Comissāo de Ética para Análise de Projetos de Pesquisa do HCFMUSP e da FMUSP

Diretoria Clínica do Hospital das Clínicas da Faculdade de Medicina da Universidade de São Paulo Rua Ovídio Pires de Campos. 225, $5^{\circ}$ andar - CEP 05430010 - São Paulo - SP Fone: 011 - $30696442 \mathrm{fax}: 011-30696492$ - e-mail : cappesq@ehcnet.usp.br / secretariacappesq2@hcnet.usp.br
} 


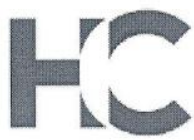

Ao

Departamento de Neurologia

A Comissão de Ética para Análise de Projetos de Pesquisa - CAPPesq da Diretoria Clínica do Hospital das Clínicas e da Faculdade de Medicina da Universidade de São Paulo, em sessão de 15.04.09. APROVOU as alterações abaixo no Protocolo de Pesquisa $n^{\circ}$ 0889/05. Intitulado. "O perfil do nível de atenção antes e depois do uso do metilfenidato em crianças com transtorno do déficit de atenção /hiperatividade".

Mudança de titulo "Avaliação neuropsicológica das funções executivas e da atenção em crianças com transtorno do déficit de atenção/ hiperaiividacie (TDAH)"

Carta datada de 25/03/2009 modificação do desenho do projeto

Pesquisador (a) Responsável: Prof. Dra. Umbertina Conti Reed

CAPPesq, 15 de abril de 2009.

PROF. DR. EDUARDO MASSAD

Presidente da Comissão Ética para Análise de Projetos de Pesquisa

Comissão de Ética para Análise de Projetos de Pesquisa do HCFMUSP e da FMUSP Diretoria Clínica do Hospital das Clínicas da Faculdade de Medicina da Universidade de São Paulo
Rua Ovídio Pires de Campos. $2255^{\circ}$ andar - CEP 05430010 - São Paulo - SP Fone: 011 - 30696442 fax: 011 - 30696492 - e-mail: $\frac{\text { cappesq@hcnet. usp.br / secretariacappesq2@hcnet.usp.br }}{\text { Julio Cesar }}$

Anexo 
Prezada Sra. Diretora da Escola,

São Paulo, 18 de Outubro de 2007.

Meu nome é Cristiana P. M. Bolfer. Sou psicóloga (CRP-08/06562-5) e aluna do programa de Pós-Graduação em Ciências, área de concentração-Neurologia, da Faculdade de Medicina de São Paulo (FMUSP). Estou realizando uma pesquisa para obtenção do título de Mestre e toda a pesquisa está sob a orientação do Dr. Erasmo B. Casella, CRM 41.485 Neurologista Infantil do ICr-HCFMUSP, Doutor em Neurologia pela FMUSP.

O projeto de pesquisa que vem sendo desenvolvido é intitulado: "Avaliação das Funções Executivas e da Atenção antes e depois do uso do Metilfenidato em crianças com o Transtorno do Déficit de Atenção/Hiperatividade (TDAH)."

A pesquisa vem sendo realizada no Instituto da Criança do Hospital das Clínicas na sala 21 do ambulatório do Distúrbio do Aprendizado que fica no prédio do Instituto da Criança situado na Av. Dr. Enéas Carvalho de Aguiar, 647, São Paulo - SP - Brasil CEP - 05403.000 ás quartas-feiras das 13 ás 17 horas, com meninos de 09 e 12 anos de idade, que saibam ler $\mathbf{e}$ escrever e apresentem desatenção e hiperatividade.

Esta pesquisa tem 0 objetivo de avaliar se os testes neuropsicológicos são eficazes para avaliar o Transtorno de Déficit de Atenção/Hiperatividade (TDAH) antes e depois do uso do Metilfenidato.

O contato com a escola visa o interesse de que a mesma através de seus professores indique e encaminhe ao $\mathrm{ICr}$, vinte (20) meninos de 09 e 12 anos de idade, que saibam ler e escrever e apresentem desatenção e hiperatividade, como também, permita que a pesquisadora avalie (na própria escola) vinte (20) meninos de 09 e 12 anos que saibam ler e escrever e não apresentem TDAH.

Espero contar com o apoio da escola e dos professores neste projeto e desde já deixo o meu agradecimento.

Atenciosamente.

Cristiana P.M. Bolfer*

${ }^{*}$ Caso queira entrar em contato com a pesquisadora, a psicóloga Cristiana P.M. Bolfer, você poderá encontrá-la no telefone (11) 96775567 ou (44) 91130480, ou buscar informações na sala 21 do ambulatório do Distúrbio do Aprendizado que fica no prédio do Instituto da Criança situado na Av. Dr. Enéas Carvalho de Aguiar, 647, São Paulo - SP - Brasil CEP - 05403.000 ás quartas-feiras das 13 ás 17 horas. 


\section{Anexo E}

\section{TERMO DE CONSENTIMENTO LIVRE E ESCLARECIDO}

Meu nome é Cristiana P. M. Bolfer. Sou psicóloga (CRP-08/06562-5) e aluna do programa de Pós-Graduação em Neurologia da Faculdade de Medicina de São Paulo (FMUSP). Estou realizando uma pesquisa para obtenção do Mestrado em Neurologia e toda a pesquisa está sob a orientação do Dr. Erasmo B. Casella, CRM 41.485 Neurologista Infantil do ICr-HCFMUSP, Doutor em Neurologia pela FMUSP.

Esta pesquisa tem o objetivo de avaliar se os testes neuropsicológicos são realmente bons para avaliar o Transtorno de Déficit de Atenção/Hiperatividade (TDAH).

Para a conclusão deste estudo, há a necessidade da avaliação em crianças que não apresentem TDAH ou nenhum outro tipo de distúrbio. Diante da indicação da escola, venho através deste solicitar a participação do seu filho nos testes neuropsicológicos que serão realizados na própria escola durante o período de aulas.

Fica claro que esta participação terá grande importância para a sociedade brasileira.

Como responsável pelo meu filho, autorizo a sua participação e colaboração no presente estudo.

Ao decidir aceitar e deixar meu filho participar desta pesquisa, tomei conhecimento de que:

- Ele será submetido a testes neuropsicológicos onde serão utilizados lápis, papel, borracha e computador.

- Todas estas informações serão usadas, somente, para esta pesquisa e

- Esta atividade não é obrigatória e, caso eu não estiver disposto (a) a deixar meu filho continuar a participar, isto não nos trará nenhuma conseqüência indesejada.

São Paulo, de de 200

Pai ou

responsável:

Pesquisadora*:

Orientador: 
* Caso queira entrar em contato com a pesquisadora, a psicóloga Cristiana P.M. Bolfer, você poderá encontrá-la no telefone (11) 96775567 ou (44) 91130480, ou buscar informações na sala 21 do ambulatório do Distúrbio do Aprendizado que fica no prédio do Instituto da Criança situado na Av. Dr. Enéas Carvalho de Aguiar, 647, São Paulo - SP - Brasil CEP - 05403.000 ás quartas-feiras das 13 ás 17 horas.

OBS: CASO AUTORIZAR SEU FILHO A PARTICIPAR DESTA PESQUISA, FAVOR ASSINAR E DEVOLVER ESTA FOLHA Á COORDENADORA DA ESCOLA ELOISA. 


\section{Anexo $F$}

\section{TERMO DE CONSENTIMENTO LIVRE E ESCLARECIDO}

Meu nome é Cristiana P. M. Bolfer. Sou psicóloga (CRP-08/06562-5) e aluna do programa de Pós-Graduação em Neurologia da Faculdade de Medicina de São Paulo (FMUSP). Estou realizando uma pesquisa para obtenção do Mestrado em Neurologia e toda a pesquisa está sob a orientação do Dr. Erasmo B. Casella, CRM 41.485 Neurologista Infantil do ICr-HCFMUSP, Doutor em Neurologia pela FMUSP.

Esta pesquisa tem o objetivo de avaliar se os testes neuropsicológicos são realmente bons para avaliar o Transtorno de Déficit de Atenção/Hiperatividade (TDAH) antes e depois do uso do remédio.

Como responsável pelo meu filho, autorizo a sua participação e colaboração no presente estudo.

Ao decidir aceitar e deixar meu filho participar desta pesquisa, tomei conhecimento de que:

2. Inicialmente será realizada com os pais ou responsável uma entrevista clínica para dados da história de vida do meu filho;

3. Após isto ele será submetido a uma série de exames:

- eletroencefalograma, exames laboratoriais que analisam as funções hepáticas, tireodianas, glicemia e hemograma completo, conforme pedido médico do neurologista;

- testes neuropsicológicos onde serão utilizados lápis, papel, borracha e computador.

4. Durante a realização dos exames e testes, meu filho não deverá fazer uso de nenhuma medicação;

5. Depois da realização dos testes, meu filho deverá tomar o remédio (fornecido pela própria instituição) proposto na pesquisa, pois vai ajudar ele a prestar mais atenção e não ser tão agitado;

6. Três meses depois que estiver dando remédio para meu filho, comprometo-me a trazê-lo novamente ao Instituto da Criança para refazer os testes neuropsicológicos;

7. Todas estas informações serão usadas, somente, para esta pesquisa;

8. Quando terminar esta pesquisa meu filho continuará a ser atendido no Instituto da Criança pelos médicos neurologistas infantis;

9. Esta atividade não é obrigatória e, caso eu não estiver disposto (a) a deixar meu filho continuar a participar, isto não nos trará nenhuma conseqüência indesejada;

São Paulo, de de 200 
Pai ou

responsável:

$-$

Pesquisadora*:

Orientador:

* Caso queira entrar em contato com a pesquisadora, a psicóloga Cristiana P.M. Bolfer, você poderá encontrá-la no telefone (11) 96775567 ou (44) 91130480, ou buscar informações na sala 21 do ambulatório do Distúrbio do Aprendizado que fica no prédio do Instituto da Criança situado na Av. Dr. Enéas Carvalho de Aguiar, 647, São Paulo - SP - Brasil CEP - 05403.000 ás quartas-feiras das 13 ás 17 horas. 

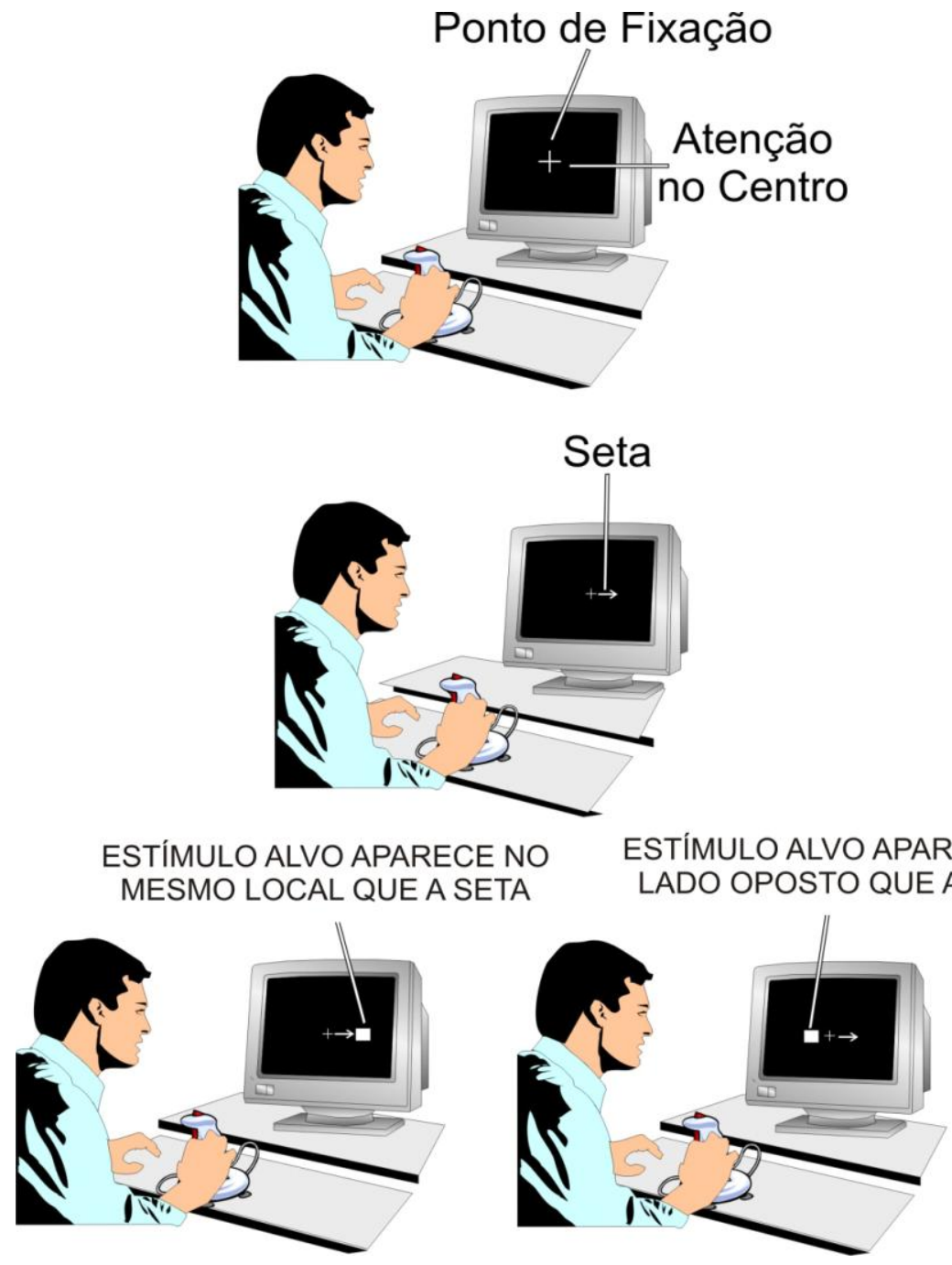
REPRESENTAÇÃO DO EXPERIMENTO DO TESTE PSICOFÍSICO DA ATENÇÃO
VOLUNTÁRIA (TPAVV)

Inicialmente é apresentada, na tela do computador, uma cruz (ponto de fixação), onde cada participante deve fixar o olhar durante todo 0 experimento. Após um intervalo de $700 \mathrm{~ms}$, é apresentada uma seta que indica com validade de $70 \%$ o aparecimento do alvo (quadrado) para o lado certo ( ${ }^{*}$ teste é composto por três blocos: seta a direita, seta a esquerda e alternada/fixa, respectivamente). Após um intervalo de $800 \mathrm{~ms}$, é apresentado um quadrado por $17 \mathrm{~ms}$ e ao percebê-lo, o participante deve responder pressionando o botão frontal de um "joystick" com o dedo indicador da mão dominante. Há duas situações diferentes de aparecimento do alvo. Na primeira situação, a seta e quadrado aparecem na mesma direção (Condição Válida) e na segunda situação, a seta e quadrado aparecem em lados opostos (Condição Inválida). 


\section{Anexo $\mathrm{H}$}

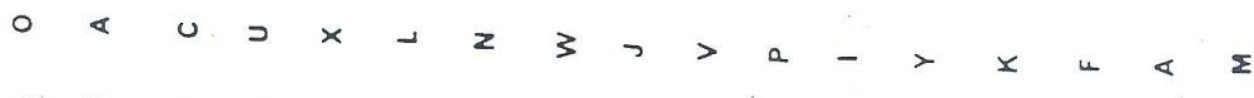

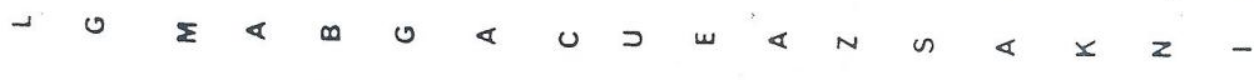

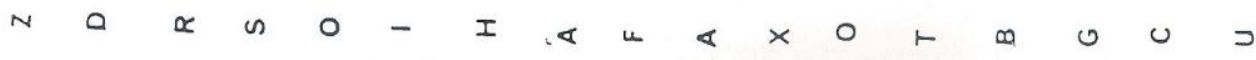

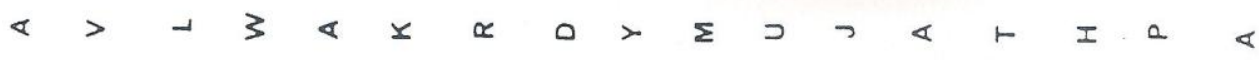

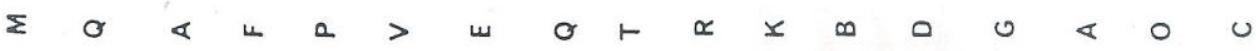

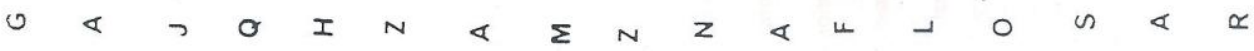

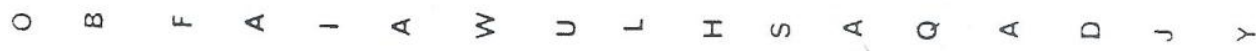

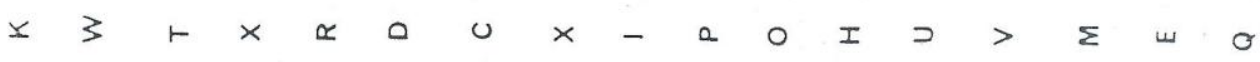

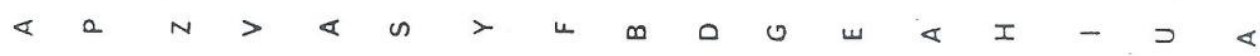

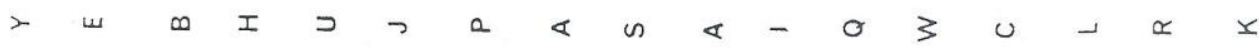

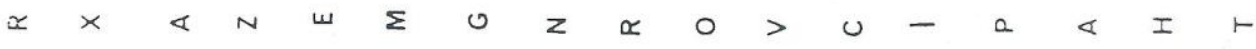

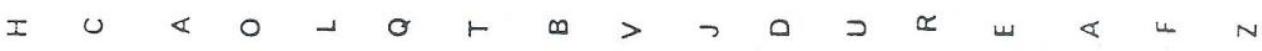

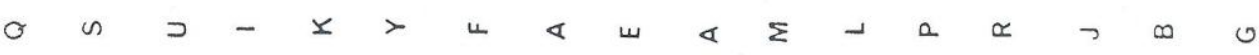

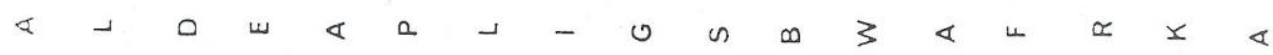

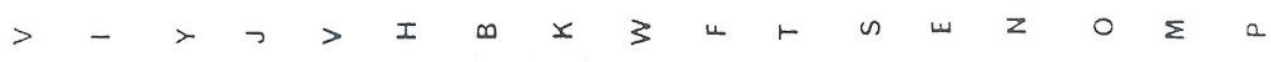

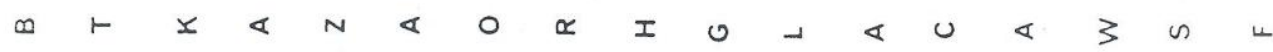

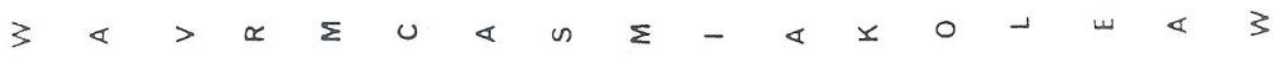

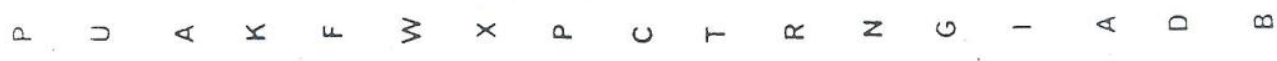

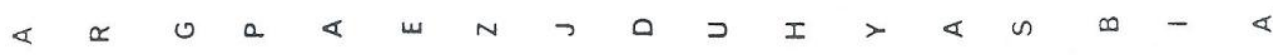

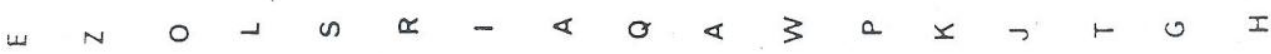

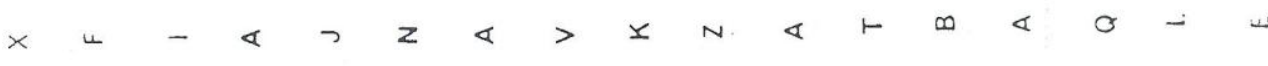

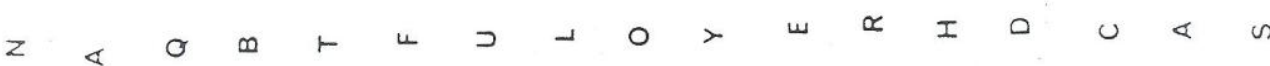




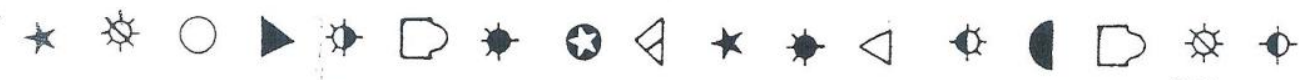

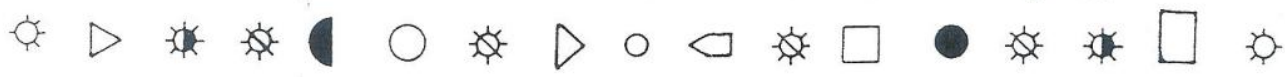

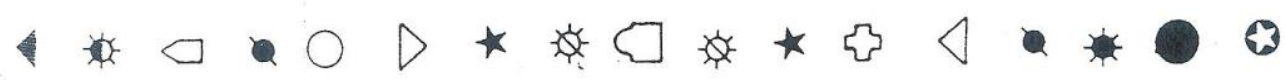

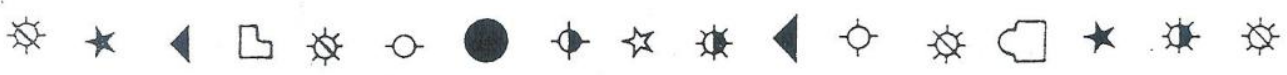

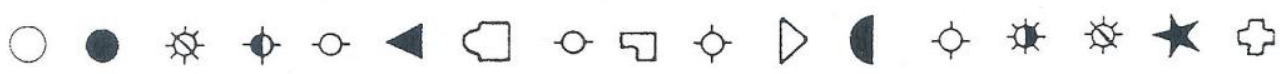

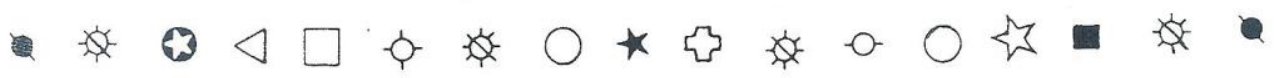

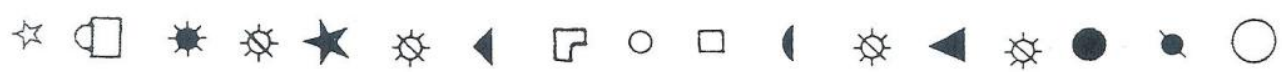

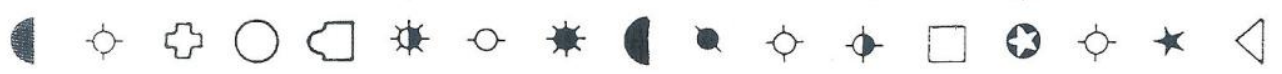

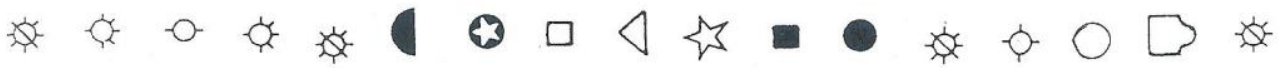

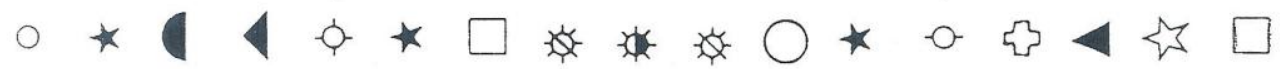

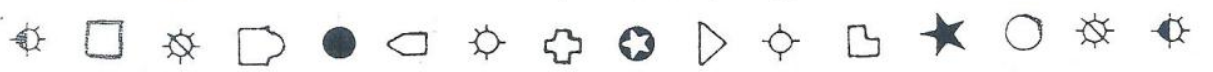

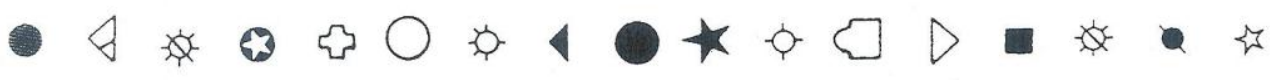

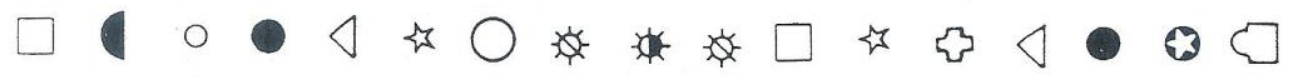

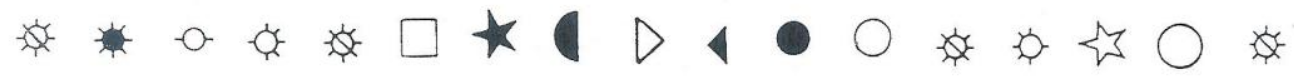

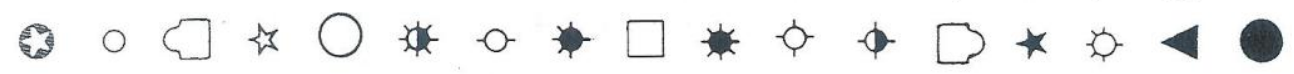

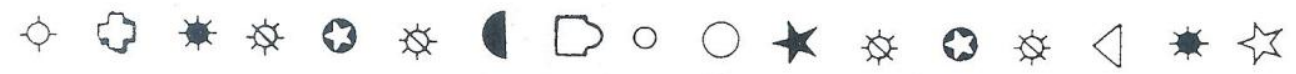
- is $\bigcirc \otimes-\phi * 4$ 0040 -

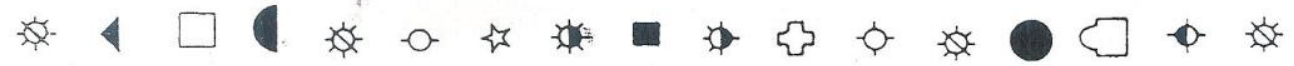

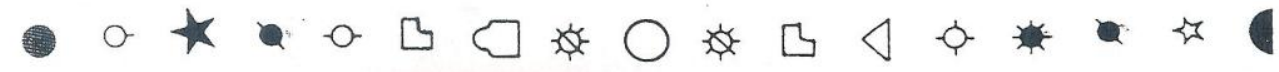
- $040 \square \square 0$

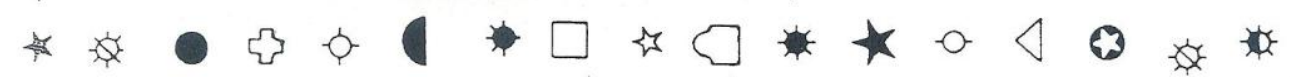




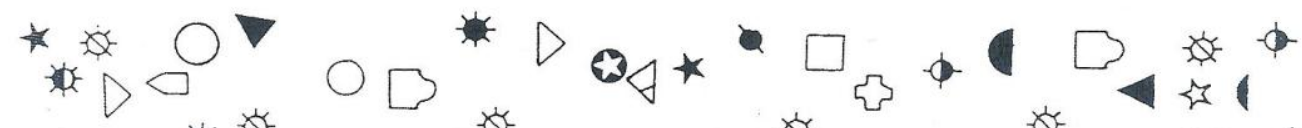

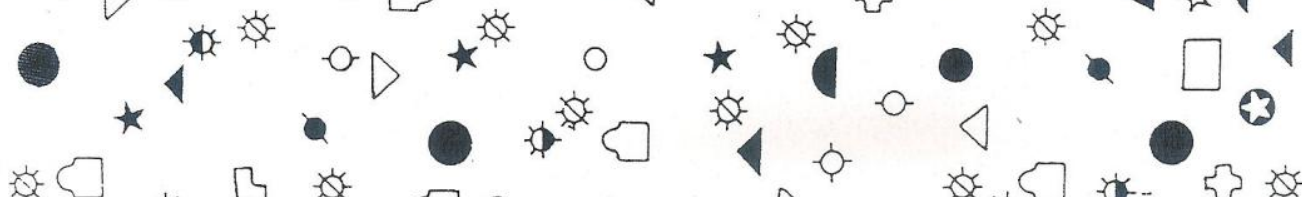

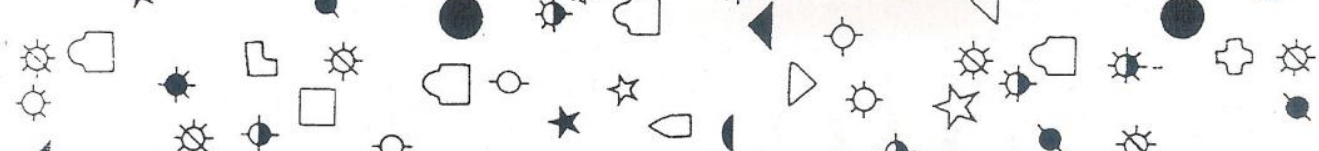

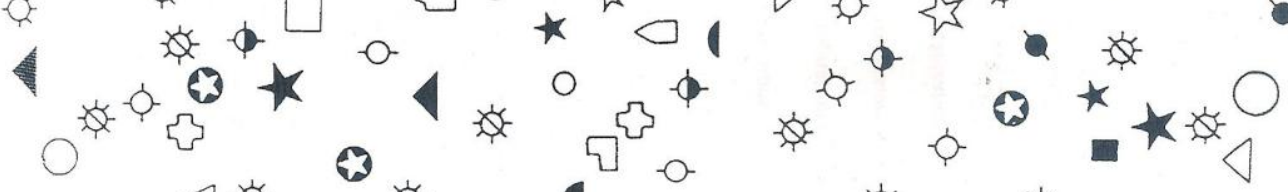

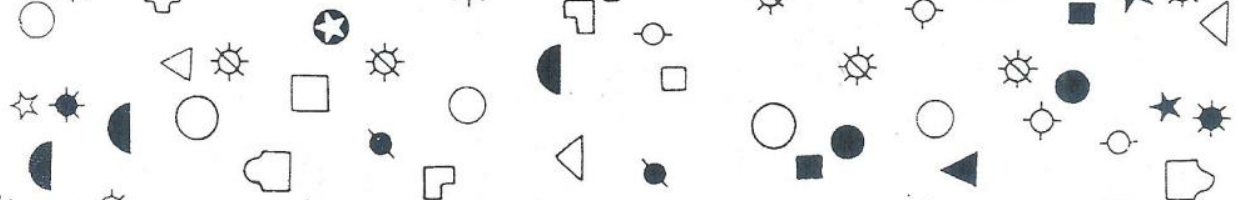

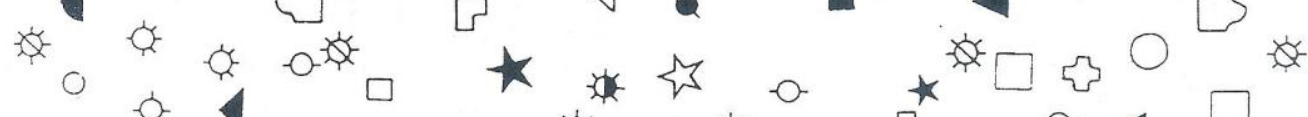

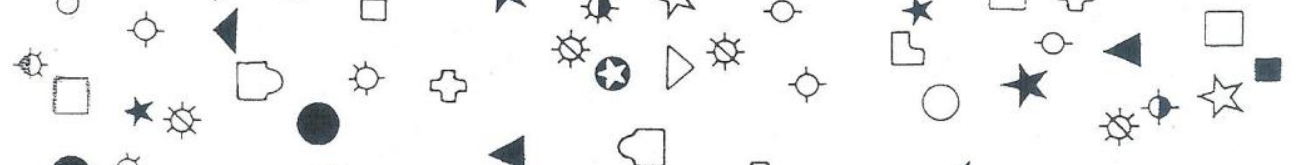

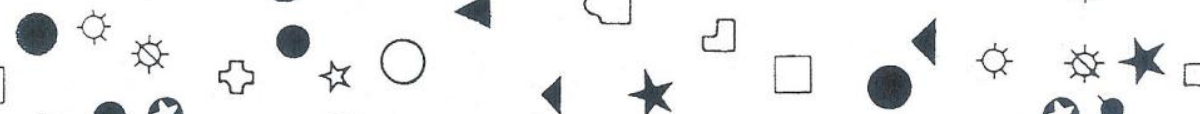

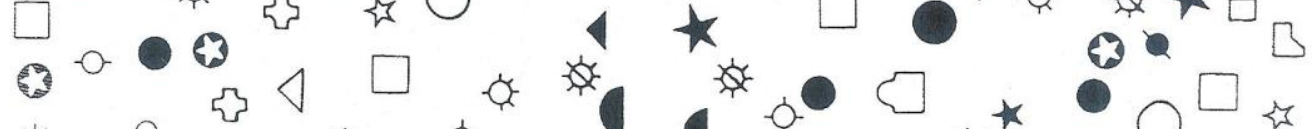

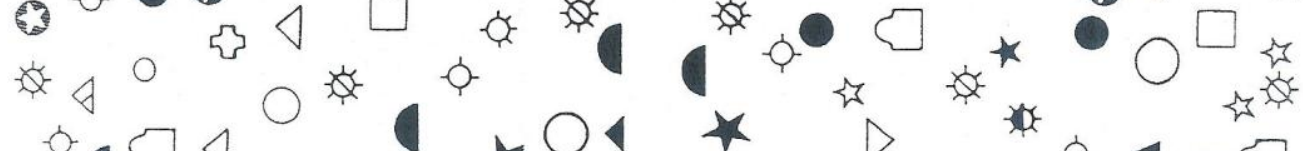

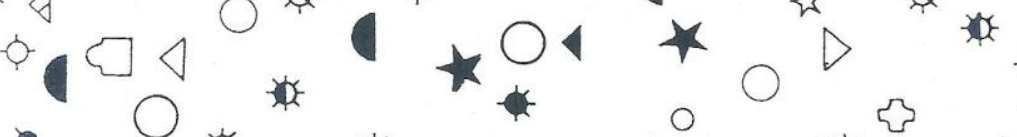

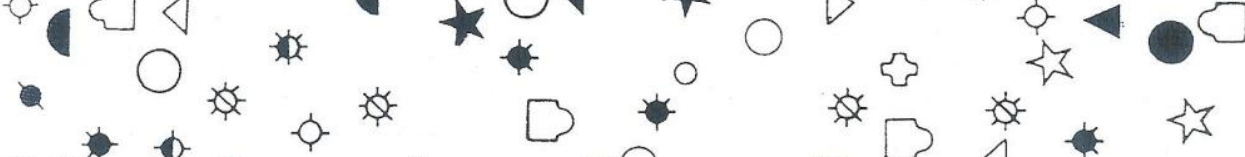

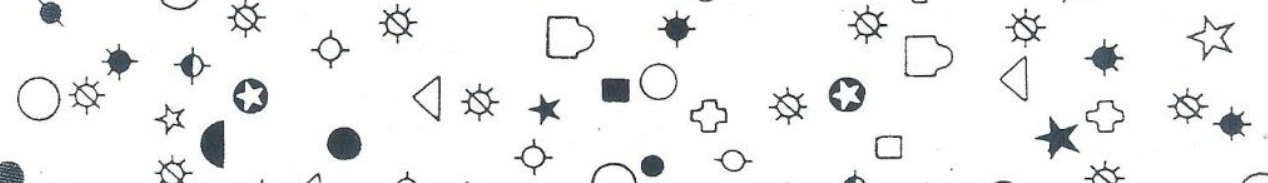

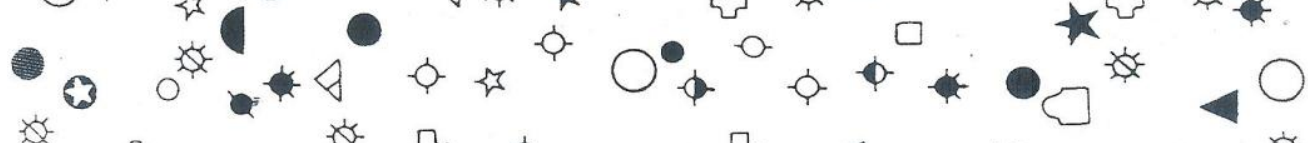

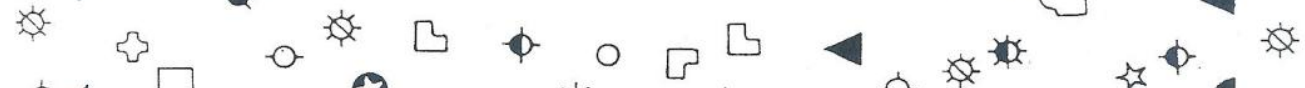

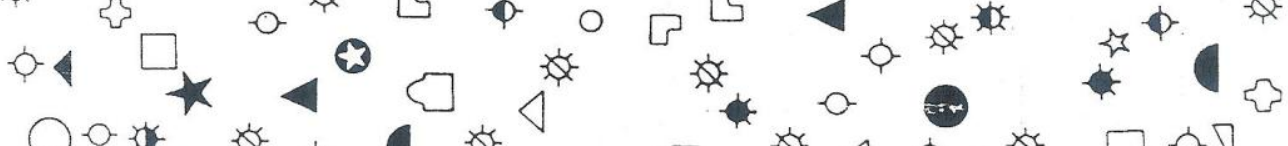

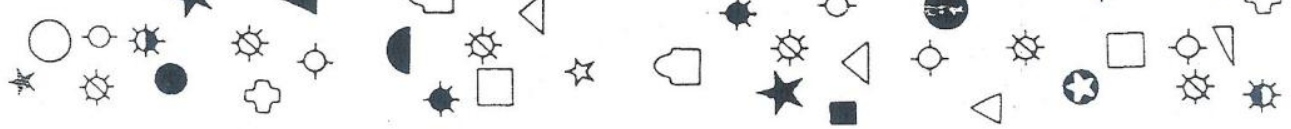




\section{Anexo I}

TRAIL MAKING

Part A

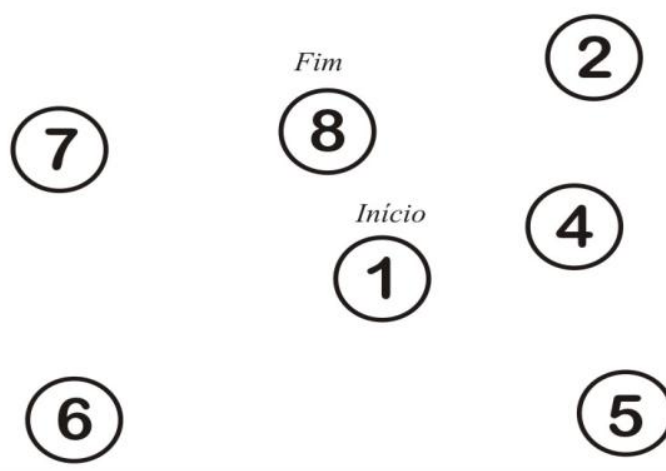

(3)

5 
(15)

(5)

(4)

(13)

(6)

(7)

(1)

(14)

(8) (10)

(3)

(9)

(12) 
TRAIL MAKING

Part B

AMostra

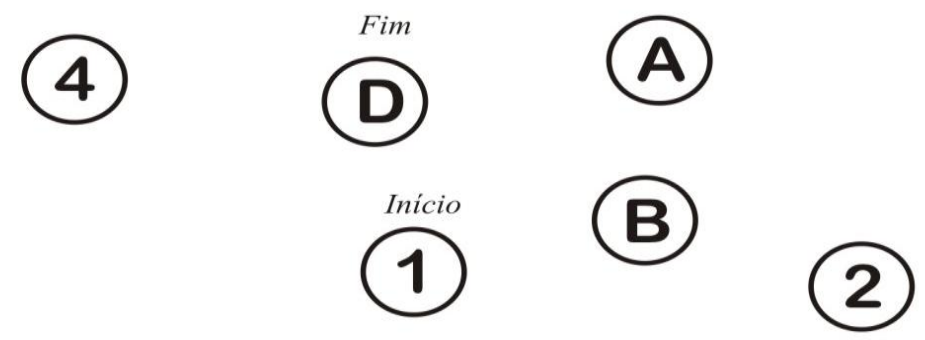

(C)

(3) 
I - 42

(8)

(D)

(B) (4)

(3)

(7)

(1)

(5)

(C)

(G)

(A)

(2) (6)

(F)

(E) 
Anexo J

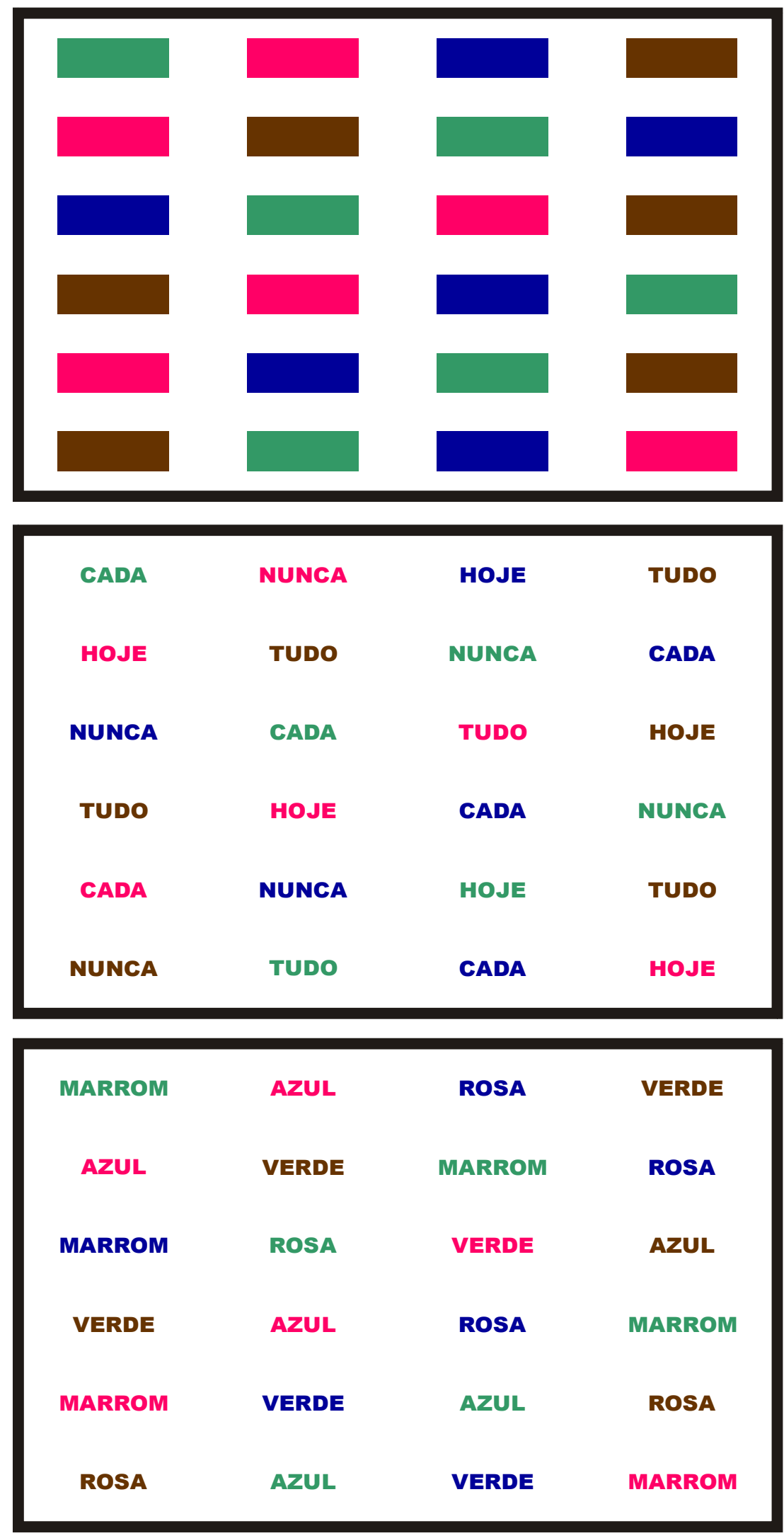


Anexo K

INSTITUTO DA CRIANÇA DO HC-FMUSP

AMBULATÓRIO DE DISTÚRBIOS DO APRENDIZADO

MTA SNAP - IV ESCALA DE AVALIAÇÃO PARA PAIS/ CUIDADORES E PROFESSORES

Nome: Sexo: Idade: Escolaridade:

Avaliado por:

Data:

Para cada item, escolha a coluna que melhor descreve esta criança:

\begin{tabular}{|c|c|c|c|c|}
\hline 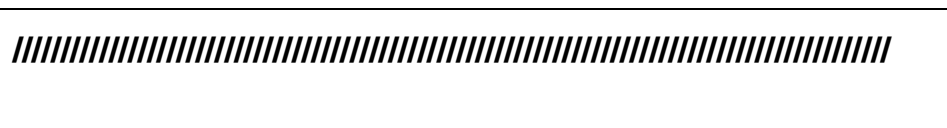 & $\begin{array}{l}\text { Nem } \\
\text { um } \\
\text { pouco }\end{array}$ & pouco & $\begin{array}{l}\text { bast } \\
\text { ante }\end{array}$ & $\begin{array}{c}\text { dema } \\
\text { is }\end{array}$ \\
\hline $\begin{array}{l}\text { 1. Falha em prestar atenção aos detalhes ou } \\
\text { comete erros por falta de cuidado em trabalhos } \\
\text { escolares e tarefas. }\end{array}$ & & & & \\
\hline $\begin{array}{l}\text { 2. Tem dificuldade em manter atenção em tarefas } \\
\text { ou em brincadeiras. }\end{array}$ & & & & \\
\hline $\begin{array}{l}\text { 3. Parece não escutar quando Ihe falam } \\
\text { diretamente. }\end{array}$ & & & & \\
\hline $\begin{array}{l}\text { 4. Não segue instruções e falha em terminar } \\
\text { temas de casa, tarefas ou obrigações. }\end{array}$ & & & & \\
\hline $\begin{array}{l}\text { 5. Tem dificuldades para organizar tarefas e } \\
\text { atividades. }\end{array}$ & & & & \\
\hline $\begin{array}{l}\text { 6. Evita, não gosta ou reluta em envolver-se em } \\
\text { tarefas que exijam manutenção de esforço mental. }\end{array}$ & & & & \\
\hline $\begin{array}{l}\text { 7. Perde coisas necessárias para suas atividade } \\
\text { (brinquedos, livros, lápis, material escolar). }\end{array}$ & & & & \\
\hline 8. É distraído por estímulos externos. & & & & \\
\hline
\end{tabular}




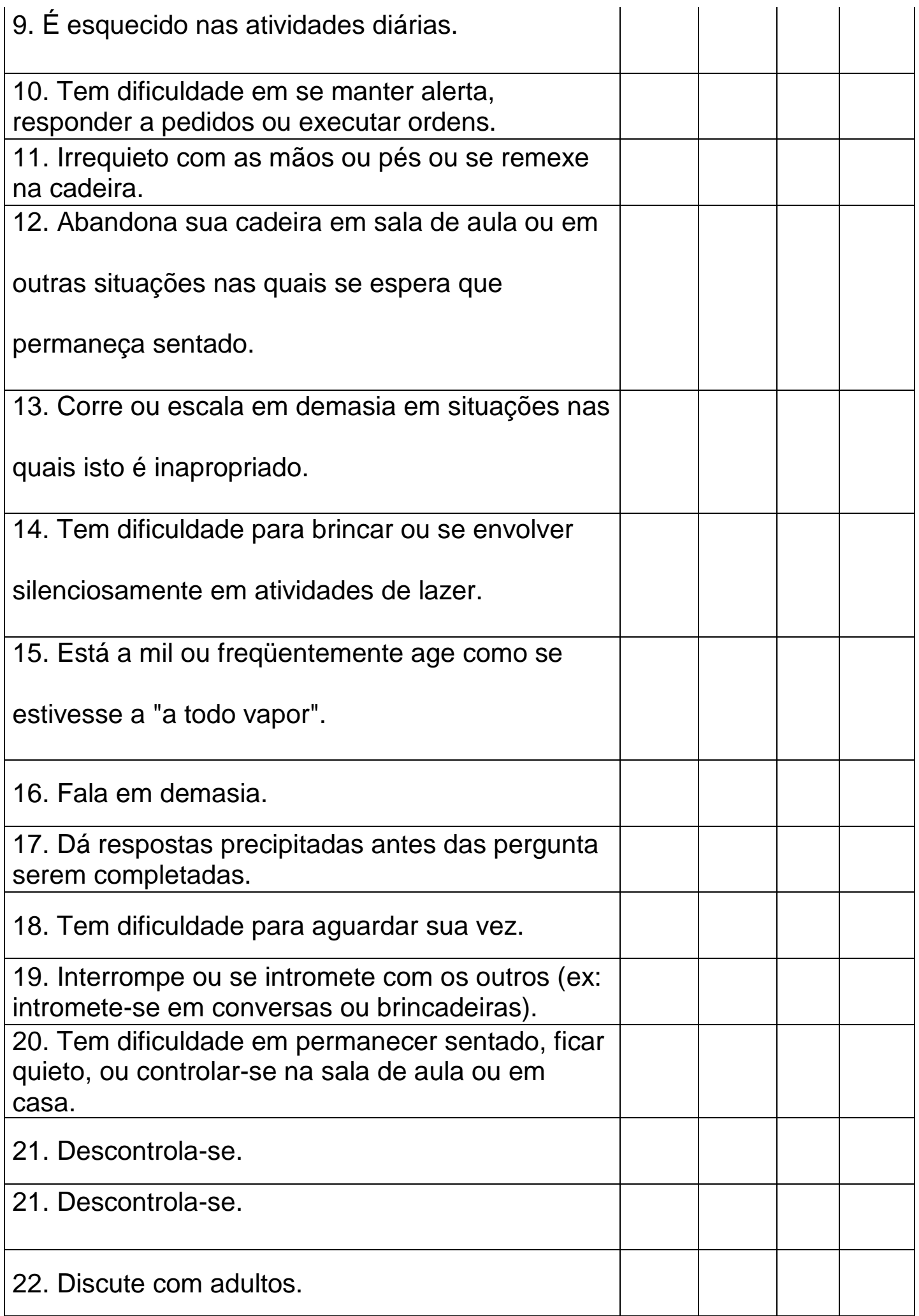




\begin{tabular}{|l|l|l|l|l|}
$\begin{array}{l}\text { 23. Ativamente desafia ou se recusa a seguir os } \\
\text { pedidos dos adultos ou as regras. }\end{array}$ & & & & \\
\hline $\begin{array}{l}\text { 24. Faz coisas que incomodam os outros de } \\
\text { propósito. }\end{array}$ & & & & \\
\hline $\begin{array}{l}\text { 25. Culpa os outros pelos seus erros ou má } \\
\text { conduta. }\end{array}$ & & & & \\
\hline $\begin{array}{l}\text { 26. É sensível ou facilmente incomodado pelos } \\
\text { outros. }\end{array}$ & & & & \\
\hline 27. É raivoso ou ressentido. & & & & \\
\hline 28. É malvado ou vingativo. & & & & \\
\hline 29. É briguento. & & & & \\
\hline $\begin{array}{l}\text { 30. É negativista, desafiador, desobediente, ou } \\
\text { hostil contra figuras e autoridades. }\end{array}$ & & & & \\
\hline
\end{tabular}

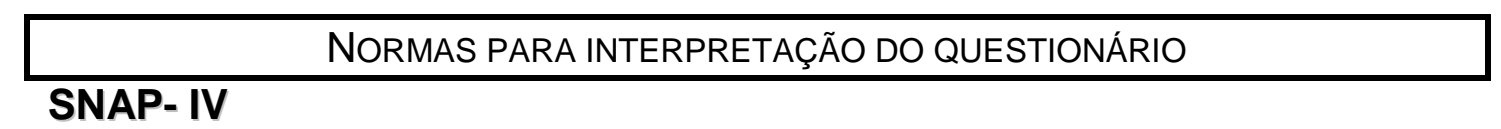

Os escores da sub-escalas são calculados pela soma do escores de cada item dividido pelo número de itens.

$\begin{array}{ll}\text { Desatenção } & \begin{array}{l}\text { Hiperatividade / } \\ \text { Impulsividade }\end{array} \\ \# 1- & \# 11- \\ \# 2 \square & \# 12 \square \\ \# 4 \square & \# 13 \square \\ \# 5 \square & \# 14 \square \\ \# 6 \square & \# 15 \square \\ \# 7 \square & \square 16 \square \\ \# 9 \square & \# 17 \square \\ \# 10 \square & \# 18 \square \\ & \# 19 \square\end{array}$

Transtorno desafiador opositor

\# 21

\# 22

\# 23

\# 24

\# 25

\# 26

\# 27

\# 28

\section{PONTOS DE CORTE}

Desatento

Hiper/ impulsivo

Combinado

TOD

\section{Professor}

2.56

1.78

2.00

1.38
Pais

1.78

1.44

1.67

1.88 
REFERÊNCIAS 


\section{Referências}

1. American Psychiatric Association Diagnostic and Statistical Manual of Mental Disorders. 4th ed. Washington, DC: American Psychiatric Association; 1994. p.78-85.

2. Halperin JM. The clinical assessment of attention. Int $J$ Neurosci. 1991; 58:171-82.

3. Barkley RA, colaboradores. Transtorno de déficit de atenção/hiperatividade-manual para diagnóstico e tratamento associados. 3a ed. Porto Alegre: Artmed; 2008. p.134-95.

4. American Academy of Pediatrics. Clinical practice guideline: diagnosis and evaluation of the child with attention-deficit/hyperactivity disorder. Pediatrics. 2000;105:1158-70.

5. Benczik EB. Transtorno de déficit de atenção/hiperatividade atualização diagnóstica e terapêutica. 2a ed. São Paulo: Casa do Psicólogo;2000.

6. Guardiola A, Fuchs F, Rotta N. Prevalence of attention-deficit hyperactivity disorders in students. Arq Neuropsiquiatr. 2000;58: 401-7.

7. National Institute of Health Consensus Development Conference Statement: Diagnosis and Treatment of Attention-Deficit/ Hyperactivity Disorder (ADHD). J Am Acad Child Adolesc Psychiatr. 2000;39:182-93.

8. Nigg JT. Neuropsychologic Theory and Findings in AttentionDeficit/Hyperactivity Disorder: The State of the Field and Salient Challenges for the Coming Decade. Biol Psychiatry. 2005;57:1424-35.

9. Klimkeit EI, Mattingley JB, Sheppard DM, Lee P, Bradshaw JL. Motor preparation, motor execution, attention, and executive functions in attention deficit/hyperactivity disorder (ADHD). Child Neuropsychology. 2005;11:153-73. 
10. Arnsten AFT, Li BM. Neurobiology of executive functions: catecholamine influences on prefrontal cortical functions. Biol Psychiatry. 2005;57:137784.

11. Doyle AE, Faraone SV, Seidman LJ, Willcutt EG, Nigg JT, Waldman ID, Pennington BF, Peart J, Biederman J. Are endophenotypes based on measures of executive functions useful for molecular genetic studies of ADHD? J Child Psychology Psychiatry. 2005;47:774-803.

12. Baldo MVC, Haddad HJr, Carreiro LR. The modulation of simple reaction time by the spatial probability of a visual stimulus. Braz J Med Biol Res. 2003;36:907-911.

13. Brown TE. Executive Functions and Attention Deficit Hyperactivity Disorder: Implications of two conflicting views. Internacional Journal of Disability, Development and Education. 2006;53:35-46.

14. Desman C, Petermann F, Hampel P. Deficit In Response Inhibition in Children With Attention Deficit/Hyperactivity Dosorder (ADHD): Impact of Motivation? Child Neuropsychol. 2008;14: 483-503.

15. Alloway TP, Gathercole SE, Holmes J, Place M, Elliot JG, Hilton K. The diagnostic utility of Behavioral checklists in identifying children with ADHD and children with working memory deficits. Child Psychiatry Hum Dev. 2009;40:353-66.

16. Diamond A. Attention-deficit disorder (attention-deficit/hyperactivity disorder without hyperactivity); A neurobilogically and behaviorally distinct disorder from attention-deficit/hyperactivity disorder (with hyperactivity). Dev Psychopathol. 2005;17:807-25.

17. Luria AR. Fundamentos de Neuropsicologia; tradução de Juarez Aranha Ricardo. Rio de Janeiro: Livros Técnicos e Científicos. São Paulo: Universidade de São Paulo;1981.

18. Mesulam M, Principles of Behavioral Neurology. F.A. Company 1985.

19. Posner Ml. The attention system of the human brain. Ann Rev Neuroscience.1990;13:25-42. 
20. Curatolo P. The Neurology of attention deficit/hyperactivity disorder. Brain Dev. 2005;27:541-3.

21. Aron AR, Robbins TW, Poldrack $R A$. Inhibition and the right inferior frontal cortex. Trends Cogn Sci. 2004;8:170-7.

22. Sergeant JA, Geurts H, Oosterlaan. How specific is a deficit of executive functioning for Attention-Deficit/Hyperactivity Disorder? Behav Brain Res. 2002;130:3-28.

23. Mota MA, Silva KC, Carreiro LRR, Piemonte MEP, Baldo MVC. Efeito do envelhecimento na atenção automática e voluntária. departamento de fisiologia e biofísica. Faculdade de Fisioterapia. Universidade de São Paulo - São Paulo; 2005.

24. Shaw P, Eckstrand K, Sharp W, Blumenthal J, Lerch JP, Greenstein D, Clasen L, Evans A, Giedd J, Rapoport JL. Attention-deficit/hyperactivity disorder is characterized by a delay in cortical maturation. PNAS. 2007; 104:19649-654.

25. Newra TR, Ohlweiler L, Riesgo RS. Transtorno da aprendizagem. abordagem neurobiológica e multidisciplinar. Porto Alegre: Artmed; 2006: 286-99.

26. Casella EB. Atenção. In: SWchelini PW. Domínios da avaliação psicológica. Campinas-SP: Editora Alínea; 2007. Cap. 2, p.31-58.

27. Lezak MD. Neuropsychological assessment. Oxford: Oxford University Press; 1995.

28. Gualtieri CT, Johnson LG. Efficient allocation of attentional resources in patients with ADHD: maturational changes from age 10 to 29. Atten Disord. 2006;9:534.

29. Diniz LFM, Capellini GM, Diniz DNM, WB Leite. Neuropsicologia - teoria e prática. Porto Alegre: Artmed; 2008. Cap. 14, p.241-55. 
30. Duchesne $M$, Mattos $P$. Normatização de um teste computadorizado de atenção visual (TAVIS). Arq. Neuropsiquiatr. 1997;55:62-9.

31. Baron IS. Executive function. In: Baron IS. Neuropsychological evaluation of the child. New York: Oxford University Press; 2004.

32. Konrad K, Günther T, Hanisch C, Dahlmann BH. Differencial Effects of methylphenidate on attentional functions in children with attentiondeficit/hyperactivity disorder. J Am Acad Child Adolec Psychiatry. 2004; 43:191-98.

33. Coutinho G, Mattos P, Araújo C, Borges M, Alfano A. Standardization of normative group for the third version of the test of visual attention TAVIS. Dement Neuropsychol. 2008;2:20-25.

34. Coutinho G, Mattos P, Araújo C, Duchesne M. Transtorno do déficit de atenção e hiperatividade: contribuição diagnóstica de avaliação computadorizada de atenção visual. Rev Psiquiatr Clin. 2007;34:215-22.

35. Booth JR, Burman DD, Meyer JR, Lei Z, Trommer BL, Davenport ND, Li W, Parrish TB, Gitelman DR, Mesulam MM. Neuronal development of selective attention and response inhibition. Neuroimage. 2003;20:737-51.

36. Posner MI, Raichle M. Imagens da mente. Porto: Porto editora; 2001.

37. Barkley RA. Attention-deficit/hyperactivity disorder, self-regulation, and time: toward a more comprehensive theory. J Dev Behav Pediatr 1997;18:271-9.

38. Bush G, Valera EM, Seidman L. Functional neuroimaging of attentiondeficit/hyperactivity disorder: a review and suggested future directions. Biol Psychiatry. 2005;57:1273-84.

39. Burgess PW. Assessment of executive function. In: Halligan PW, Marshall JC, Kischka U. Handbookof clinical neuropsychology. Oxford: Oxford University Press; 2003. p.302-21. 
40. Kieling C, Goncalves RRF, Tannock R, Castellanos FX. Neurobiology of attention-deficit/hyperactivity disorder. Child Adolesc Psychiatr Clin N Am. 2008;17:285-307.

41. McAlonan GM, Cheung V, Cha SE, Oosterlaan J, Hung SF, Tang CP, Lee CC, Kwong SL, Ho TP, Cheung C, Suckling J, Leung PW. Agerelated grey matter volume correlates of response inhibition and shifting in attention-deficit hyperactivity disorder. Br J Psychiatr. 2009;194:123-29.

42. Vaidya CJ, Stollstorff M. Cognitive neuroscience of attention deficit hyperactivity disorder: current status and working hypotheses. Dev Disabil Res Rev. 2008;14:261-67.

43. Wodka EL, MOstofsky SH, Prahme C, Larson JCG, Loftis C, Denckla MB, Mahone EM. Process examination of executive function in ADHD: sex and subtype effects. Clin Neuropsychol. 2008;22:826-41.

44. Barkely RA, Brown TE. Unrecognized attention-deficit/hyperactivity disorder in adults presenting with other psychiatric disorders. CNS Spectr. 2008;13:997-84.

45. McMenamy JM, Perrin EC, The Impact of experience on children's Understanding of ADHD. J Dev Behav Pediatr. 2008;29:483-92.

46. Capovilla AG, Assef EC, Cozza HFP. Avaliação neuropsicológica das funções executivas e relação com desatenção e hiperatividade. Aval Psicol. 2007;651-60.

47. Meltzer L, Executive function in education: from theory to practice. New York: The Guiford Press; 2007. p.5-38; 39-54; 55-72; 73-105.

48. Ávila R, Miotto Ec. Funções Executivas no envelhecimento normal e na doenças de Alzheimer. J Bras Psiquiatr. 2003;52:53-63.

49. Drechsler R, Brandeis D, Fo"Ide'nyi M, Imhof K, Steinhausen HC. The course of neuropsychological functions in children with attention deficit hyperactivity disorder from late childhood to early adolescence. $J$ Child Psychol Psychiatr. 2005;46:824-36. 
50. Geurts HM, Verté S, Oosterlaan J, Roeyers H, Sergeant JA. ADHA subtypes: do they differ in their executive functioning profile. Arch Clin Neuropsychology 2005;20:457-77.

51. Halperin JM, Trampush JW, Miller CJ, Marks DJ, Newcorn JH. Neuropsychological outcome in adolescents/young adults with childhood ADHD: profiles of persisters, remitters and controls. J Child Psychol Psychiatr. 2008;49:958-66.

52. Gonzalez RM, Perez PAG, Hernandez MI, Expósito SH, Rodriguez MAA, Fuentes IQ, Morell BR. Evaluación neuropsicológica de La memória em El trastorno por déficit de atención/hiperactividad: papel de las funciones ejecutivas. Rev Neurol. 2008;47:225-30.

53. Johnson LA, Safranek S, Friemoth J. What the most effective treatment for ADHD in children? J Fam Pract. 2005;54:166-8.

54. Solanto MV, Abikoff H, Sonuga-Barke H, Schachar R, Logan GD, Wigal T, Hechtman L, Hinshaw S, Turkel E. The ecological validity of delay aversion and response inhibition as measures of impulsivity in AD/HD: A supplement to the NIMH Multimodal Treatment Study of AD/HD. J Abnorm Child Psychol. 2001;29:215-28.

55. Dimoska A, Johnstone SJ, Barry RJ, Clarke AR. Inhibitory motor control in children with attention-deficit/hyperactivity disorder: event-related potentials in the stop-signal paradigm. Biol Psychiatry. 2003;54:13451354.

56. Overtoom CCE, et al. Inhibition in Children with attentiondeficit/hyperactivity disorder: a psychophysiological study of the stop task. Biol Psychiatry. 2002;51:668-76.

57. Schulz KP, Fan J, Tang CY, Newcorn JH, Buchsbaum MS, Cheung AM, Halperin JM. Response Inhibition in Adolescents Diagnosed With Attention Deficit Hyperactivity Disorder During Childhood: An eventrelated FMRI Study. Am J Psychiatry. 2004;161:1650-57.

58. D'esposito M. Working memory. Clin Neurol. 2008;88:237-47. 
59. Gropper RJ, Tannock R. A pilot study of working memory and academic achievement in college students with ADHD. J Atten Disord. 2009;12:57481.

60. Pliszka SR, Glahn DC, Clikeman MS, Franklin C, Perez R, Xiomg J, Liotti $M$. Neuroimaging of inhibitory control areas in children with attention deficit hyperactivity disorder who were treatment naive or in long-term treatment. Am J Psychiatry. 2006;163:1052-1060.

61. Arnsten AF, Dudley A. Methylphenidate improves prefrontal cortical cognitive function through alpha2 adrenoceptor and dopamine D I receptor actions: relevance to therapeutic effects in attention deficit hyperactivity disorder. Behav Brain Funct. 2005;1:2.

62. Mahone EM, Mostofsky SH, Lasker AG, Zee D, Denckla MB. Oculomotor abnormalities in attention-deficit/hyperactivity disorder: evidence for deficits in response preparation and inhibition. $J$ Am Acad Child Adolec Psychiatry. 2009;48:749-56.

63. Wechsler D. WISC III: Escala de inteligência Wechsler para crianças: manual/David Wechsler. 3a ed. Adaptação e padronização de uma amostra Brasileira. São Paulo: Casa do Psicólogo; 2002.

64. Stein LM. TDE: teste de desenvolvimento escolar: manual para aplicação e interpretação. São Paulo: Casa do Psicólogo; 1994.

65. Mesulam M. Principles of behavioral and cognitive neurology. 2th ed. New York: Oxford University Press; 2000.

66. Reitan RM. Trail making Test Manual for Administration and Scoring, 1992 Arizona: Reitan Neuropsycology Laboratory.

67. Vieira S. Introdução à bioestatística. São Paulo: Editora Elsevier; 2004. 360p.

68. Bussab W, Morettin P. Estatística básica. 5a ed. São Paulo: Saraiva; 2002.

69. Pagano M, Gauvreau K. Princípios de bioestatística. Ed Thompson; 2004. 
70. Scoring Instructions for the SNAP-IV-C Rating Scale.[cited 2008 dez 28]. Available from: http:// www.adhd.net/snap-iv-instructions.

71. Willcutt EG, Doyle AE, Nigg JT, Faraone SV, Pennington BF. Validity of the Executive Function Theory of Attention-Deficit/Hyperactivity disorder: A Meta-Analytic Review. Biol Psychiatry. 2005;57:1336-46.

72. Haddad HJR. Estudo de mecanismos atencionais e pré-atencionais envolvidos na percepção visual de ordem temporal. [dissertação] Instituto de Ciências Biomédicas da Universidade de São Paulo, São Paulo; 2003.

73. Stuss DT, Stethem LL, HugenHoltz H, Picton TW, Pivik J, Richard MT. Reaction Time after head injury: Fadigue, divided and focused attention and consistency of performance. $J$ Neurol Neurosug Psychiatry. 1989;79:81-90.

74. Arnsten AF. Dopaminergic and noradrenergic influences on cognitive functions mediated by prefrontalcortex. In: Solanto MV, Arnsten AF, Castellanos FX, editors. Stimulant drugs and ADHD: basic and clinical neuroscience. New York: Oxford; 2001. p.185-208.

75. Posner M, Petersen SE. The attention system of the brain. Ann Rev Neuroscience. 1990;13:35-42.

76. Sergeant AJ, Modeling attention-deficit/hyperactivity disorder: a critical appraisal of the cognitive-energetic Model. Biol Psychiatry. 2005;57:1248-255.

77. Geurts HM, Verté S, Oosterlaan J, Roeyers H, Sergeant JA. ADHD subtypes: do they differ in their executive functioning profile? Arch Clin Neuropsychol. 2005;20:457-77.

78. Solanto MV, Gilbert SN, Raj A, Zhu J, Pope-Boyd S, Stepak B, Vail L, Newcorn JH. Neurocognitive functioning in AD/HD, predominantly inattentive and combined subtypes. J Abnorm Child Psychol. 2007; 35:729-44. 
79. Riccio CA, Homack S, Jarratt KP, Wolfe ME. Differences in academic and executive function domains among children with ADHD Predominantly Inattentive and Combined Types. Arch Clin Neuropsychol. 2006;21:65767.

80. Loe IM, Feldman HM, Yasui E, Luna B. Oculomotor performance identifies underlying cognitive déficits in attention-defict/hyperactivity disorder. J Am Acad Child Adolec Psychiatry. 2009;48:431-40.

81. Castellanos FX, Lee PP, Sharp W, et al. Attention-Deficit/Hyperactivity Disorder Abnormalities in Children and Adolescents With Developmental Trajectories of Brain. JAMA. 2002;288:1740-748.

82. Sonuga-Barke EJS. Causal models of attention-deficit/hyperactivity disorder: from common simple deficits to multipl developmental pathways. Biol Psychiatry. 2005;5:1231-238.

83. Plummer C, Humphrey N. Time perception in children with ADHD: The effects of task modality and duration. Child Neuropsychol. 2008;29:1-16. 